\title{
ON THE DYNAMIC FORCING OF SHORT-TERM CLIMATE FLUCTUATIONS BY FEEDBACK MECHANISMS
}

by

Elmar R. Reiter

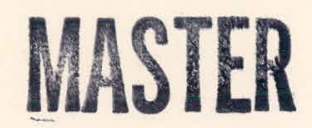

\section{Environmental Research Papers COLORADO STATE UNIVERSITY Fort Collins, Colorado}




\section{DISCLAIMER}

This report was prepared as an account of work sponsored by an agency of the United States Government. Neither the United States Government nor any agency Thereof, nor any of their employees, makes any warranty, express or implied, or assumes any legal liability or responsibility for the accuracy, completeness, or usefulness of any information, apparatus, product, or process disclosed, or represents that its use would not infringe privately owned rights. Reference herein to any specific commercial product, process, or service by trade name, trademark, manufacturer, or otherwise does not necessarily constitute or imply its endorsement, recommendation, or favoring by the United States Government or any agency thereof. The views and opinions of authors expressed herein do not necessarily state or reflect those of the United States Government or any agency thereof. 


\section{DISCLAIMER}

Portions of this document may be illegible in electronic image products. Images are produced from the best available original document. 
Research on the environment constitutes an important component of the graduate programs pursued by a number of Colorado State University departments. The more noteworthy results of these research efforts are normally published in the conventional professional journals or conference proceedings, but in very much abridged form. ENVIRONMENTAL RESEARCH PAPERS has been established to provide a formal means of disseminating such CSU accomplishments in all significant details, in order that individuals concerned with related interests at other institutions may review a more comprehensive treatment of the research reported than is customarily available.

Price $\$ 4.50$ in USA

Dr. Myron L. Corrin, Department of Atmospheric Science

Professor Lewis 0. Grant, Department of Atmospheric Science

Dr. Judson M. Harper, Agricultural Engineering

Dr. Elmar R. Reiter, (Editor), Department of Atmospheric Science

Dr. David W. Seckler, Department of Economics

Dr. Rodney K. Skogerboe, Department of Chemistry

Dr. Evan C. Vlachos, Department of Sociology

Subscriptions and correspondence to these papers should be addressed to: Secretary of Environmental Research Papers, Department of Atmospheric Science, Colorado State University, Solar Village, Ft. Collins, C0 80523. 
ON THE DYNAMIC FORCING OF SHORT-TERM CLIMATE FLUCTUATIONS BY FEEDBACK MECHANISMS

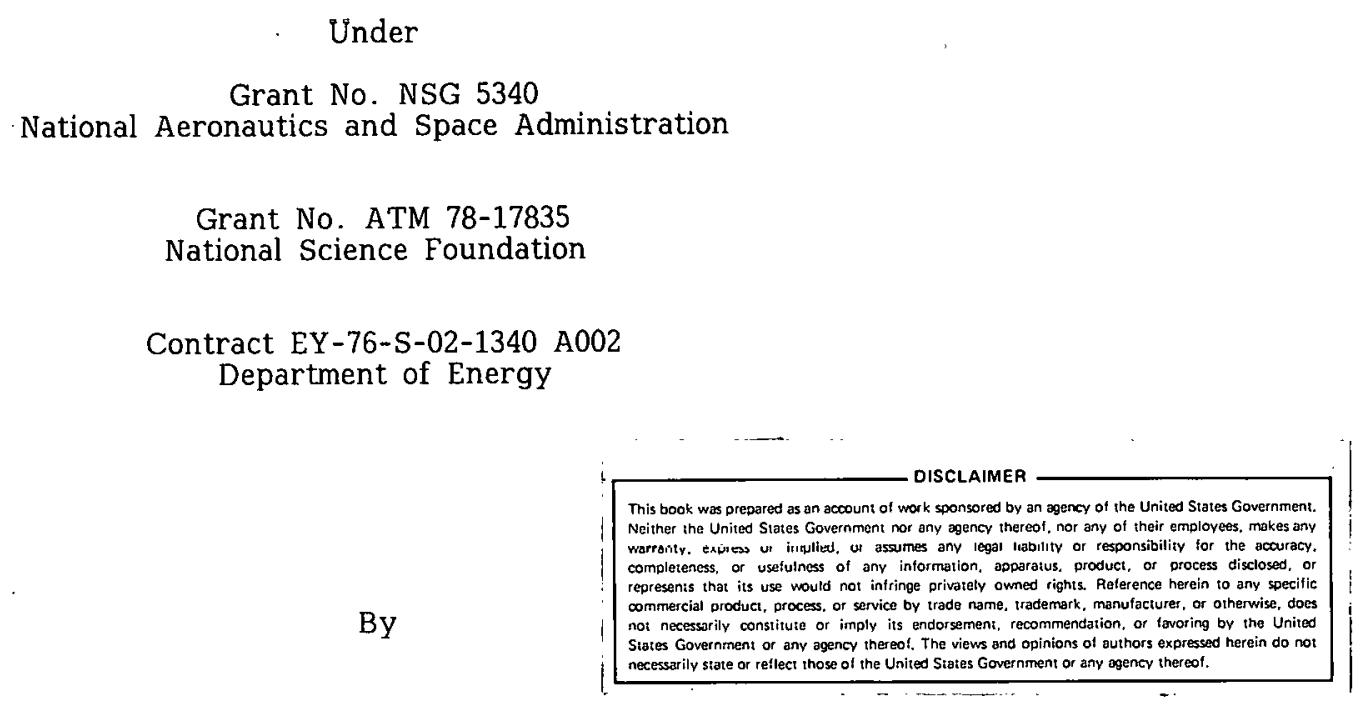

Elmar R. Reiter

Principal Investigator

Environmental Research Papers

Colorado State University

Fort Collins, Colorado

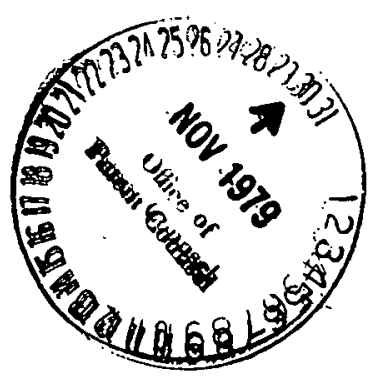

September 1979

No. 21

This report was prepared as an account of work sponsored by the United States Government. Neither the United States nor any of its agencies, nor any of their employees, nor any of their contractors, subcontractors, or their employees, makes any warranty, express or implied, or assumes any legal liability or responsibility for the accuracy, completeness, or usefulness of any information, apparatus, product or process disclosed, or represents that its use would not infringe privately owned rights. 
THIS PAGE

WAS INTENTIONALLY

LEFT BLANK 
1. Introduction ........................................2

2. Evidence of Recent $\mathrm{Climate}$ Variations . . . . . . . . . . . . . . . . . . . . . . . . . 2

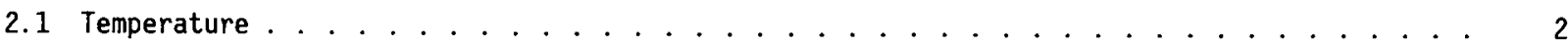

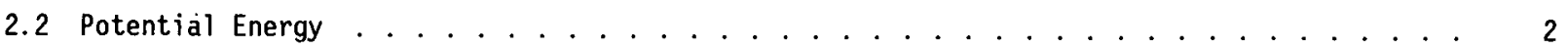

2.3 The Hydrological Cycle . . . . . . . . . . . . . . . . . . . . . . . . . . . . . 4

3. Regional, Short-Term Climate Variability and Geophysical Feedback Mechanisms . . . . . . . . . 15

3.1 Observed Trends in SST Anomalies . . . . . . . . . . . . . . . . . . . . . . . . . . . 15

3.2 SST Anomalies in the North Pacific . . . . . . . . . . . . . . . . . . . . . . . . . . . 18

3.3 Trade Wind Surges, Precipitation Anomalies and El Niño Events. . . . . . . . . . . . . . . 35

3.4 The Atlantic Quasi-Biennial 0scillation . . . . . . . . . . . . . . . . . . . . . 39

4. Conclusions ... . . . . . . . . . . . . . . . . . . . . . . . . . . 53

REFERENCES . . . . . . . . . . . . . . . . . . . . . . . . . . . . . . . 58 
The research summarized in this report was carried out under the sponsorship of several U.S. Government agencies. The precipitation variability studies were supported by the National Aeronautics and Space Administration Grant No. NSG 5340. The present report is to be considered as a Final Report under that grant. Investigations of air-sea interaction and of climate variability on time scales of several years relied on support from the National Science Foundation Grant No. ATM 78-17835 and from the Department of Energy Contract EY-76-S02-1340 A002. This document is intended, therefore, to serve as a Progress Report on these two projects.

Many of the calculations whose results are presented here have been conducted at the computer facility of the National Center for Atmospheric Research (NCAR) in Boulder. We are grateful for help in the form of free computer time. NCAR is supported by the Atmospheric Science Division of the National Science Foundation.

I am indebted to Dr. John Middleton for his most helpful input into the computation of spectra and of filtered time series. His contributions will be summerized in a forthcoming report. Mr. Dan Westhoff has to be credited with computer program development, including programs for computer graphics.

Portions of this paper were presented as an invited contribution at the symposium on Empirical and Model Assisted Diagnosis of Climate and Climate Change in Tbilisi, USSR, October 15-23, 1979. 
ON THE OYNAMIC FORCING OF SHORT-TERM CLIMATE FLUCTUATIONS BY FEEDBACK MECHANISMS

by

Elmar R. Reiter

Atmospheric Science Department

Colorado State University

Fort Collins, Colorado

\section{ABSTRACT}

The energies involved in the general circulation of the atmosphere, especially the zonal available potential energy, show considerable interannual variability, suggesting the presence of various internal feedback mechanisms in the ocean-atmosphere system. The presence or absence of stratospheric warming events and of tropospheric blocking ridges has a profound effect on winter weather in the northern hemisphere. An interannual as well as a long-term variability of the hydrological cycle, largely ignored in present climate research, can affect the general circulation especially through the generation of available potential energy. Such variations in the hydrological cycle become apparent in the variability of northern hemisphere continental precipitation. Effects also have to be suspected in the storage of precipitable water in the troposphere and in the evaporation rate from the ocean which, in turn, is influenced by the general circulation. Sea-surface temperature (SST) variations appear to have some effect on the hydrological cycle.

These SST variations, appearing as large-scale and long lasting anomalies, can have a variety of causes, such as local anomalies in wind stress and advection within the large-scale oceanic current systems. These ocean currents appear to undergo interannual variations as well as long-term trends. The possible existence of feedback mechanisms between ocean and atmosphere seem to be evident in some of the data from the North Pacific and North Atlantic. One of these proposed mechanisms involves the variation in the convergence between the North and South Pacific trade-wind systems and is strongly reflected in rainfall variability within the dry region of the equatorial Pacific. Similar variations appear in low-latitude SST anomalies of selected regions, notably off the coasts of California and Peru, the latter area known for the "El Niño" phenomenon. That phenomenon also appears to be tied to the aforementioned trade-wind variability over the Pacific.

The convergence between the two trade-wind systems in the Atlantic region also undergoes marked interannual variations, strangely enough in a quasi-biennial cycle. This quasi-biennial oscillation (QBO) in trade-wind convergence over the Atlantic (not present over the Pacific) appears to be tied to the global QBO of equatorial stratospheric winds and to regional rainfall regimes in the dry region of northeastern Brazil. $A$ variability pattern of SST's with a QBO has been detected off the coast of Senegal, in the Gulf of Guinea and even in the Gulf Stream as it leaves the North American continental shelf. Possible physical connections between some of these QBO's are pointed out by a hypothetical feedback model. It is also suggested that interaction of a $Q B O$ with the annual cycle may lead to "beating frequencies" resembling climatic trends of a duration of several [years, and being evident in some rainfall records of the dry region of northeastern Brazil. 
The fact that climatic changes have occurred during the last millennium is clearly evident from historical records. Epochs like the "Little Ice Age", the "Irish Potato Famine" and the climatic optimum of the $1940^{\prime} \mathrm{s}$ are but a few examples of documented climate extremes of hemisphere-wide impact (see e.g. Lamb, 1972, 1977).

During the last two decades some of our geophysical data bases have achieved a good enough quality to be scrutinized for clues as to the causes of the recent climate deterioration that seems to have occurred, at least in the northern hemisphere, since the
1940 's. Some of these data have been used to search for climatic changes that implicate the behavior of the general circulation of the atmosphere on large, even hemispheric, scales. We have come up with a wealth of interesting evidence that is still too diversified to lend itself to a unified modelling of climatic change. Nevertheless, the evidence available so far strongly suggests the existence of several important feedback mechanisms within the geophysical system that may cause climatic fluctuations of magnitudes similar to those observed during recent history.

\section{EVIDENCE OF RECENT CLIMATE VARIATIONS}

\subsection{Temperature}

Ange 11 and Korshover $(1977,1978)$ have recently analyzed northern hemisphere temperature trends from a selection of radiosonde data. Their choice of stations was intended to minimize geographical bias. Figure 1 indicates a cooling trend in the early 1960's, especially in extratropical latitudes. This trend appears to have diminished, perhaps even disappeared, lately. The overall amplitude of the decline in the mean temperature of the extratropical atmosphere during the last two decades appears to have been of the order of $1^{\circ} \mathrm{C}$. The tropics, according to Fig. 1, reveal a relatively strong interannual variability of mean temperature, but not much of a longterm trend. This means that the meridional temperature gradient between equator and pole undergoes interannual fluctuations as well as long-term trends. Since it is this temperature gradient which drives the general circulation of the atmosphere we should search for manifestations of climatic change in parameters which characterize the general circulation. Secondly, we might explore possible causes for the interannual variability of atmospheric meridional temperature gradients.

\section{2 . Potential Energy}

A parameter which is relatively easy to measure and which characterizes the main energy reservoir of the general circulation of the atmosphere is the zonal available potential energy, $A_{z}$ (Lorenz, 1965, 1967; Muench, 1965; Reiter, 1969a) defined as

$$
A_{z}=\int_{p_{1}}^{p_{2}} \frac{\left[([T](\lambda))^{2}\right]_{(\lambda, \phi)} d p}{2[\sigma](\lambda, \phi)}
$$

where $[\sigma]_{(\lambda, \phi)}=\left[T\left(\frac{g}{c_{p}}-\frac{\partial T}{\partial Z}\right)\right](\lambda, \phi)$

in units of energy per unit of mass and unit of area. $A$ somewhat different definition of $A_{Z}$ has been proposed by Pearce (1978) which makes it unnecessary to estimate the vertical temperature lapse rate. In these two equations we have used an averaging notation introduced by Reiter (1969b), whereby bracketed terms with parenthesized subscripts indicate mean values, averaged with respect to the subscripts in parentheses. Similarly, parenthesized terms with parenthesized subscripts symbolize departures from the mean values along coordinates given by the subscripts. Standard meteorological notation has been used ( $T=$ temperature, $\mathrm{g}=$ acceleration due to gravity, $\mathrm{c}_{\mathrm{p}}=$ specific heat of air at constant pressure, $z=$ height, $\lambda=$ geographic longitude, $\phi=$ geographic latitude. $\sigma$ is a measure of the thermal stability of the atmosphere. The above formulations do not include moist available energy (MAE), expressions for which were derived recently by Lorenz (1978, 1979).

The widely fluctuating behavior of $\mathrm{A}_{2}$ is evident from Fig. 2 which contains unsmoothed and 7-month smoothed monthly departures of this parameter from its long-term monthly mean values.

Computations were made using data compiled by the National Meteorological Center (NMC) and available at the National Center of Atmospheric Research (NCAR). Integrations performed according to Eqn. (1) comprised the atmospheric volume north of $20^{\circ} \mathrm{N}$ and from $1000 \mathrm{mb}$ to $100 \mathrm{mb}$.

The unruly behavior of $A_{Z}$ is not always compensated for by opposite fluctuations in eddy available potential energy, $A_{E}$, or in the zonal and eddy modes of kinetic energy, $K_{Z}$ and $K_{E}$. Therefore the sum of the four zonal and eddy, available potential and kinetic energy modes is essentially non-constant. This fact is also reflected in Fig. 2 which contains in its lower portion the monthly departures from the mean values of the $A_{Z}+A_{E}+K_{Z}+K_{E}$.

One interesting feature of Fig. 2 is the large amplitude of interannual fluctuations in $A_{Z}$ especially in the 1960's. The winter of 1976/1977 -- one of the most anomalous seasons on record in the eastern United States - again seems to herald a period of increasing fluctuations in $A_{z}$ as well as in the total energy.

Especially noticeable is the appearance in some years of a "mid-winter dip" in $A_{Z}$ that is not compensated for by the remaining three energy modes. Starr (1976) showed that such dips in the energy distribution occur together with stratospheric warming 
A

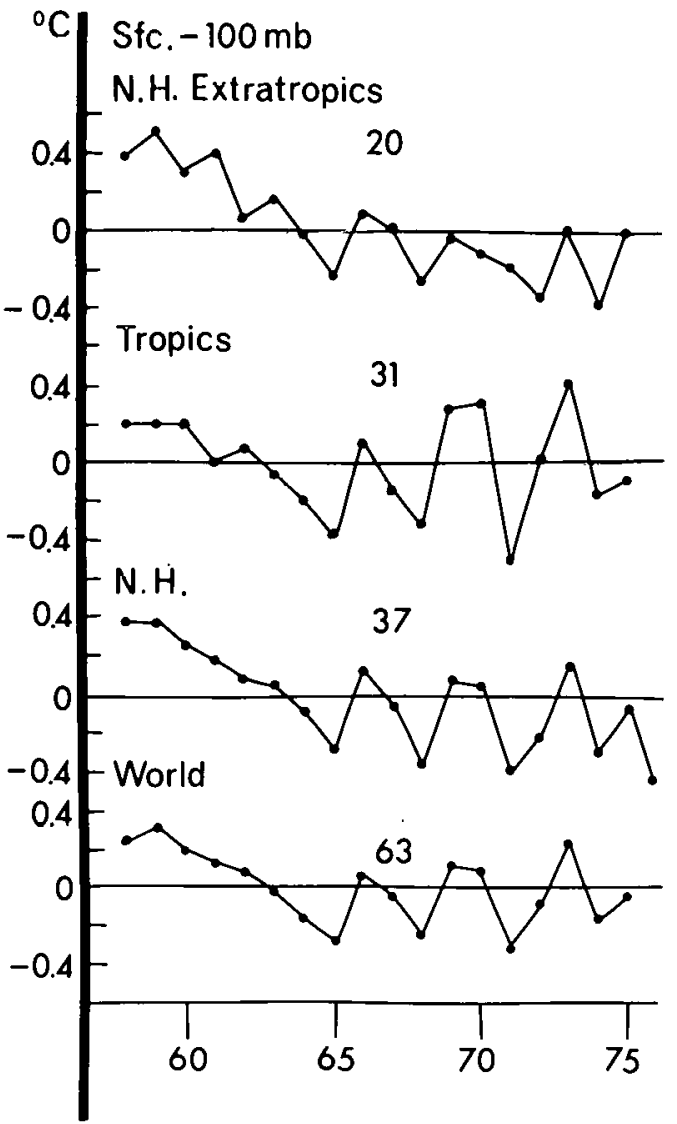

B

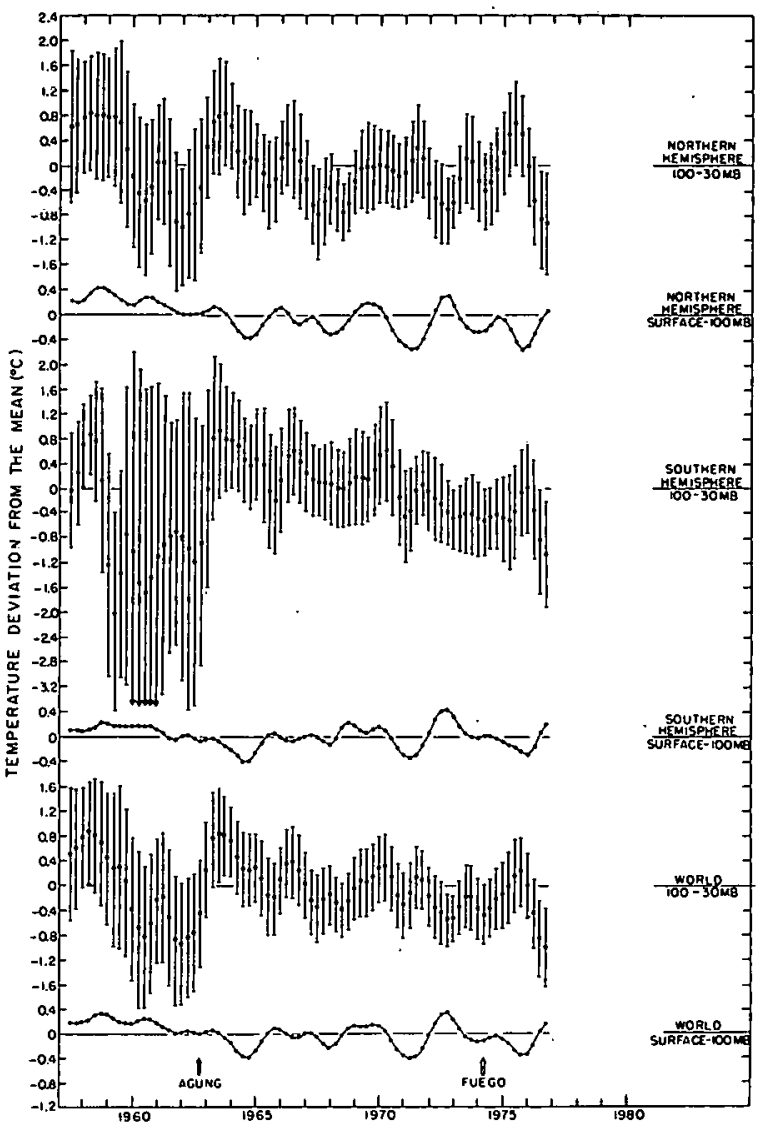

Fig. 1. (a) Annual mean temperature $\left({ }^{\circ} \mathrm{C}\right)$ from surface to $100 \mathrm{mb}$ for regions indicated. The numbers refer to the number of stations used in each temperature estimate. (b) Temperature variations for regions and layers indicated. The Mt. Agung and Fuego eruptions are marked at the bottom of the graph. A 1-2-1 smoothing has been applied twice to the seasonal values and to the confidence limits given for the 100-30 mb layer. These bars extend over two standard deviations from either side of the mean. (From Angell and Koshover, 1977, 1978.)

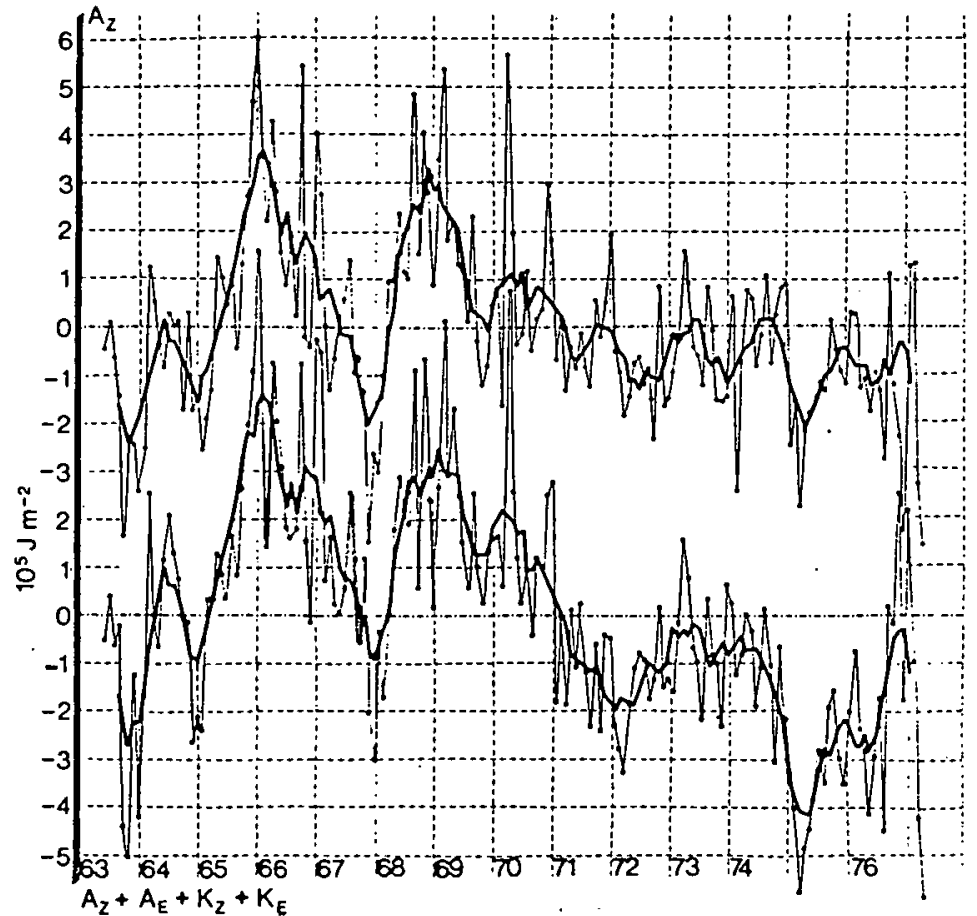

Fig. 2. Departures of monthly mean values of $A_{Z}$ (upper portion of diagram) and of $A_{Z}+A_{E}+K_{Z}+K_{E}$ (lower portion of diagram) in $10^{5} \mathrm{Jm}^{-2}$. from their respective long-term monthly mean values. Dots and thin lines represent actual monthly mean values, heavy lines were obtained by application of a sevenmonth running-mean filter. Vertical coordinate lines indicate the month of January of each year. 
events and with the establishment of blocking anticyclones in the Pacific and Atlantic sectors. These anticyclones tend to transport an abnormally large amount of heat northward in the troposphere, causing a warming in high latitudes and a cooling in middle and low latitudes, hence a hemispheric decrease in $\mathrm{A}_{Z}$ (McGuirk 1977; Reiter and McGuirk, 1976; McGuirk and Reiter, 1976, 1977). A typical example of such a "mid-winter dip" in $\mathrm{A}_{2}$ is exhibited in Fig. 3 for the winter of $1976 / 77$, which was characterized by recordbreaking low temperatures over the eastern United States and by a persistently cold sea surface temperature (SST) anomaly in the Central North Pacific during the preceding summer and autumn (Namias, 1978).

Some of the large-amplitude variations of $A_{Z}$ shown in Fig. 2 can be explained as long-term transitions of the atmospheric general circulation between a dominantly zonal configuration and a high-amplitude regime of certain long planetary wave modes.

It scems to be generally accepted that stratospheric warming events are triggered by tropospheric long-wave disturbances. As the stratospheric vortex breaks down, or at least assumes a dominant wavenumber 2 configuration (Labitzke, 1977), the tropospheric circulation is influenced by the stratosphere through a feedback mechanism (Matsuno, 1971). A dominance of Pacific and Atlantic blocking highs with strong persistence and recurrence tendencies seems to be the result of such a feedback. Because of this persistence and recurrence, large regional climatic anomalies have to be expected during periods of blocking activity (Rex, 1950a,b, 1951).

If a feedback between tropospheric and stratospheric flow disturbances were the only mechanism involved in stratospheric warming, blocking anticyclone generation, and the mid-winter dip in $A_{Z}$, why don't these processes occur randomly distributed during every cold season? Why, indeed, do we find

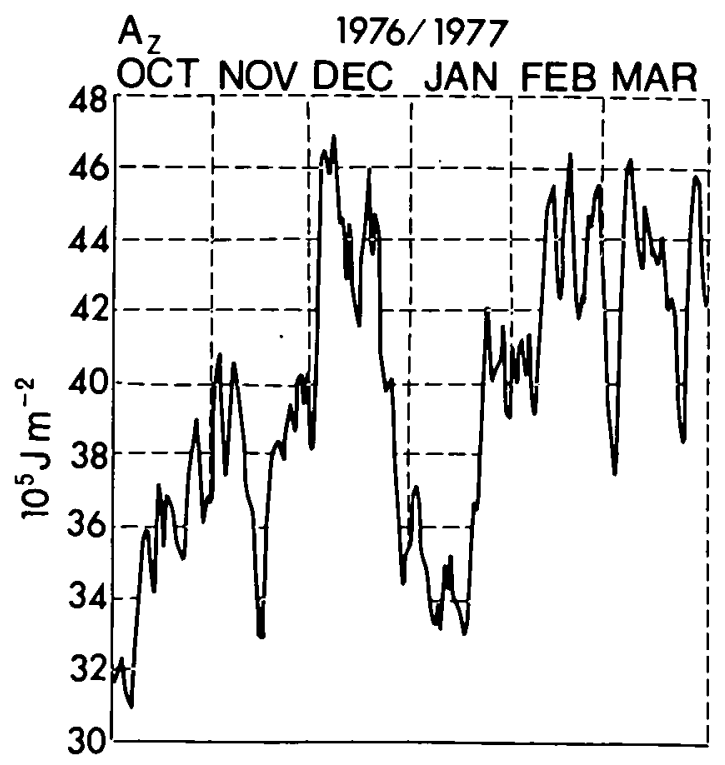

Fig. 3. Daily values of $\mathrm{A}_{Z}$ (units $10^{5} \mathrm{Jm}^{-2}$ ) during winter of 1976/77 (data courtesy of $B$. Macdonald). perturbations in $A_{Z}$ and in total energy with amplitudes as high and with periods as long as those indicated in Fig. 2?

Because of the high amplitudes of $A_{2}$ variations shown in that diagram (approximately $10 \times 10^{5} \mathrm{Jm}^{-2}$ in the unsmoothed monthly mean data and $6 \times 10^{5} \cdot \mathrm{Jm}^{-2}$ in the smoothed data, as compared to an annual average value of $\mathrm{A}_{Z}$ of approximately $30 \times 10^{5} \mathrm{Jm}^{-2}$ ) we can rule out variability in solar output as the main cause of short-term climate variations involving $A_{Z}$. The non-constancy of $\left(A_{Z}+A_{E}+K_{Z}+K_{E}\right)_{t}$ raises the suspicion that the energy "throughput" through the system called the "general circulation of the atmosphere", being controlled by diabatic energy generation and dissipation processes, might undergo significant interannual variability. These diabatic processes could be manyfold and are influenced themselves by the character and state of the general circulation through feedback processes.

In the course of our recent research we have considered, so far, only two of these processes: One involves the hydrological cycle and its potential variability. The other considers the possible effects of air-sea interaction on atmospheric circulation patterns.

\subsection{The Hydrological Cycle}

According to Eqn. (1) the zonal available potential energy depends on the variance of temperature with latitude and, therefore, on the mean meridional temperature gradient. $A 20 \%$ increase in $A_{Z}, i . e$. in the meridional variance of temperature, could be translated into an increase of the mean meridional temperature gradient between equator and pole from $40^{\circ} \mathrm{C}$ to $14^{\circ} \mathrm{C}$, i.e. hy roughly $4^{\circ} \mathrm{C}$ or $10 \%$

We have shown earlier that the development of high-amplitude blocking ridges in middle and high latitudes could have an impact on the mean meridional temperature gradient of the required magnitude. A simple estimate will convince us that a possible variability in the release of latent heat, hence in the efficiency of the hydrological cycle, might produce similar changes in the mean meridional temperature gradient.

In order to cause a variation of $4^{\circ} \mathrm{C}$ in the meridional temperature difference between pole and equator, which would be commensurate with the interannual variability of $A_{Z}$, a surplus or deficit of approximately $1.5 \mathrm{~cm}$ of precipitation in low-latitude belts of significant width would be required. (To heat one $\mathrm{kg}$ of air per $\mathrm{cm}^{2}$ by $1^{\circ} \mathrm{C}$ would require 1.0046 $x 1^{10}$ ergs. The latent heat release from $1 \mathrm{~cm}$ of precipitation per $\mathrm{cm}^{2}$ of surface amounts to $2.47 \times$ $10^{10}$ ergs. Thus, $0.41 \mathrm{~cm}$ of precipitation is required to heat the equivalent of an air column of $1 \mathrm{~cm}^{2}$ cross section by $1^{\circ} \mathrm{C}$.) A precipitation variability in high latitudes of the same magnitude, spread over a latitude belt of significant width, would have the same effect.

To test the potential interannual variability of the hydrological cycle and its impact on the general circulation we conducted two preliminary studies: One 
dealt with the interannual and long-term variabilities of continental precipitation in the northern hemisphere (Corona, 1978, 1979). The other addressed itself to the variability of rainfall in the oceanic sectors of the intertropical convergence zone.

The estimation of area-averaged precipitation over the continents poses considerable difficulties, caused by measurement errors, by sampling biases especially with shower-type precipitation (see e.g. Patrinos et al., 1979), and by the application of interpolation techniques that might give undue weight to such local sampling biases. To arrive at an assessment of hemispheric precipitation variability one requires data over the oceanic regions. Such data are presently not available. Guesses from satellite microwave and cloud-cover observations only provided the still-to-be-cherked, tentative conclus iuil that the variability of precipitation over the northern hemisphere oceans does not counterbalance the variability observed over the continents -- allowing for all the shortcomings in these estimates.

Combining monthly precipitation data from over 1000 stations and for the period 1935-1974 into continental area averages, several interesting features can be pointed out with regard to possible long-term trends in the hydrological cycle of the northern hemisphere.

Figures 4 to 9 contain the monthly anomalies of area-averaged precipitation for North and Central America and for the continental complex of Europe, Asia, and Africa north of the equator. Seven- and eleven-month smoothed time series of the anomalies are aiso shown. The North American droughts of the midfifties and mid-sixties appear in the smoothed time series of that continent. A significant decrease of precipitation was recorded over the Eurasian and North African continental regions between 1940 and 1946 . We became suspicious that this decrease in precipitation might have been due to better observational coverage of rainfall, especially in the region south of the Sahara (Fig. 10). With a hetter dcfinition of the rainfall gradient between the moist tropical belt and the dry Sahara, the applied interpolation routine, consisting of an area triangulation between observing stations (Corona, 1978), would delineate the dry subtropical belt more precisely and assign to it a greater relative weight. In the absence of observing stations in the transition region from a dry to a moist regime the triangle interpolation scheme assumes too high a rainfall in the dry interior of North Africa.

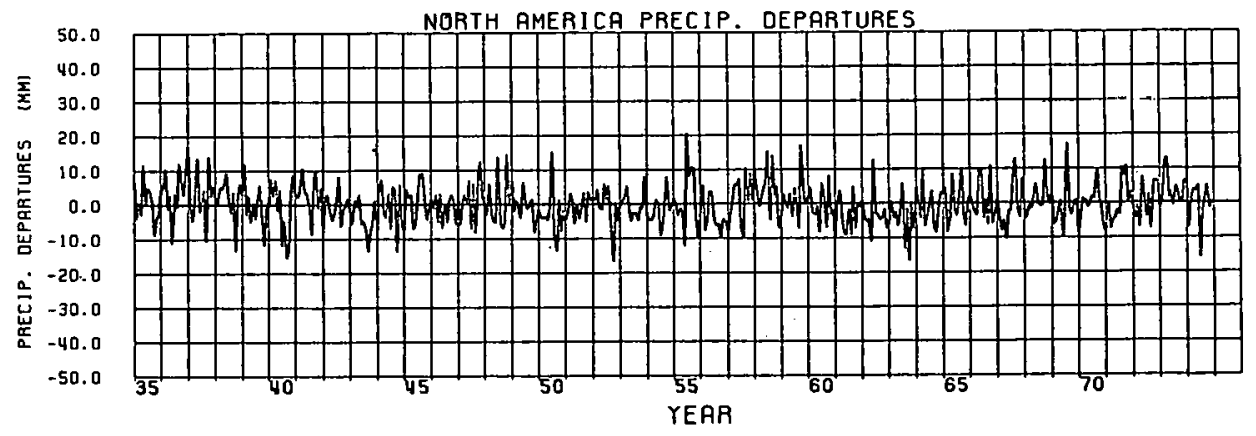

Fig. 4. Time series containing 40 years of average monthly continental precipitation departures from monthly mean values for North America. Vertical lines indicate the month of January (Corona, 1979).

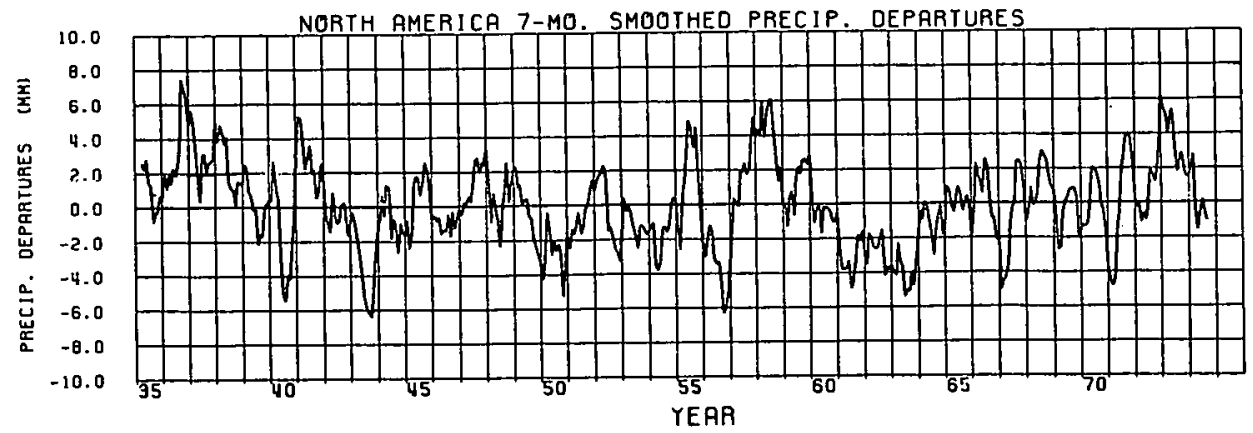

Fig. 5. Data set of Fig. 4 with seven-month running-mean filter applied (Corona, 1979). 


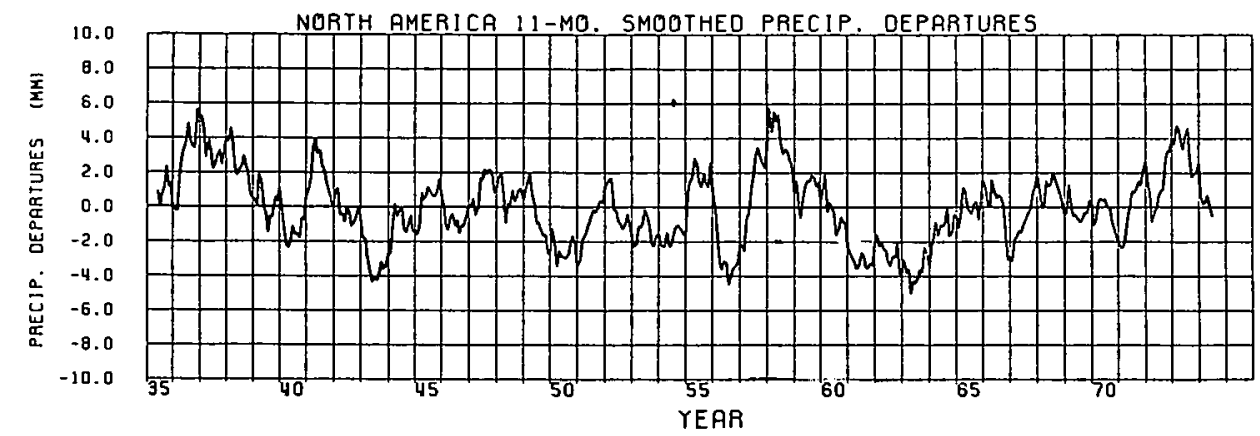

Fig. 6. Data set of Fig. 4 with eleven-month running-mean filter applied (Corona, 1979).

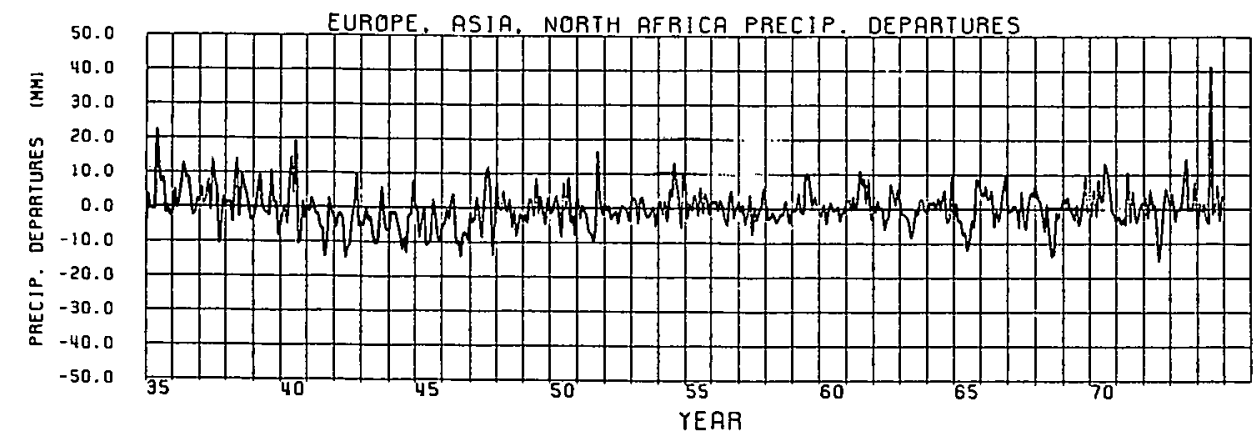

Fig. 7. Time series containing 40 years of average monthly continental precipitation departures for Europe, Asia and North Africa. Vertical lines indicate the month of January from monthly mean values (Corona, 1979).

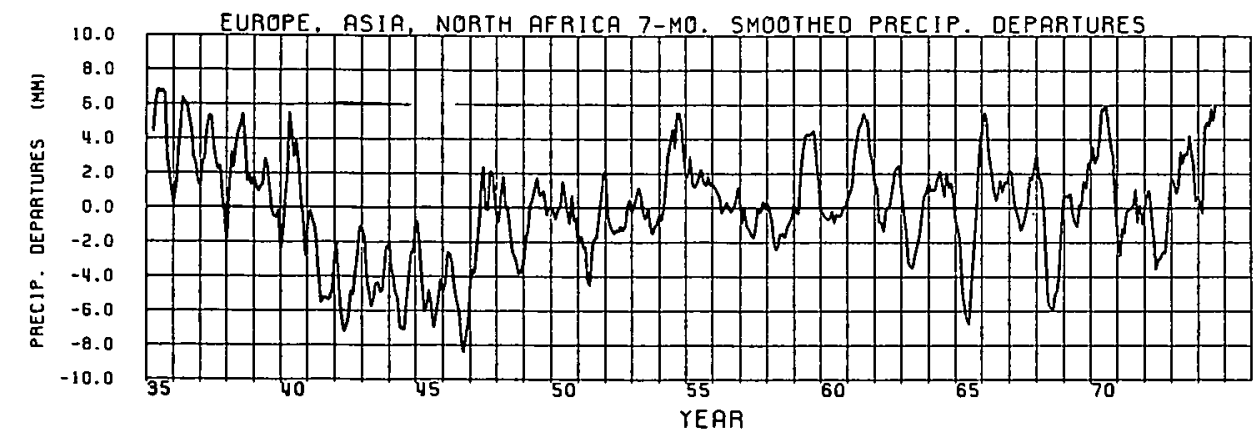

Fig. 8. Data set of Fig. 7 with seven-month running-mean filter applied (Corona, 1979).

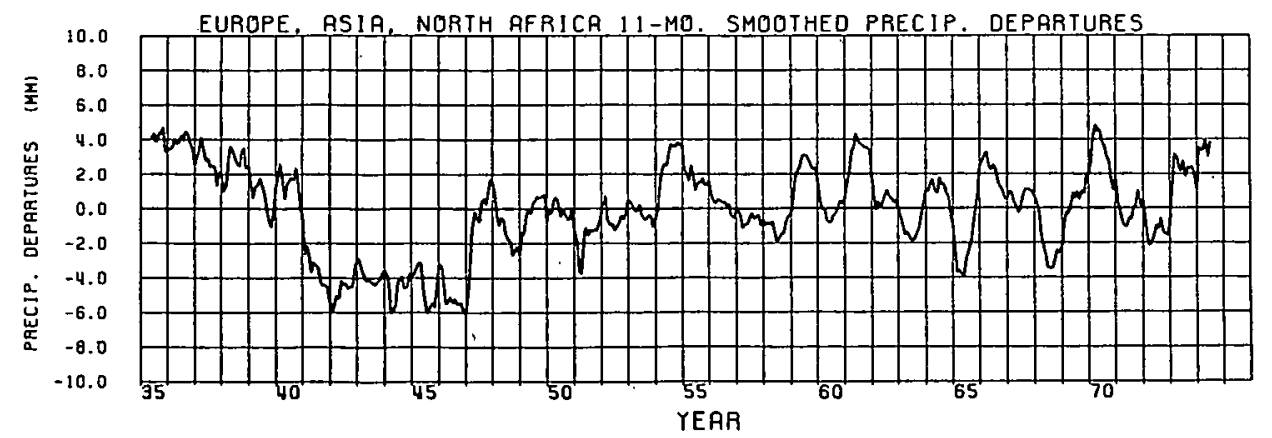

Fig. 9. Data set of Fig. 7 with eleven-month running-mean filter applied (Corona, 1979). 
To test for this possible bias produced by the interpolalion routine the European, Asian and North African monthly area-averaged precipitation anomalies were computed without the 50 North African stations that had been added during the 1940's and are shown in Fig. 10. Results of these adjusted computations are shown in Figs. 11 to 13 . We are still faced with a decline of precipitation until 1947. We are inclined to believe, therefore, that a climatic fluctuation in the hydrological cycle of the northern hellisphere, at least over its continental regions, is revealed in these data.

Such a decline of precipitation from the 1930 's to the 1940's was also observed by Kraus (1977a), who comments on the fact that subtropical droughts can be of a wide-spread nature. He cites the example of the 1972 precipitation anomaly, widely known as the "Sahelian drought". Deluw-normal summer precipitation during that year characterized the subtropical belts of both hemispheres (see also Katz, 1978).

Tables 1 and 2 indicate that the precipitation decrease in the early $1940^{\prime} s$ and the sudden increase between 1945 and 1948 were most pronounced in low latitudes. Whereas the increase between 1945 and 1948 characterized both, winter and summer precipitation, the earlier decrease was most pronounced in the summer rainfall. This different seasonal trend behavior also becomes obvious from Figs. 8 and 12 . Prior to 1940 strong positive summer anomalies are evident in the European, Asian and North African precipitation, giving way to negalive summer anomalies between 1941 and 1946 .

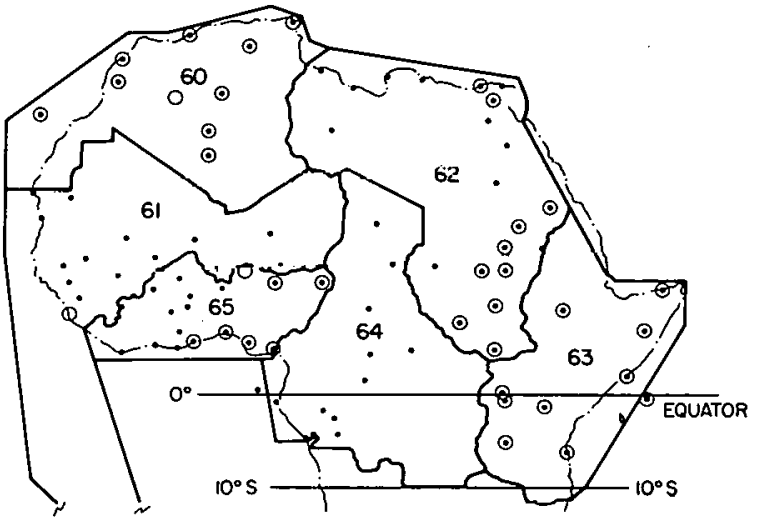

Fig. 10. Map of North Africa containing stations that existed before 1941 (open circles) and stations established between 1941 and 1945 (dots). Circled dots indicate stations that existed from 1935 through 1950 (Corona, 1979).

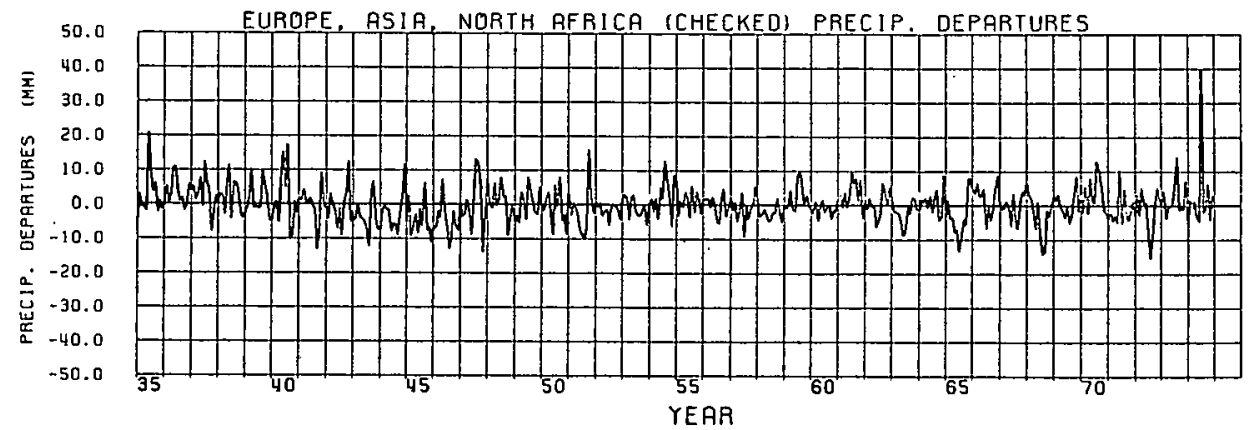

Fig. 11. A time series containing 40 years of average monthly continental precipitation departures from monthly mean values for Europe, Asia and North Africa which shows the effect of removing 50 North African stations between 1941 to 1949 only. Vertical lines indicate the month of January (Corona, 1979).

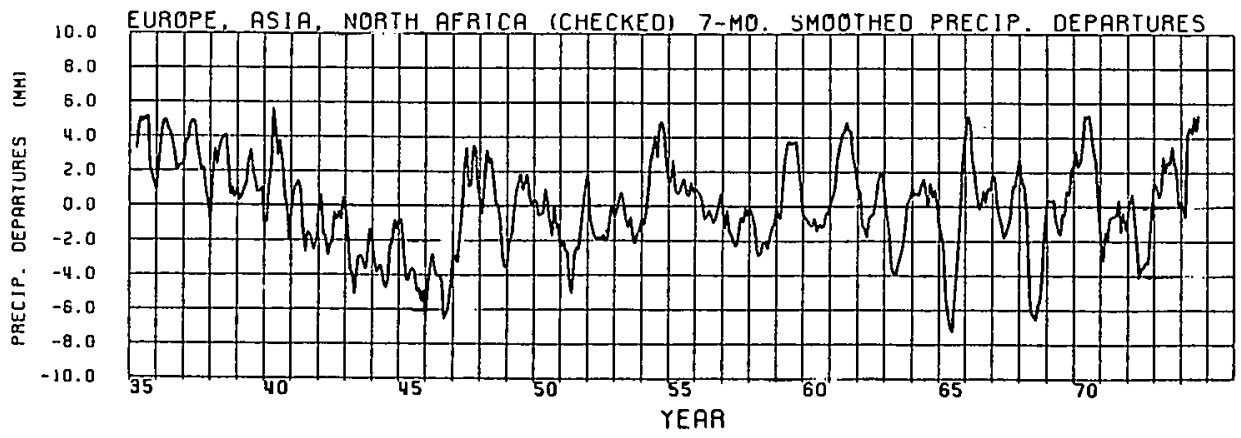

Fig. 12. Data set of Fig. 11 with seven-month running-mean filter applied (Corona, 1979). 


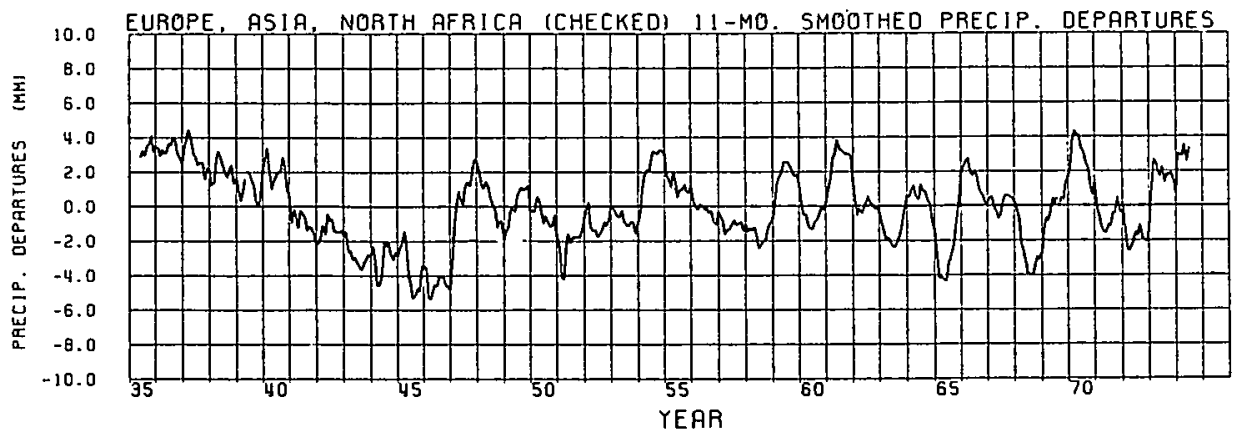

Fig. 13. Data set of Fig. 11 with eleven-month running-mean filter applied (Corona, 1979).

TABLE 1. Latitude dependence of average precipitation for Europe, Asia and North Africa in the month of June at the start of the "dip" (1940-1941) and at the end of the "dip" (1945-1948). All values in $\mathrm{mm}$. (After Corona, 1979.)

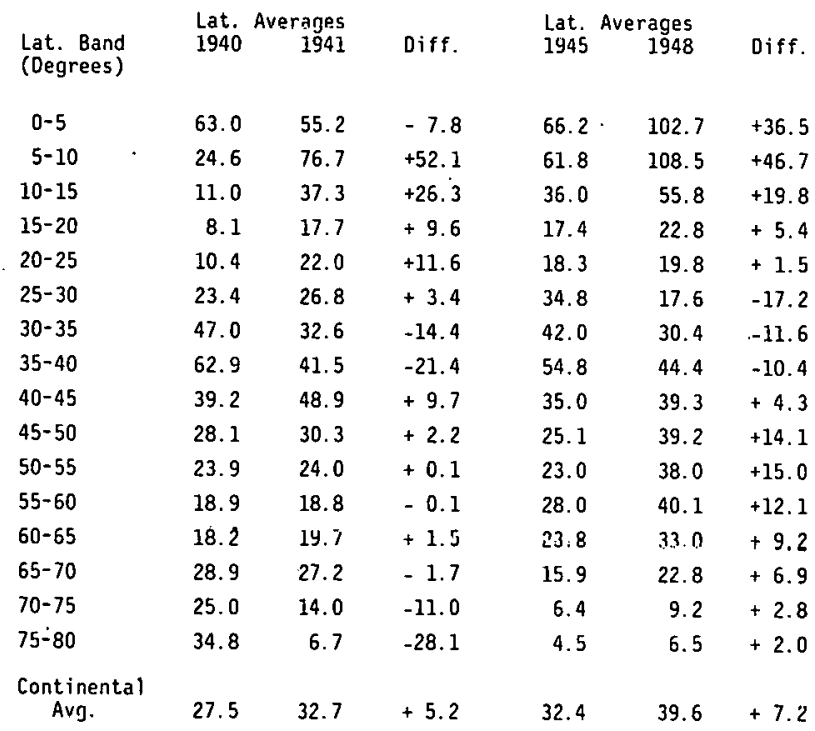

TABLE 2. Similar to Table 1, except for the month of January. (After Corona, 1979.)

\begin{tabular}{|c|c|c|c|c|c|c|}
\hline $\begin{array}{l}\text { Lat. Band } \\
\text { (Degrees) }\end{array}$ & $\begin{array}{l}\text { Lat. } \\
1940\end{array}$ & $\begin{array}{r}\text { Averages } \\
1941\end{array}$ & Diff. & $\begin{array}{l}\text { Lat. A } \\
1945\end{array}$ & $\begin{array}{l}\text { rages } \\
1948\end{array}$ & Diff. \\
\hline $0-5$ & 251.5 & 153.7 & -97.8 & 162.5 & 126.2 & -36.3 \\
\hline $5-10$ & 258.2 & 170.5 & -87.7 & 165.7 & 189.5 & +23.8 \\
\hline $10-15$ & 170.3 & 140.7 & -29.6 & 103.3 & 148.3 & +45.0 \\
\hline $15-20$ & 190.7 & 112.0 & -78.7 & 80.5 & 137.6 & +57.1 \\
\hline $20-25$ & 135.3 & 125.6 & -9.7 & 81.9 & 89.3 & +7.4 \\
\hline $25-30$ & 87.7 & 108.9 & +21.2 & 102.5 & 88.2 & -14.3 \\
\hline $30-35$ & 49.8 & 54.4 & +4.6 & 69.3 & 55.6 & -13.7 \\
\hline $35-40$ & 36.8 & 33.4 & -3.4 & 39.4 & 40.2 & +0.8 \\
\hline $40-45$ & 41.0 & 45.4 & +4.4 & 46.3 & 53.3 & +7.0 \\
\hline $45-50$ & 52.7 & 53.7 & +1.0 & 51.5 & 72.4 & +20.9 \\
\hline $50-55$ & 50.4 & 50.9 & +0.5 & 52.1 & 60.5 & +8.4 \\
\hline $55-60$ & 46.3 & 52.1 & +5.8 & 65.7 & 60.2 & -5.5 \\
\hline $60-65$ & 60.7 & 63.3 & +2.6 & 64.1 & 55.7 & -8.4 \\
\hline $65-70$ & 63.2 & 54.6 & -8.6 & 34.1 & 41.0 & +6.9 \\
\hline $70-75$ & 37.0 & 36.6 & -0.4 & 15.9 & 23.1 & +7.2 \\
\hline $75-80$ & 24.8 & 40.4 & +15.6 & 16.5 & 13.1 & -3.4 \\
\hline $\begin{array}{c}\text { Continental } \\
\text { Avg. }\end{array}$ & 101.1 & 84.6 & -16.5 & 75.3 & 85.3 & +10.0 \\
\hline
\end{tabular}

This trend in summer precipitation is reflected in the behavior of the Indian monsoon as depicted by Bryson (1974), (Fig. 14), and also in the "southern oscillation" given by the surface pressure anomalies at Jakarta according to Berlage (1966), (Fig. 15). There is a tendency by which positive pressure anomalies at Jakarta coincide with below-normal rainfall yields of the Indian summer monsoon. On the other hand, above-normal rain in the equatorial dry area of the Pacific is expected during high-pressure anomalies over Indonesia, as can be seen from a comparison of Fig. 15 with Fig. 16. From the latter diagram it becomes evident that only during the first half of the continental drought period in the northern hemisphere (1941-1946) did the Line Island region show abovenormal precipitation. The second half of that period witnessed below-normal precipitation also over the equatorial Pacific.

If the long-term precipitation trends over the continental regions of the northern hemisphere (Figs. $17,18,19)$ were, indeed, representative of the whole hemisphere and were not totally compensated by opposite trends in oceanic precipitation, we will have to look rur other evidence in the hydrological cycle that might substantiate our findings. Figure 20 sliows estimates of surface temperatures of both hemispheres and of the whole earth as given by Lamb (1977) and based upon work by Mitchell (1961) and others. According to this diagram the climatic optimum occurred at the beginning of the precipitation drop showi in Fig. 19. A comparison of Fig. 19 with Fig. 1 suggests that peaks in continental precipitation coincide with relatively warm northern hemispheric temperatures in the layer between the surface and $100 \mathrm{mb}$. We are tempted to conclude that the interannual variability of mean tropospheric temperatures is positively correlated with the storage of precipitable water in the troposphere, and also with the amount of precipitation released in synoptic disturbances when averaged over sufficiently long time periods and sufficiently large areas.

This admittedly vague indication of the moisture storage in the atmosphere varying in phase with continental precipitation gives us further encouragement to assume that variations in oceanic rainfall are not compensating those in continental precipitation amounts. If this hypothesis were indeed true, one ought to find a reasonably strong interannual variability in the evaporation rate from the oceans of the northern hemisphere. Computation of these rates is presently in progress but is faced with considerable difficulties because of inaccurate and inadequate data. In anticipation of these computational results, let us take a preliminary look at some of the parameters influencing the bulk transfer of moisture from the ocean to the atmosphere (see e.g. Hess, 1959; 


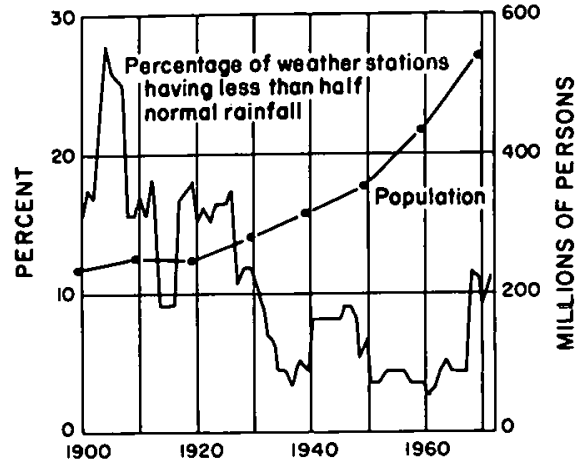

Fig. 14. Percent of weather stations in northwest India reporting less than half of the normal rainfall, and population of India (dots). (After Bryson, 1974.)

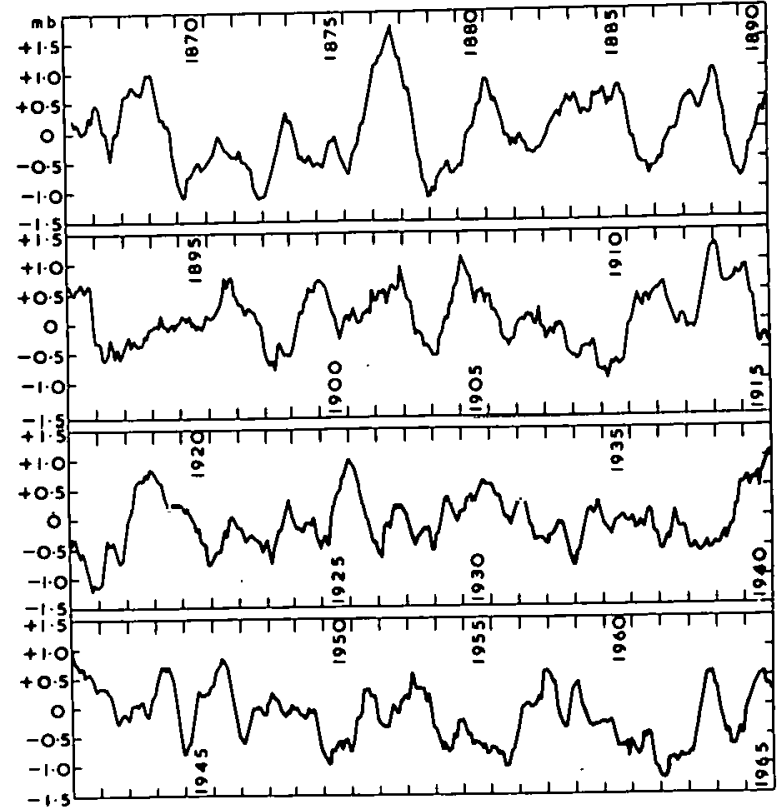

Fig. 15. Southern oscillation, as indicated by surface pressure anomalies at Jakarta, Indonesia. (From Berlage, 1966.)
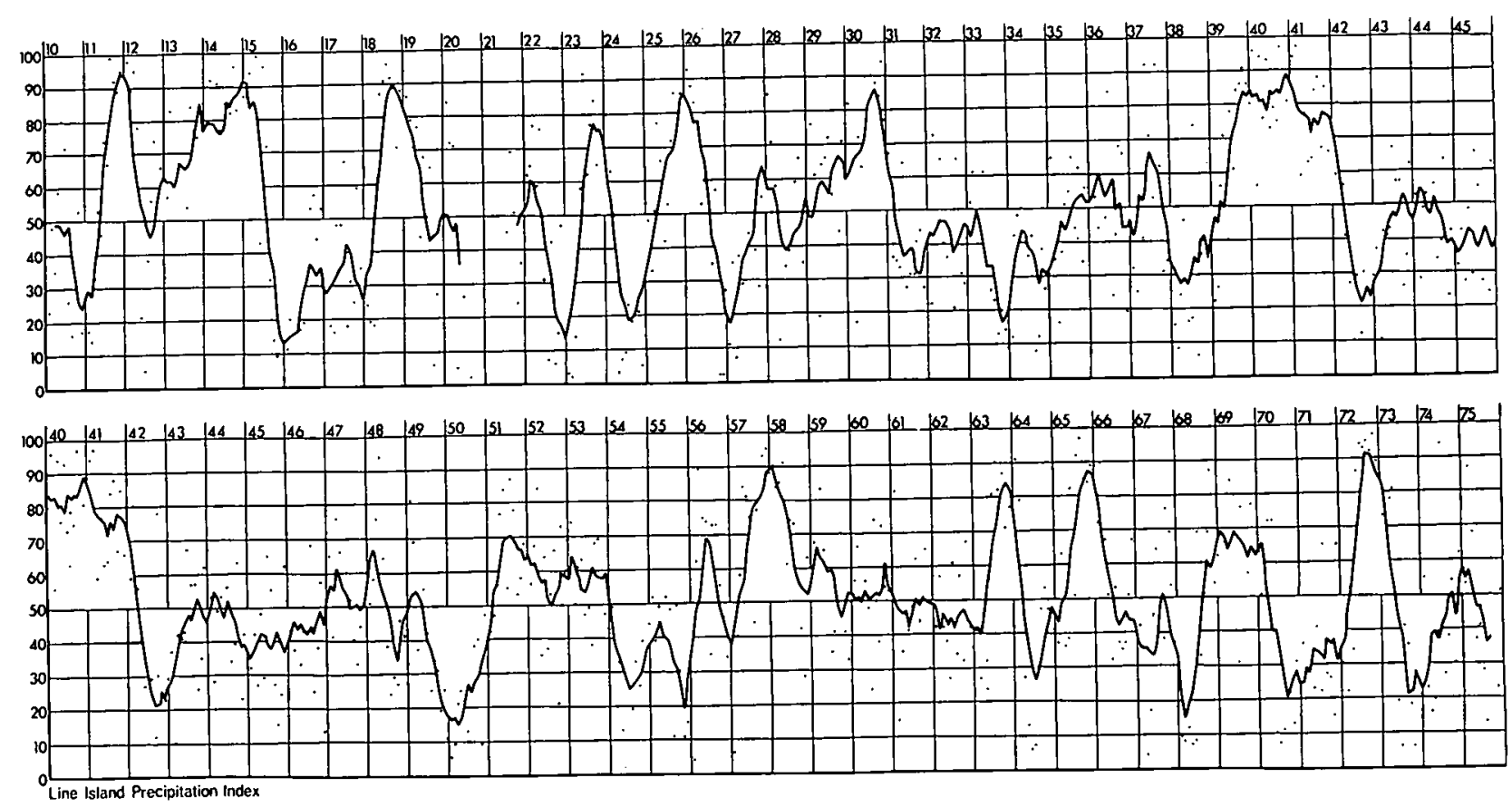

Fig. 16. Line Island precipitation index for the years 1910 to 1975 . Dots indicate monthly values, the heavy line stands for a 7 -month running average. (Data from Meisner, 1976.) 


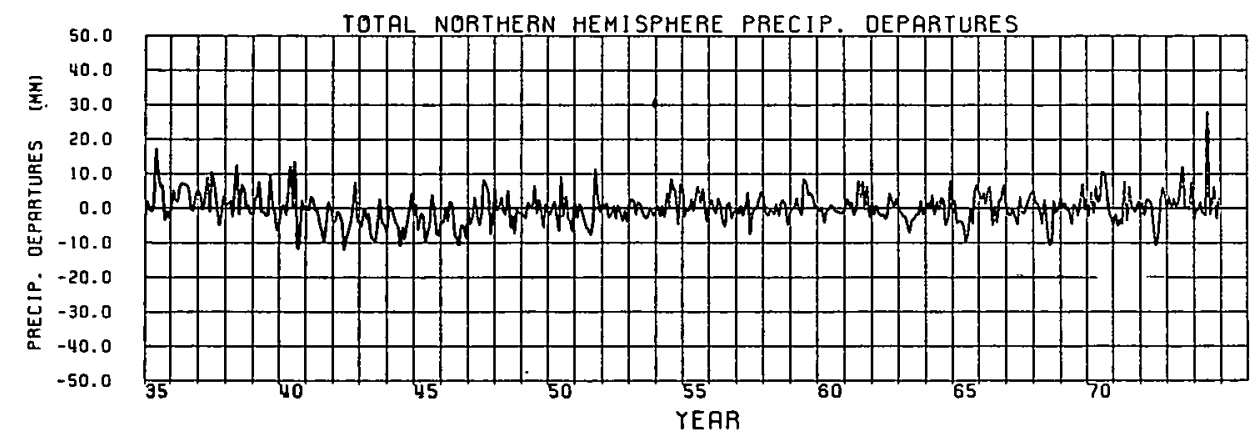

Fig. 17. Time series combining the 40 years of average monthly continental precipitation departures from monthly mean values for North American and Europe, Asia and North Africa to obtain the average monthly continental precipitation for the northern hemisphere. Vertical lines indicate the month of January (Corona, 1979).

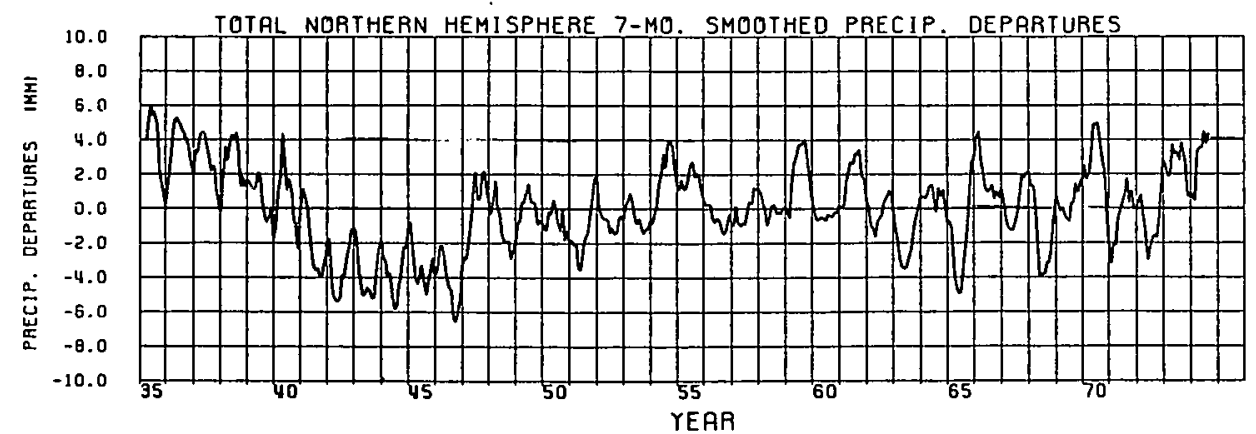

Fig. 18. Data set of Fig. 17 with seven-month running-mean filter applied (Corona, 1979).

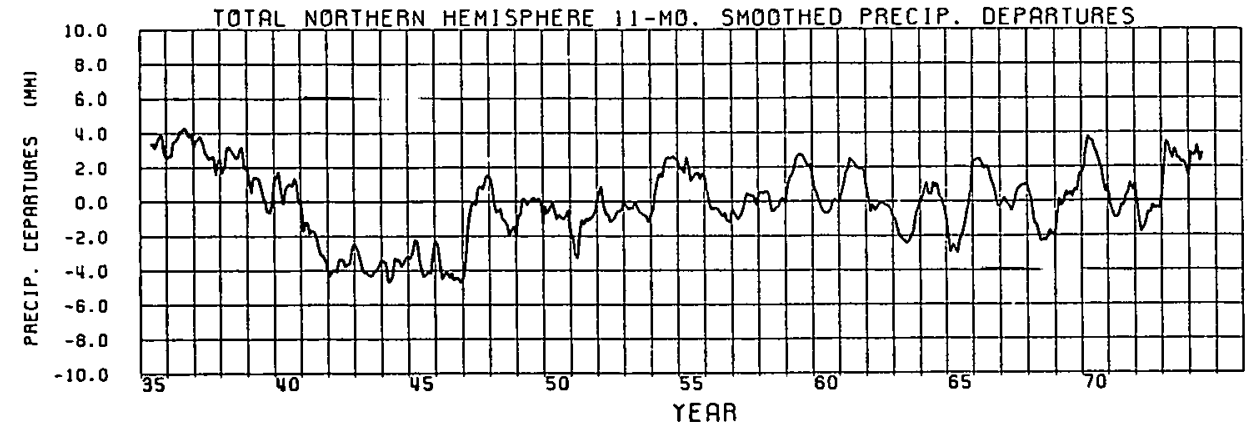

Fig. 19. Data set of Fig. 17 with eleven-month running-mean filter applied (Corona, 1979).

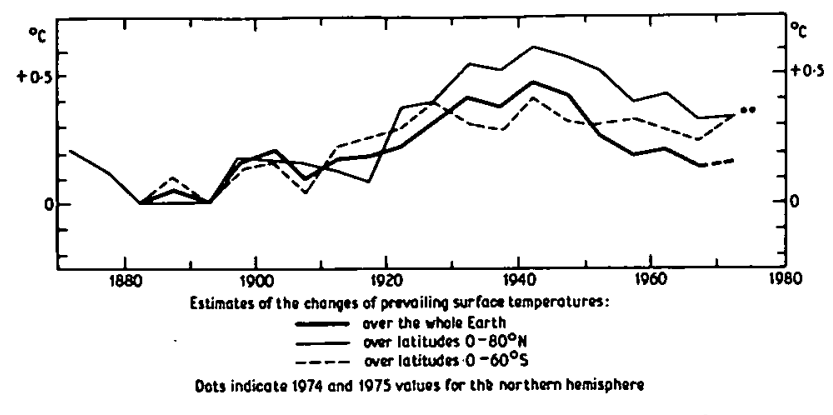

Fig. 20. Average temperature over the whole earth since 1870. (From Lamb, 1977, based upon data by Mitchel1, 1961, and others.) 
Laevastu, 1963; Scige1, 1977). The evaporation rate in $\mathrm{m} \mathrm{sec}^{-1}$ can be written as

$$
E=-\frac{\rho k\left[k u_{10} / \ln \left(\frac{10}{z_{0}}\right)\right]}{\ln \left(10 / z_{0}\right)}\left(\bar{q}_{10}-\bar{q}_{z_{0}}\right)
$$

$\left(\rho \cong 1.3 \times 10^{-3} \mathrm{~g} \mathrm{~cm}^{-3}\right.$, air density; $k=0.38$, von Kármán constant; $u_{10}=$ wind speed in $\mathrm{m} / \mathrm{sec}$ at shipdeck level, i.e. $10 \mathrm{~m}$ above the ocean; $z_{0}=$ roughness height, a function of wind velocity; $\bar{q}_{10}$ and $\bar{q}_{z}=$ specific humidities at ship-deck level and at the ocean surface). According to Eqn. (3) evaporation is strongly influenced by the wind speed in the lowesl layers above the ocean, and by the difference between the saturation vapor pressure at the sea surface (mainly a function of sea-surface temperature, SST) and the actual vapor pressure at a certain distance from the ocean surface.

SST's in middle latitudes of the Pacific, according to $\mathrm{Fig} .31$, have changed by as much as $2^{\circ} \mathrm{C}$ between 1963 and 1976. Figure 1 indicates a much smaller, if any, systematic cooling trend in the atmosphere during the same period of time. That the atmosphere of mid-latitudes did not respond readily to the long-term cooling trend of the North Pacific is also brought out by Fig. 21 which relates, among other things, the meridional SST gradient between $20^{\circ} \mathrm{N}$ and $50^{\circ} \mathrm{N}$ (showing a pronounced trend) with the meridional gradient in atmospheric thickness $300 / 850 \mathrm{mb}$, in the same latitude band over the Pacific sector. The latter curve reveals no significant trend. We are emboldened, therefore, to assume that oceanic temperatures in middle latitudes cooled more between 1963 and 1976 than atmospheric temperatures, hence the difference $\left(q_{10}-q_{z_{0}}\right)$ might have increased during that time period over the North Pacific, enhancing evaporation.

As shall be pointed out later, there also is a disagreement between North Atlantic SST trends and atmospheric temperature trends.

On a regional rather than hemispheric scale, McLain and Favorite (1976) show an approximate agreement between air and sea-surface temperature trends in the southeastern Bering Sea (Fig. 22). The long-term air temperature fluctuations appear to be about twice as large as those of SST. The economic impact of such temperature trends becomes evident from the same study. Low catches in salmon and halibut resulted from the severe winters of 1970-71 and 1971-72.

In this context we find it interesting that North American precipitation revealed a gradual increasing trend since 1963 (Fig. 5). Furthermore it should be noted that Pacific SST maxima of mid-latitudes in 1963, 1967, 1970/71 and 1972 correspond to North American precipitation minima at roughly the same times (compare Fig. 31 with Fig. 5), whereas SST minima in 1964,1966,1970,1971 and 1973 appear to coincide with precipitation maxima. One has to be careful with such a comparison between North Pacific SST anomalies and North American precipitation, however, because both could be related to a preferred atmospheric long-wave pattern. Such a pattern might influence North American precipitation more than variations in the evaporation rate from the mid-latitude Pacific. Furthermore, one should not expect to find a perfect correlation between North Pacific SST's and North American precipitation because, after all, the surface wind characteristics enter in an important way into Eqn. (3) through the shape of the low-level wind profile and the ocean roughness. Furthermore, North America receives significant amounts of moisture from the Gulf of Mexico. For similar reasons we cannot attempt to find a significant correspondence between Atlantic SST variability and precipitation over the European, Asian and North African continental complex, since that land mass has additional, important source regions for its water vapor, such as the Indian 0cean.

In the furegoing discussion we have pointed out several interesting aspects of the long-term variability of continental precipitation. A description of our preliminary analysis results would not be complete without demonstrating the possible existence of trends in seasonal precipitation over the northern hemisphere continental regions. In Figs. 23 to 30 the seasonally averaged precipitation amounts for the two northern hemisphere continental blocks are shown, together with the amounts for individual months, and the seasonal values subjected to a 5- and 7-year smoothing. Moreover, an indication of the number of stations involved in the statistics is also provided. As should be suspected from our earlier discussion, the noise in the diagrams on an interannual time scale is considerable. Several features, apparent from the smoothed data presentations, should be pointed out. North American winter precipitation (Fig. 23) showed a marked decrease from about 1937 to 1946, reminiscent of the general precipitation decrease in the northern hemisphere mentioned earlier. The spring precipitation seems to have undergone a much more prolonged decreasing trend (Fig. 24). A weak 22-year cycle is apparent in Fig. 25, depicting the summer rainfall. Such a cycle has been described by Mitchell (1979) in drought index data of the North American west (see also Herman and Goldberg, 1978). Autumn precipitation (Fig. 26) shows cycles of approximately 11 and 22 years.

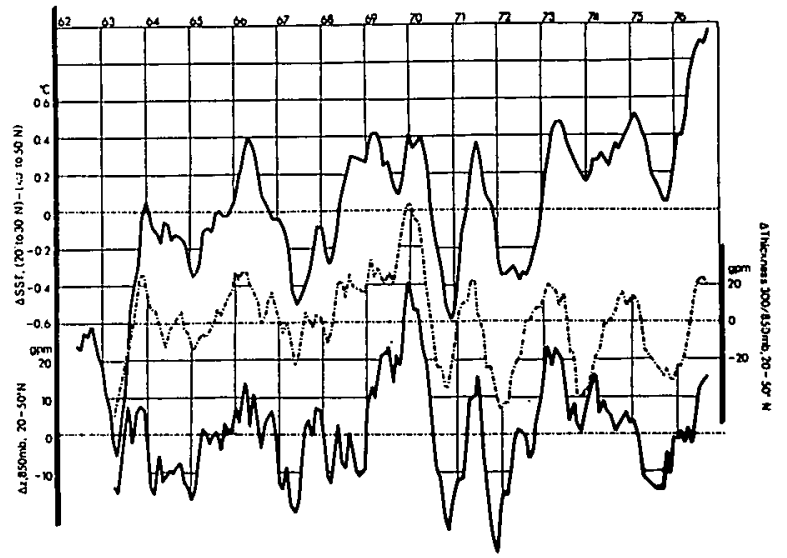

Fig. 21. Mean meridional SST gradient anomalies $20^{\circ}-$ $50^{\circ} \mathrm{N}$ averaged over longitudinal width of Pacific (upper curve, solid line, ${ }^{\circ} \mathrm{C}$ ), thickness gradient $300 / 850 \mathrm{mb}$ (middle curve, dashed-dotted, geopotential meters) and height gradients of $850-\mathrm{mb}$ surface (lower curve, solid line, geopotential meters) computed over the same region as SST gradients. Each data series was subjected to a 7-month running-mean filter. 

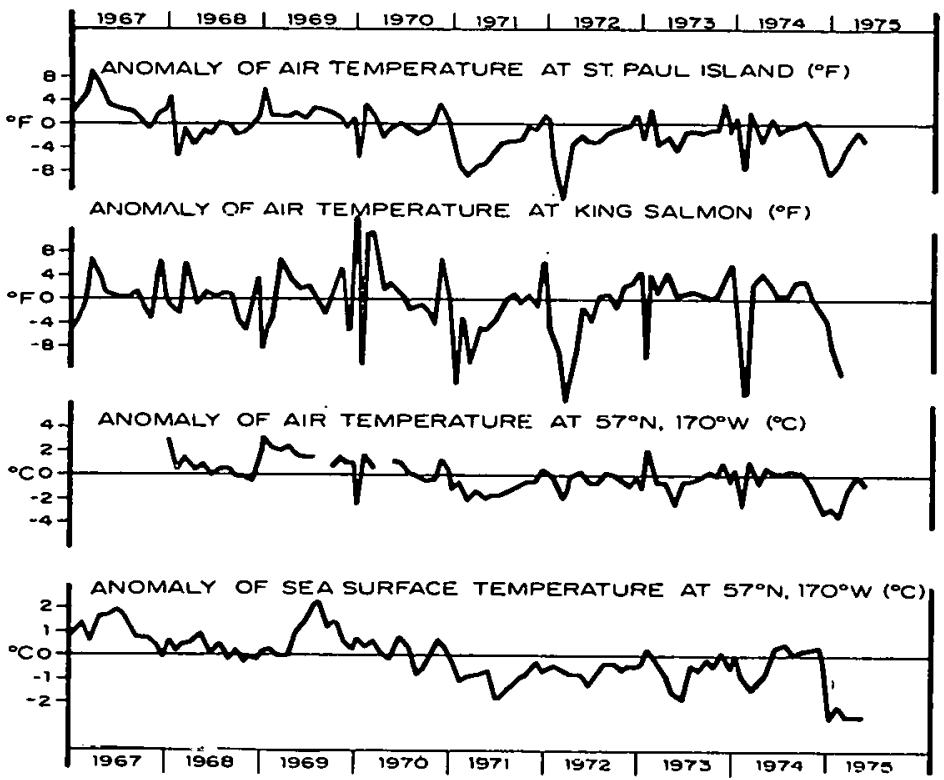

Fig. 22. Anomaly of air temperature and sea surface temperature in the southeastern Bering Sea during 1967-75. Series 1 is anomaly of air temperature in ${ }^{\circ} \mathrm{F}$ at St. Paul Island, Alaska from 1941-70 mean. Series 2 is anomaly of air temperature in ${ }^{\circ} \mathrm{F}$ at King Salmon, Alaska from 1941-70 mean. Series 3 is anomaIy of air temperature in ${ }^{\circ} \mathrm{C}$ at $57^{\circ} \mathrm{N}, 170^{\circ} \mathrm{W}$ (near St. Paul Island) from April 1962-May 1975 mean. Data for Series 1 and 2 from National Climatic Center and data for Series 3 and 4 from Fleet Numerical Weather Central. (After McLain and Favorite, 1976.)
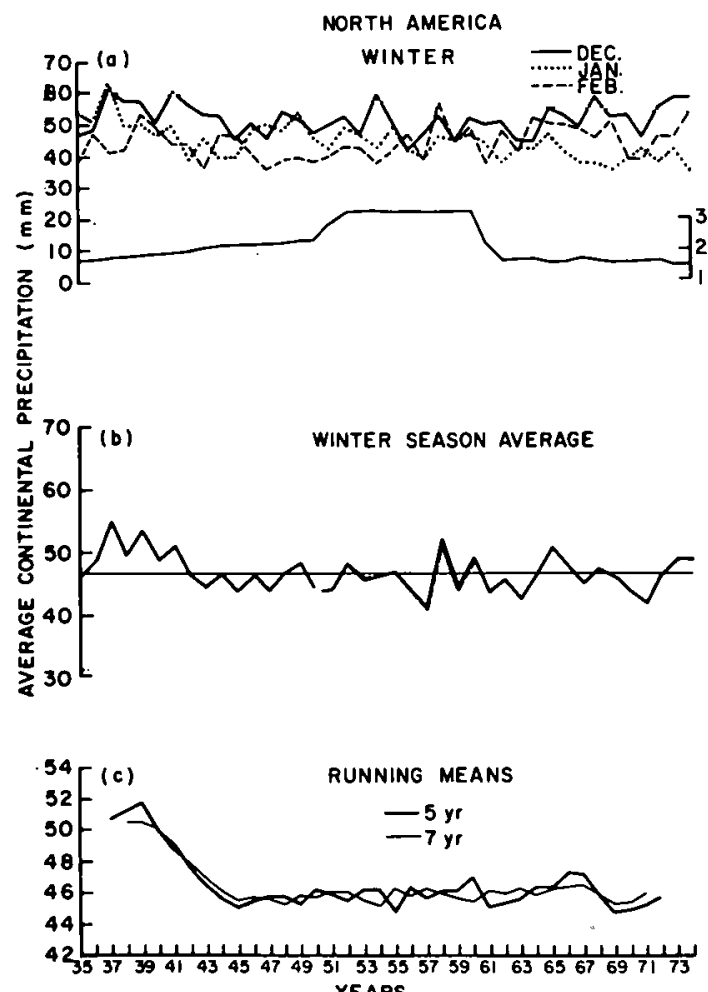

Fig. 23. Plots of (a) monthly average continental precipitation, (b) seasonal mean and (c) 5and 7-year running means for forty years of winter months in the North American continental areas. Included in (a) is a plot of the number of stations per year used in the derivation of the continental averages and a correction of the seasonal mean (dashed line in c), when 70 Central American stations were removed. Also included is the 40-year seasonal mean of the data (horizontal line in b). (Corona, 1979.) 
NORTH AMERICA SPRING

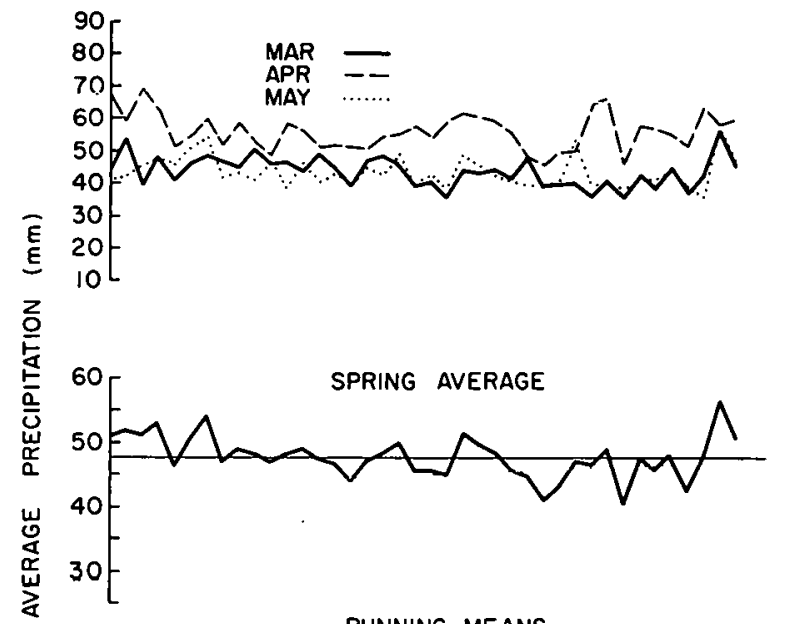

RUNNING MEANS

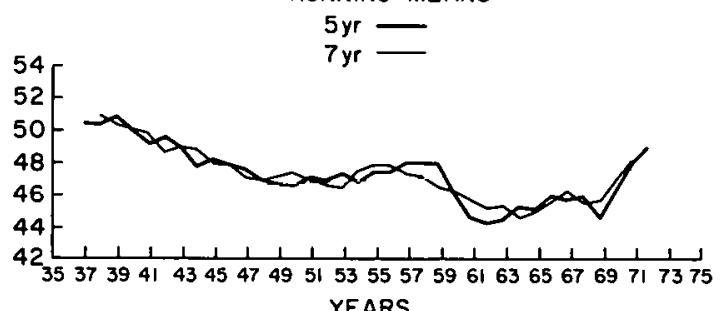

Fig. 24. Similar to Fig. 23, except for spring season in North America. (Corona, 1979.)

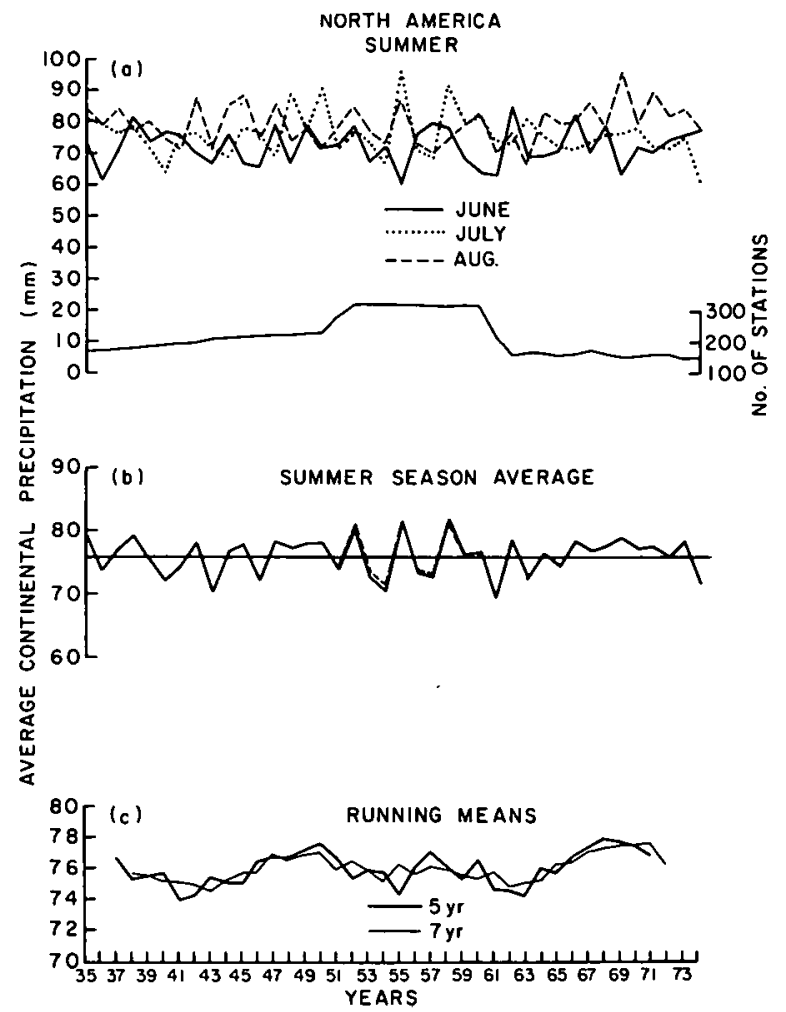

Fig. 25. Similar to Fig. 23, except for summer season in North America. (Corona, 1979.)
NORTH AMERICA AUTUMN
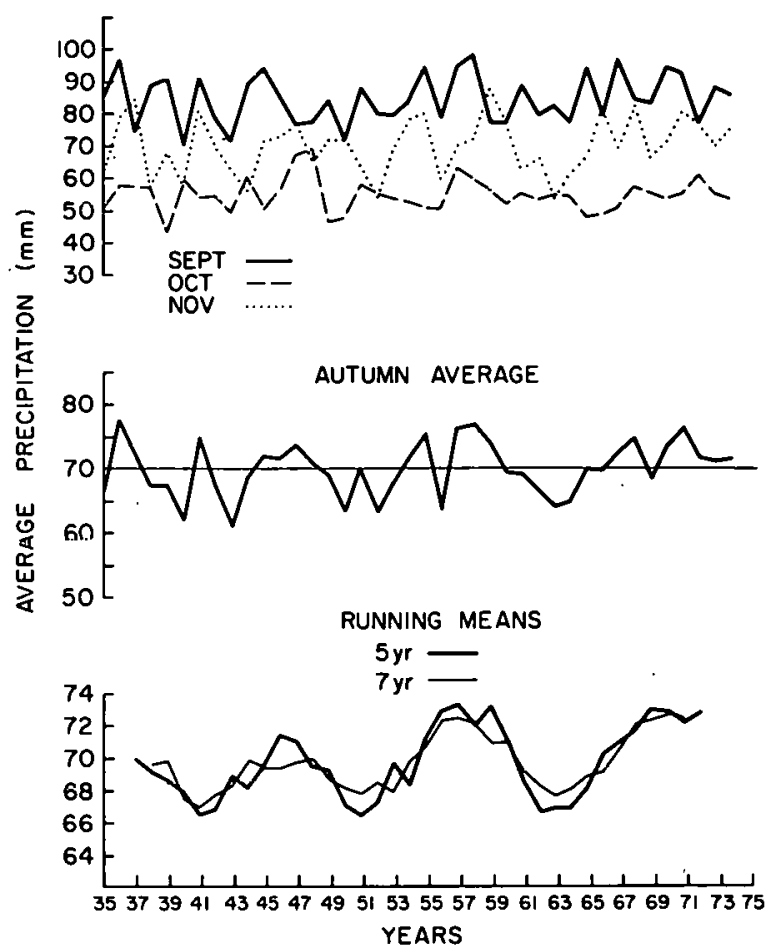

Fig. 26. Similar to Fig. 23, except for autumn season in North America. (Corona, 1979.)
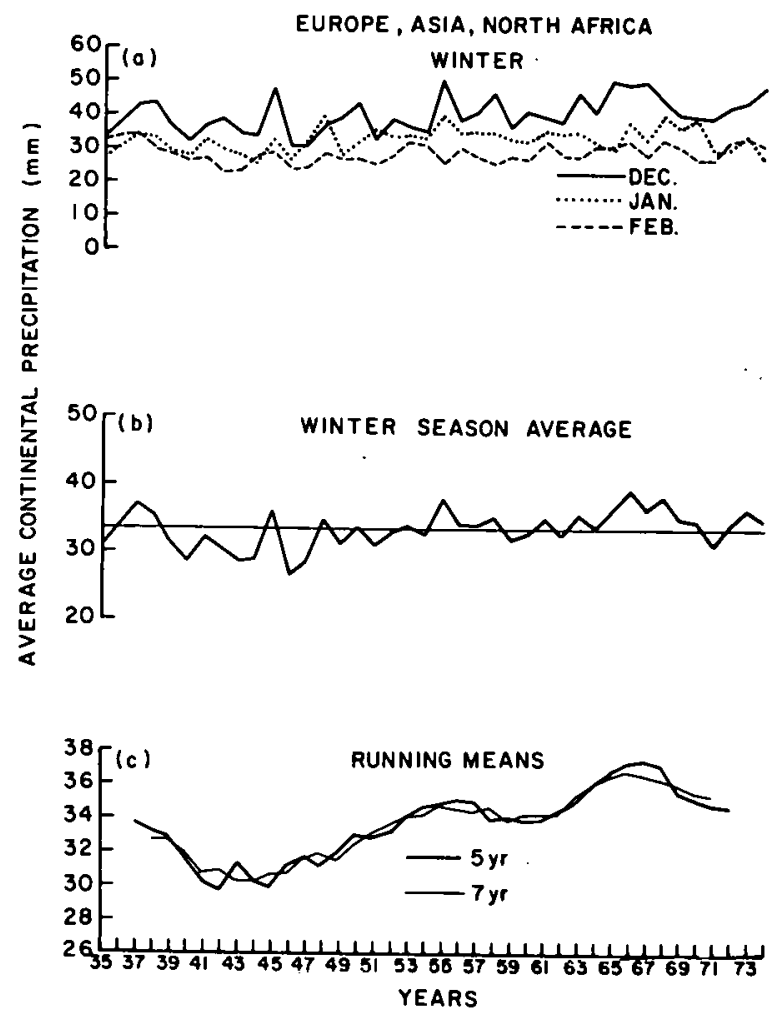

Fig. 27. Plots of (a) monthly continental average precipitation, (b) seasonal mean and (c) 5and 7-year running means for forty years of winter months in European, Asian and North African continental areas. Also included is the 40-year seasonal mean of the data (horizontal line in b). (Corona, 1979.) 
EUROPE, ASIA + NORTH AFRICA SPRING

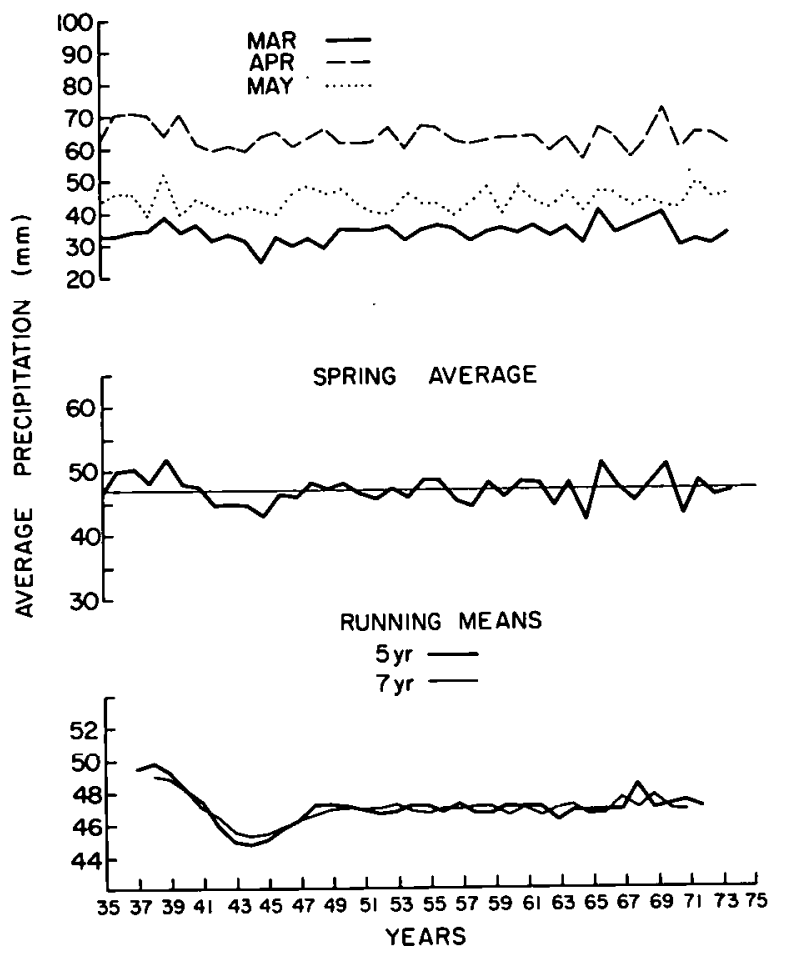

Fig. 28. Similar to Fig. 27, except for spring season. (Corona, 1979.)
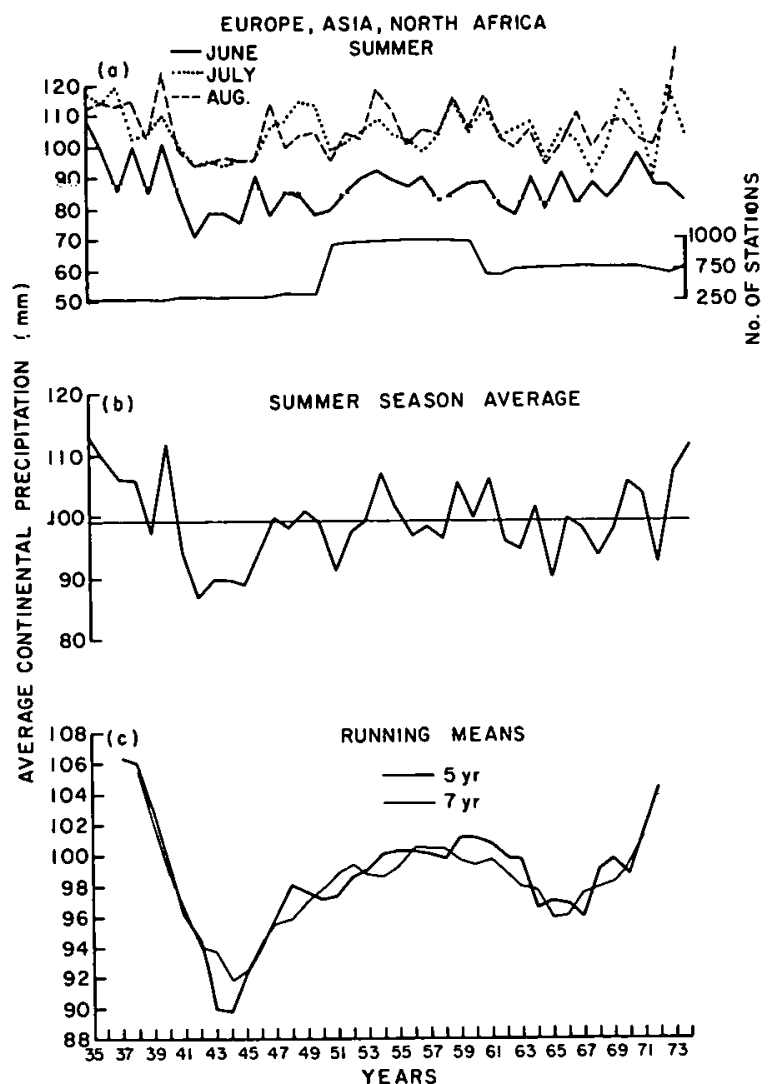

Fig. 29. Similar to Fig. 27, except for summer season. Also included is a plot of the number of stations per year used in the derivation of the continental averages (part a). (Corona, 1979.)
EUROPE, ASIA + NORTH AFRICA AUTUMN
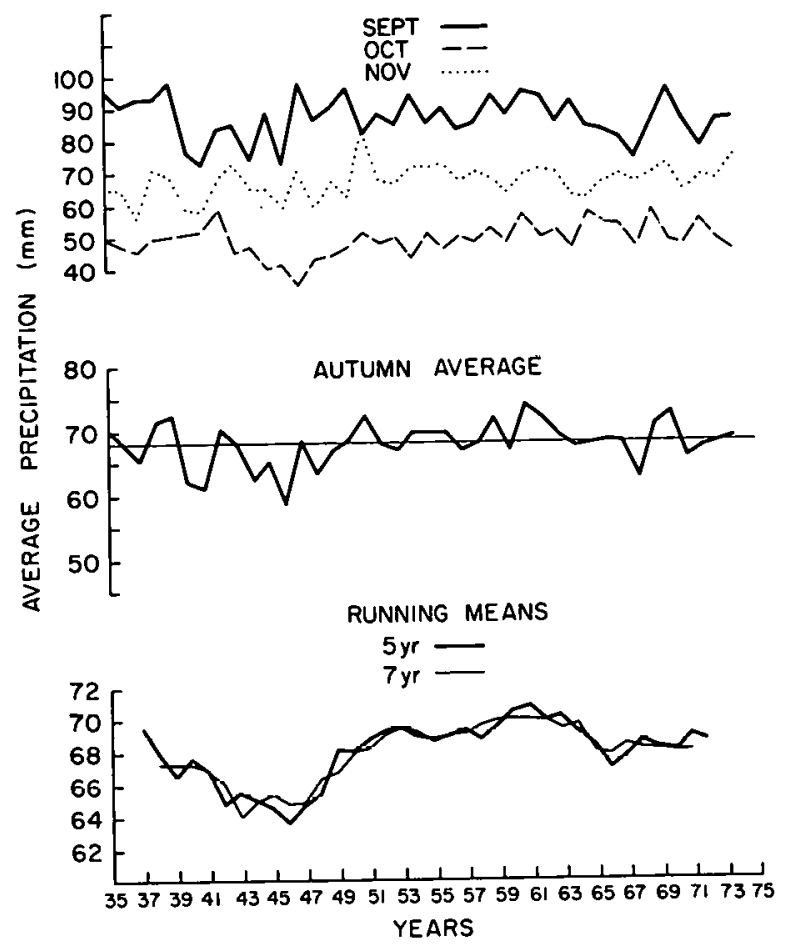

Fig. 30. Similar to Fig. 27, except for autumn season. (Corona, 1979.)

Over Europe, Asia and North Africa a cycle of approximately 22 years appears in the summer data and one of similar length but of smaller amplitude in the autumn data (Figs. 29 and 30). Winter and spring (Figs. 27 and 28) show a more irregular trend behaviur. The decrease of precipitation prior to 1946 is quite pronounced in the summer data, as mentioned earlier.

In summary, we can state that the observed variability of continental precipitation holds out the possibility of climatic changes in the hydrological cycle, involving moisture storage in the atmosphere and evaporation from the ocean. Since latent heat released in the atmosphere tends to generate eddy available potential energy (it rains more in warm than in cold air masses), climatic variations in the hydrological cycle may have a non-negligible impact on the general circulation of the atmosphere.

We have to realize that the interaction between the hydrological cycle and the general circulation can come about in more than one way, however. Release of latent heat in precipitation is perhaps the most obvious of such interaction possibilities. We have mentioned the probability of variable moisture storage in the atmosphere, affected by variable atmospheric mean temperatures and variable precipitation. Such trends in moisture storage are expected to influence the radiation budget of the atmosphere, especially in the infrared absorption bands of water vapor, but also may affect cloud cover and albedo. A connection between SST variations and evaporation may also be subject to feedback processes as heat losses to the atmosphere produce cooling of the oceanic surface layers (Camp, 1976; Elsberry and Camp, 1978; Camp and Elsberry, 1978; Elsberry and Garwood, 1978). Such feedback mechanisms make an assessment of the role of 
the hydrological cycle in climatic changes extremely difficult and complex. It should also be mentioned that besides evaporation, moisture storage in the atmosphere, and precipitation, the zunal and meridional water vapor transports undergo significant interannual variability (Rosen and Salstein, 1979). This fact adds an additional dimension of complexity to an exploration of the impact of the hydrological cycle on climate variation. Ignoring the variability of the hydrological cycle, as is conveniently done in much of climatological research, will not make results and conclusions more reliable.

\section{REGIONAL, SHORT-TERM CLIMATE VARIABILITY AND GEOPHYSICAL FEEDBACK MECHANISMS}

\subsection{Observed Trends in SST Anomalies}

Figures 31 and 32 depict the zonally averaged SST distributions in various latitude bands of the Pacific and Atlantic Oceans. The Parific reveals a strully cooling trend which appears to be confined to middle and high latitudes. Superimposed upon this trend are excursions of temperature of shorter duration. SST trends in the Atlantic are somewhat less pronounced than in the Pacific, especially in middle latitudes (see also Fieux and Stommel, 1975). Shorter-period perturbations are of similar amplitudes in both oceans. The subtropical Atlantic seemed to have undergone a moderate warming trend which, as of 1974 , may have spilled over into higher latitudes.

It is of interest to compare these SST data, obtained from the U.S. Navy Fleet Numerical Weather Central in Monterey, California, with a time series of data on Arctic sea-ice extent, published recently by Walsh and Johnson (1979): Figure 33 shows unsmoothed and smoothed monthly anomalies of sea-ice extent. In the Atlantic sector the interannual variability has a year-around effect on the data, whereas in the Bering Sea, influenced by Pacific conditions, the interannual variability of ice conditions makes a contribution only to the cold-season aspects of Fig. 33. During

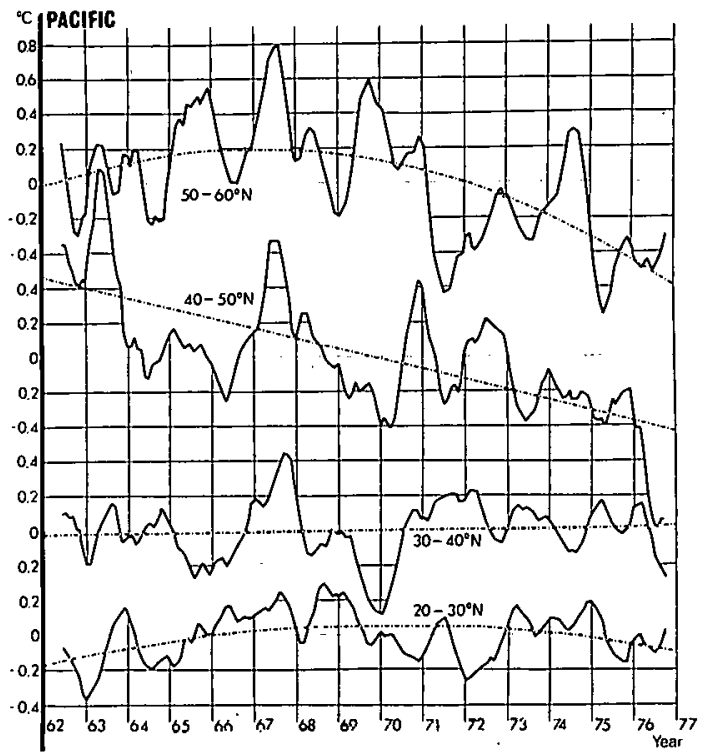

Fig. 31. Monthly SST anomalies in the North Pacific $\left({ }^{\circ} \mathrm{C}\right)$ averaged over the latitude bands as indicated. A seven-month running-mean filter has been applied to the monthly anomaly data. Dashed-dotted lines indicate the least-squares fit of first-, second-, or third-order polynomials. the warm season the Bering Sea has been essentially ice free. With this preferential weighting of Atlantic contributions to the ice extent variability (Fig. 34) one would expect a certain mirrnr-image match lelween FIgs. 32 and 33 . Instead, the iciest period between 1967-1971 (see also Sanderson, 1975) follows a peak in North Atlantic (and North Pacific) high-latitude SST's. The ice minimum in 1974 coincides with coldest North Atlantic temperatures, even though the pacific at $50-60^{\circ} \mathrm{N}$ had a short respite in its cooling trend. From the short, overlapping data sample which we have available, it almost appears that a warm North Atlantic goes with expanded sea-ice cover, whereas below-normal SST's coincide with below-normal sea-ice extent.

Surface temperature data in the polar cap north of $60^{\circ} \mathrm{N}$ have been compiled from available records, including those from ice stations, by Walsh (1977) and Walsh and Johnson (1979). Figure 35 shows a smoothed time-series of these data. There is reasonable agreement between the trends revealed in Figs. 33 and 35 . The period of warm polar regions around 1960 agrees with a relatively small sea-ice extent. The rapid cooling until 1965 coincides with a rapid buildup of sea ice, and a subsequent warming trend in air temperatures is loosely matched by a shrinking ice cover.

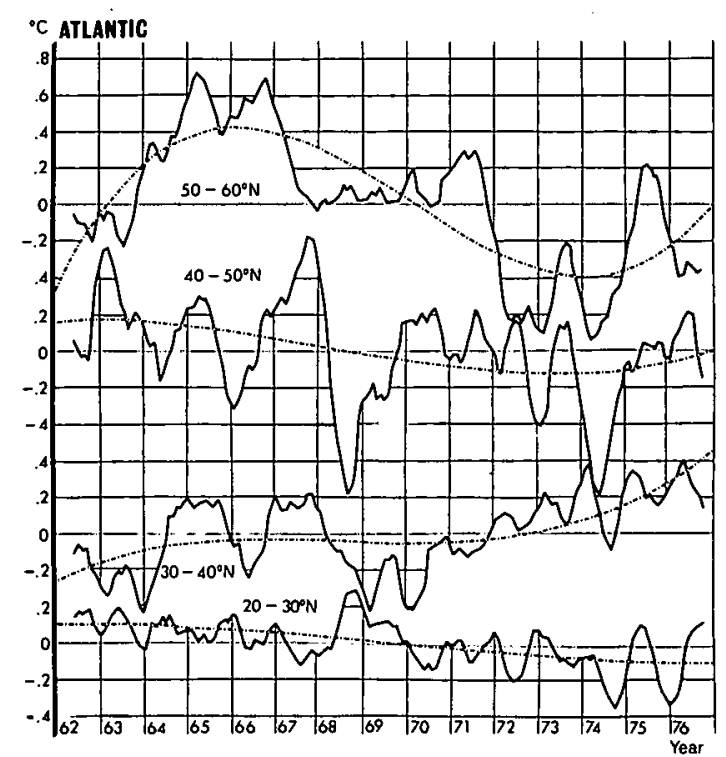

Fig. 32. Similar to Fig. 31, except for Atlantic. (Data courtesy of Fleet Numerical Weather Central, Monterey, CA.) 

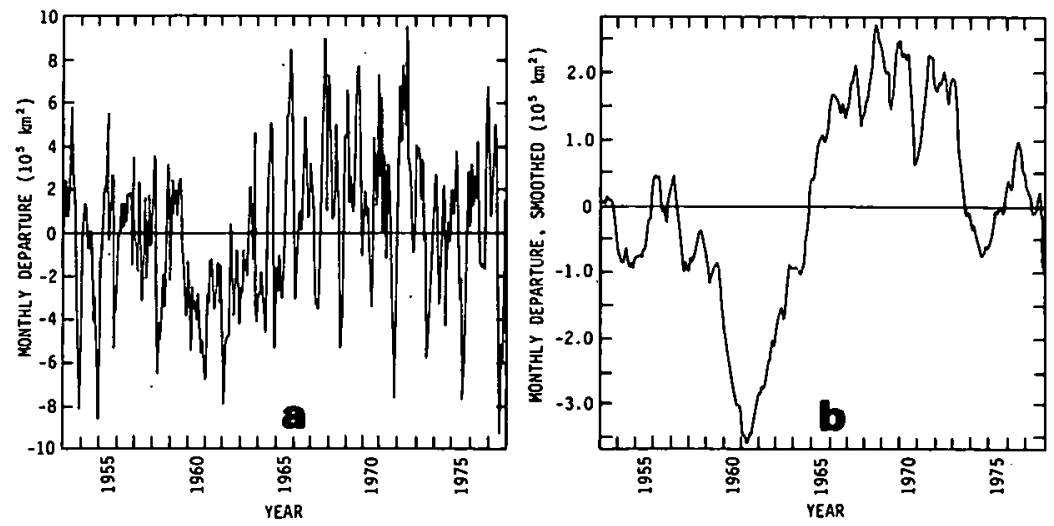

Fig. 33. Time series of departures from monthiy means of the area covered by Arctic sea ice $\left(10^{5} \mathrm{~km}^{2}\right.$ ), unsmoothed values (a) and 24 -month running means (b). (From Walsh and Johnson, 1979.)

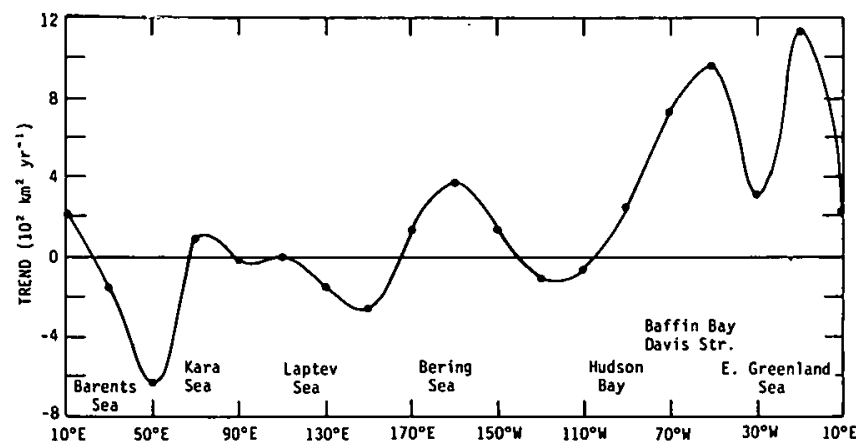

Fig. 34. Longitudinal dependence of trends of sea ice extent $\left(10^{2} \mathrm{~km}^{2}\right.$ year $\left.{ }^{-1}\right)$ during the $300-$ month period shown in Fig. 33 and obtained from the slopes of least-squares lines fitted to time series of departures from monthly means in each $20^{\circ}$ longitude sector. (From Walsh and Johnson, 1979.)

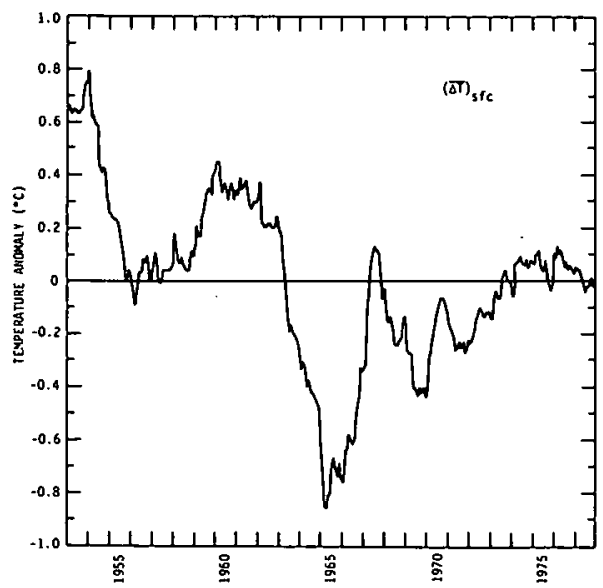

Fig. 35. 24-month running means of the departures $\left({ }^{\circ} \mathrm{C}\right)$ from the 25 -year normal area-weighted monthly mean surface air temperatures of the polar cap north of $60^{\circ} \mathrm{N}$. (From Walsh and Johnson, 1979.)
It is easy to visualize a positive feedback mechanism between polar air temperatures and sea-ice extent if we consider ice formation to be mainly a consequence of heat loss to the atmosphere. Extended sea-ice cover inhibits heat flux from the ocean to the atmosphere and also increases the albedo. Both factors tend to reduce the energy made available to the lower layers of the troposphere.

Apparently the increase in the combined snow and ice extent observed by Kukla (1978) between 1971 and 1973 is not reflected in the sea-ice conditions only, as shown in Fig. 33, nor in the polar temperature trend of Fig. 35. We have to entertain some doubt, therefore, as to the power of a feedback mechanism between air temperature and snow-plus-ice cover, if it exists at all. This lack of an obvious feedback should not be surprising because snow cover not only tepends on continental temperatures but also on the availability of moisture, butl, factors being strongly influenced by the planetary-wave characteristics of the general circulation. As a matter of fact, with what has been said in Chapter 2, one might even anticipate that abnormally cold temperature regimes are somewhat deprived of precipitation because of the reduced moisture-storage capacity of the atmosphere.

One might note, that the winter $1977 / 78$ showed the largest area of continental snow cover in the northern hemisphere. since satellite monitoring became feasible (Fig. 36) (Wiesnet and Matson, 1979).

We are not yet able to explain the disagreement, or perhaps the out-of-phase relationship, between ocean-ice conditions and high-latitude SST anomalies, especially in the Atlantic sector. The significance of these SST trends in the northernmost regions of the Atlantic and the Pacific and their possible relation to ice cover will have to be explored in greater detail before pertinent conclusions can be reached. As a preliminary attempt for such an exploration we present in Fig. 37 the SST differences between February, March and April, 1974, a relatively cold period according to Fig. 32, and February, March and April, 1965, which corresponds to a warm period. Both periods conform to the season of maximum ice cover (Walsh and Johnson, 1979).

During this nine-year period the Gulf Stream south of Newfoundland underwent a warming trend. This 


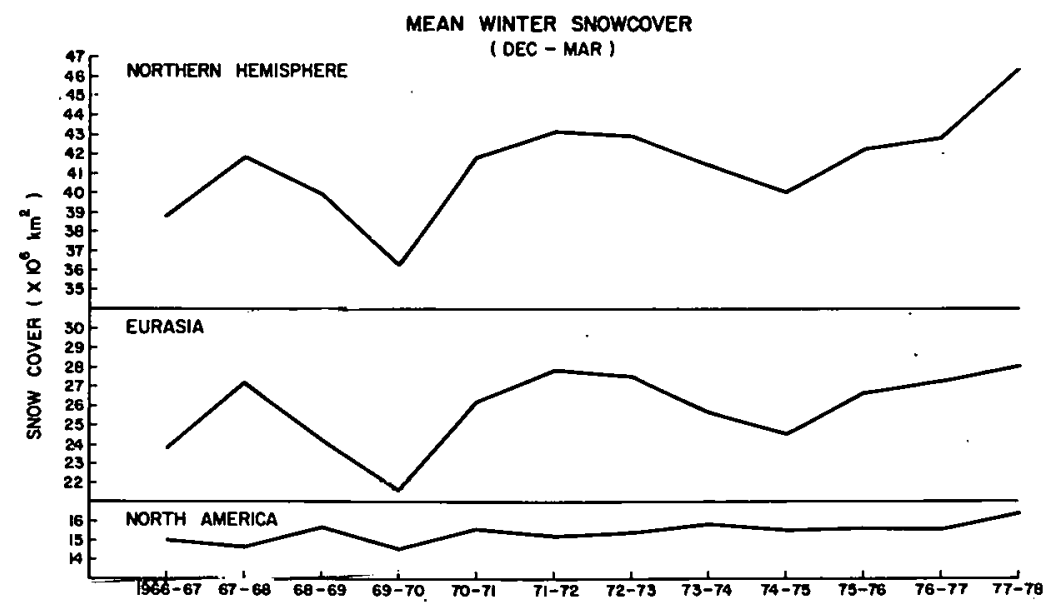

Fig. 36. Graph of mean winter snowcover for the northern hemisphere, Eurasia and North America from 1966-1978. (From Wiesnet and Matson, 1979.)

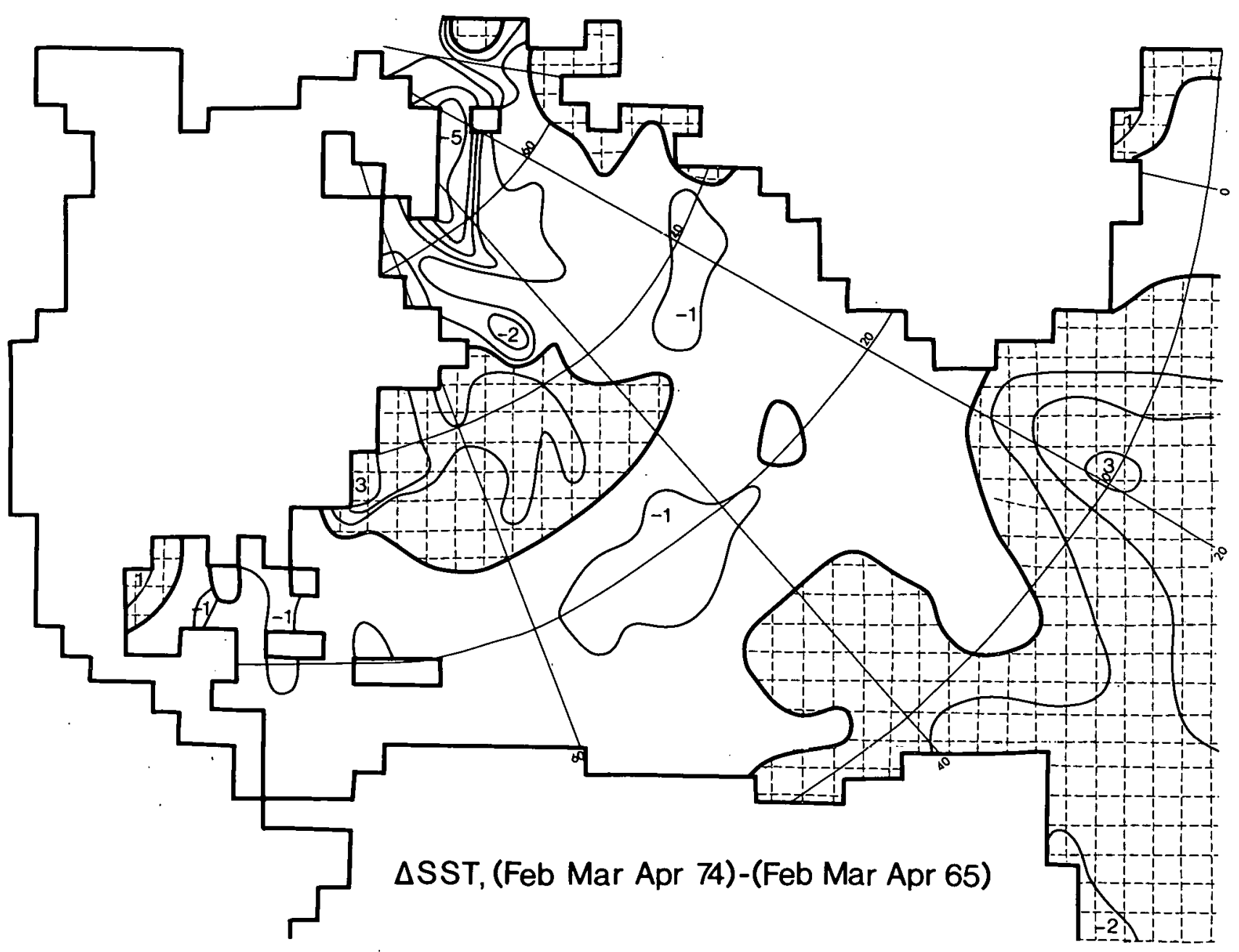

Fig. 37. Difference in sea-surface temperatures, in ${ }^{\circ} \mathrm{C}$, over the Atlantic between the average of February, March and Apri1, 1974 and February, March and April, 1965. Warming trends from 1965 to 1974 are indicated by shading. 
trend would agree well with an increase in the zonal wind stress of the North Atlantic trades during the same time period, suggested by Fig. 66 (presuming that the winds did not slacken significantly after 1972, the end of the records presently available to us). The Norwegian Sea, and the regions of the Greenland and Labrador currents exhibit a marked cooling trend while slight warming is observed along the North European coast. This SST distribution suggests an acceleration of the North Atlantic circulation in middle and high latitudes between 1965 and 1974 . It could be that an enhanced southward movement of the cold water masses between Greeland and Labrador and along the east coast of Greenland brought about negative SST trends but, at the same time, led to enhanced ice transport and to a more rapid melting of ocean ice.

Our findings reported here are, in certain aspects, consistent with those of Barnett (1978). His analysis of surface air temperatures ascribes the largest standard deviations of winter and annual mean temperatures to the continental regions. Thus, continenlal anomalies tend to "swamp" the hemispheric anomalies in a given season or year. Furthermore, an eigenvector analysis of his data reveals that continental and oceanic anomalies are often out of phase.

One of the largest continental anomalies was encountered in North America during the extremely cold winter of 1976-77. Leetmaa (1977) reports on a newlyformed we $11-$ mixed layer of $18^{\circ} \mathrm{C}$ water as deep as $550 \mathrm{~m}$ in the Sargasso Sea, as a consequence of winter cooling. The thermocline south of the Gulf Stream was 100 to $150 \mathrm{~m}$ deeper in March and April 1977, than is normally the case in this region. Gulf Stream water transport, therefore, appeared to be stronger-thannormal after this extremely cold winter, consistent with the anomaly pattern shown in Fig. 37 .

The preliminary data presented here indicate that high-latitude air temperatures, sea-surface temperatures and ocean-ice cover apparently do not operate together in a positive feedback loop. Even though, at this point of our investigation, we are not able to provide a reasonable account of these feedback mechanisms -- other than the vague indications given above -- the preliminary indication is that a negative feedback link exists somewhere between these three parameters and it operates on a time scale of several years. Perhaps it is such a negative link which prevents. Arctic temperatures and ice cover to engage in frequent runaway cycles. For this reason it appears important to investigate and model in detail the feedback processes involved between these three parameters. (For modelling attempts of feedbacks on long-time scales see for instance Budyko, 1969; Lindzen and Farre11, 1977; Saltzman, 1978; Moritz, 1979; Sergin, 1979; Warren and Schneider, 1979.)

\subsection{SST Anomalies in the North Pacific}

As we have pointed out in the previous chapter, SST anomalies can have an influence on the latent heat transfer between ocean and atmosphere, but in doing so there will be a feedback effect on the SST anomalies themselves (see e.g. Hasselmann, 1977). As an oceanic area gives off energy to the atmosphere by evaporation, the surface layers of the ocean will cool and a negative SST anomaly will result. The magnitude of this cooling effect depends on the efficiency of the mixing processes in the ocean and on the depth to which this mixing proceeds. Since the stability and depth of the mixed layer near the ocean surface are also functions of season and of geographic location, the same amount of heat transferred from the ocean to the atmosphere may have different effects on SST's in different seasons, different locations, and even in different years. These potential complications make a quantitative assessment of feedback mechanisms between ocean and atmosphere, involving SST anomalies, very difficult.

Nevertheless, preliminary analyses of SST records from the North Pacific but also from the North Atlantic (Daly, 1978) have given us several clues on the potential impact of a variety of mechanisms. The heat budget of an oceanic volume can be written as follows (Reiter, 1979b, c)

$\Delta Q_{\Theta}=Q_{I S}+Q_{H A}-Q_{O L}-Q_{S H}-Q_{E V}-Q_{U W}-Q_{D}$

or since

$\Delta Q_{\text {SST }}=\Delta Q_{S T}+\Delta Q_{\theta}$,
$\Delta Q_{S S T}=Q_{I S}+Q_{H A}-Q_{O L}-Q_{S H}-Q_{E V}-Q_{U W}-Q_{D}+\Delta Q_{S T}$

$\Delta Q_{\theta}$ is the heat content change of the oceanic volume, resulting in a certain mean temperature change during the time interval $\Delta t$;

$\Delta Q_{\overline{S S T}}$ is the sea surface temperature change during $\Delta t$; $\Delta Q_{S T}$ expresses the effects of thermal stratification changes during $\Delta t$;

$Q_{\text {IS }}$ is the heat gain by direct and indirect solar radiation during $\Delta t$;

$Q_{H A}$ is the heat gain (or loss) through horizontal advection by longitudinal temperature advection in the direction of the current, by meanders in the current system, or by current shifts in a meridional direction;

$-Q_{O L}$ is the heat loss by outgoing (long-wave) radiation during the time interval $\Delta t$;

$-Q_{S H}$ is the oceanic heat loss by sensible heat transfer to the atmosphere;

$-Q_{E V}$ is the oceanic heat loss by evaporation (latent heat transfer) to the atmosphere;

$Q_{U W}$ describes the heat exchange through the bottom of the oceanic volume by large-scale upwelling (Ekman pumping);

$-Q_{D}$ is the diffusive heat loss by small-scale motions, mainly acting across the bottom-surface of the oceanic volume.

$-Q_{S H}$ and $-Q_{E V}$ depend significantly on atmospheric wind speed which, through induced wave action and turbulence, also affects mixing processes, hence thermal stratification, in the oceanic box under consideration. Thus, effects of $-Q_{S H}$ and $-Q_{E V}$ might first be recognized in $\Delta Q_{S S T}$ and in $\Delta Q_{\Theta}$ if the upper layers of the ocean are stably stratified to begin with. As time goes on, effects in $\Delta Q_{S T}$ may start to dominate. If the oceanic volume under consideration is neutrally 
or unstably stratified to begin with, heat losses $-Q_{S H}$ and $-Q_{E V}$ from the surfaces might leave their major impact on $Q_{D}$.

Our present data sources have been organized in terms of anomalies, from which seasonal trends have been removed. Hence all terms in Eqn. (6) might also be regarded as anomalies from seasonal mean values. We will have to allow for the fact, however, that SST anomalies will respond differently to anomalies in the forcing terms on the right side of Eqn. (6), depending on the seasonally different state of mean stability in the oceanic volume under consideration. Thus, in spite of the fact that seasonal variability has been removed from the anomaly data, a dependence of tan. (6) on season still has to be expected.

Unfortunately, at this lime, most of the terms in Eqn. (6) are not yet available to us with sufficient accuracy to allow a complete heat budget calculation of an oceanic volume. Nevertheless, we are in a position to estimate the effects of some of the terms, at least qualitatively, from observational data.

\section{a. Radiation Budget Effects.}

Evidence for the impact of long-term variations in cloudiness on $Q_{I S}$ and $Q_{0 L}$ is presently being collected (see also Bunker and Worthington, 1976). The study by Elsberry and Camp (1978) seems to relegate this process into the category of minor effects.

There is an indication that incoming solar radiation decreases during periods of storminess. Thus, the loss of solar radiation would tend to foster the formation of negative SST anomalies. Heat loss by $-Q_{0 L}$ would be reduced at the same time, however.

\section{b. Effects of Thermal Stability.}

Changes and anomalies of oceanic thermal structure $\Delta_{S T}$, should leave a major, seasonally dependent, imprint on SST anomaly formation. One should expect a negative correlation between SST anomalies and $\tau^{3 / 2}$ or $u_{*}{ }^{3}$ prevailing for relatively short time scales, especially with high winds (Elsberry and Camp, 1978; Elsberry and Garwood, 1978; Elsberry and Raney, 1978; see also Price et. al., 1978). $\quad$ is the wind stress and $u_{*}$ the friction velocity. Mixed-layer deepening could also be viewed as depending on the wind-induced vertical gradients of velocity across the base of the mixed layer (Price et al., 1978).

Unfortunately, data on the thermal structure of the upper ocean are not readily available in synoptic format, which makes their application difficult on an ocean-wide basis. Also, the data used in our own present study have been subjected to a considerable amount of space- and time-smoothing, and seasonal trends have been removed. A judgement on the effectiveness of $\Delta Q_{S T}$ in forming SST anomalies will, therefore, be tentative and will have to await further data analysis.

It should be pointed out that Dorman and Saur (1978), by analyzing XBT (expendable bathythermograph) data between Honolulu and San Francisco, found no correlation between SST anomalies and temperature anomalies in the main thermocline at ca. $170 \mathrm{~m}$ depth throughout the year. Summer warming generates a thin mixed layer near the surface with a seasonal thermocline between 60 and $80 \mathrm{~m}$. Correlation coefficients $>0.5$ of temperatures at depth with SST anomalies seem to be restricted to the uppermost $40 \mathrm{~m}$ along this shipping route.

A qualitative assessment of stability effects on SST anomaly formation has been conducted in the following way: Let us consider that oceanic fronts within the region of the North Pacific Drift become evident from high values of meridional SST gradients. At the same time these fronts delineate the northern boundary of a well-established warm, mixed surface layer of the ocean with a stable thermocline layer underneath. We should expect, therefore, that longlived and large-scale SST anomalies wnilld show a preference fur development along, and perhaps somewhat to the south of,such oceanic fronts. A deviation of the frontal position from its seasonal mean position would also give rise to an SST anomaly. The seasonal preference for the establishment of large meridional temperature gradients in the mid-latitudes of the Central Pacific appears to fall between May and July (Fig. 38). This reasoning is in line with evidence presented by Elsberry and Garwood (1978) who showed that an advance or delay in the transition date from the winter to the summer regime at Weathership Papa $\left(50^{\circ} \mathrm{N}, 145^{\circ} \mathrm{W}\right)$ causes positive or negative SST anomalies that tend to persist throughout summer (Fig. 39).

According to Roden (1972, 1975) observational data indicate the presence of several frontal systems in the North Pacific (Fig. 40 and Table 3). Of greatest interest to our investigation is the behavior of the subarctic temperature and salinity front somewhat north of $40^{\circ} \mathrm{N}$, and of the subtropical front near $30^{\circ} \mathrm{N}$. The latter reveals itself as a salinity front all year, but as a temperature front only during the cold season. In the subarctic front temperature and salinity gradients tend to balance each other in the upper $100 \mathrm{~m}$ of the ocean, resulting in only small density gradients. The subtropical front, on the other hand, reveals significant horizontal density gradients in the upper $100 \mathrm{~m}$.

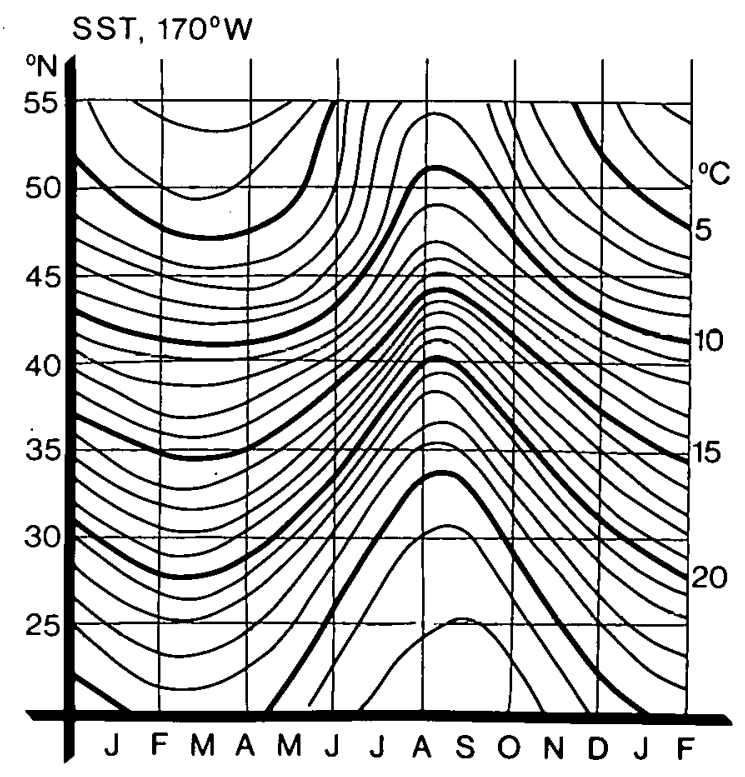

Fig. 38. Seasonal march of SST $\left({ }^{\circ} \mathrm{C}\right)$ as a function of latitude, at $170^{\circ} \mathrm{W}$. 

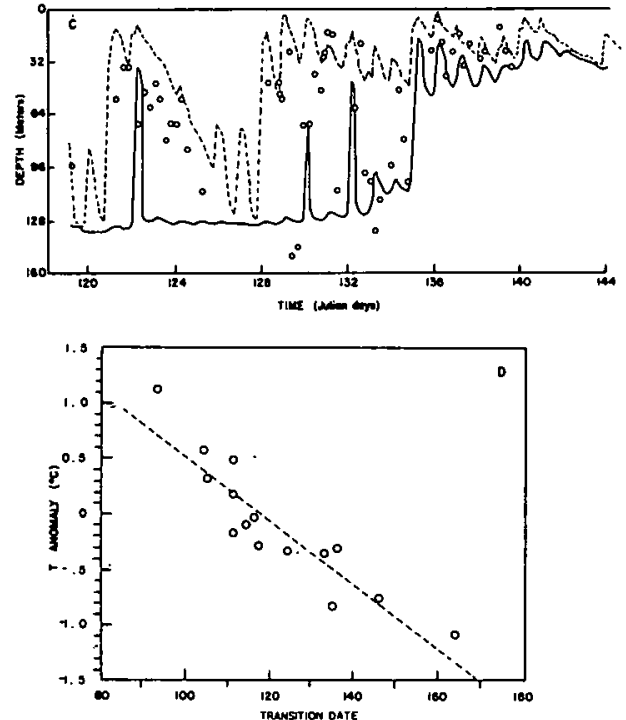

Fig. 39. Upper diagram: Observed (circles) and model-simulated (solid line) depths at which the temperature is $0.2^{\circ} \mathrm{C}$ lower than the surface temperature. Depth of the ocean boundary layer (dashed line) simulated by the model indicates the transition on day number 128 from the winter regime to the summer regime.

Lower diagram: Relative sea-surface temperature at $50^{\circ} \mathrm{N}, 140^{\circ} \mathrm{W}$, averaged over MarchDecember as a function of transition data. (From Elsberry and Garwood, 1978.)

To test the involvement of oceanic fronts in SST-anomaly generation, meridional SST gradients were analyzed for various geographic longitudes from mean monthly SST data. These data were compiled from daily records supplied by the U.S. Navy Fleet Numerical Weather Central in Monterey, California. In Fig. 41 monthly latitudinal differences of SST at $170^{\circ} \mathrm{W}$, computed over $5^{\circ}-1$ atitude intervals, are displayed for the period 1965-1977. A 7-month running-mean filter has been applied to the data. Heavy lines indicate the $0,2,4^{\circ} \mathrm{C}$, etc., isotherms of $\triangle S S T$. Thin lines are entered at $0.5^{\circ}-\mathrm{C}$ intervals. Vertical hatching delineates areas with $\triangle S S T>4^{\circ} \mathrm{C}$. The heavier hatching lines, at the same time, serve as reference marks for individual months.

In Fig. 42 the monthly SST-anomaly values, filtered by 7-month smoothing, are analyzed for the same

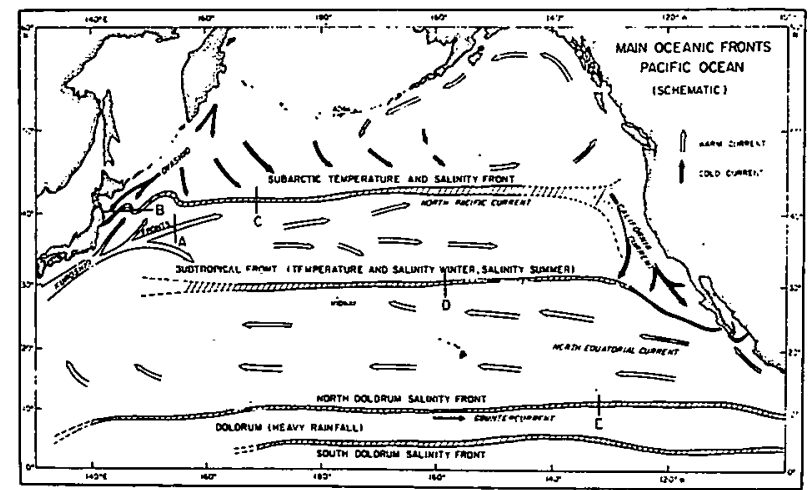

Fig. 40. Schematic map of main North Pacific fronts. Arrows indicate prevailing current directions. A, Kuroshio front; B, Oyashio front; $C$, subarctic front; D, subtropical front; $E$, doldrum front. (From Roden, 1975.)

geographic longitude. Fig. 43 shows the zonal wind stress anomalies, compuled from $1000-\mathrm{mb}$ winds and averaged over the longitude sector $150^{\circ} \mathrm{E}-180^{\circ} \mathrm{W}$, using the equation

$$
\tau_{o x}=\rho_{a} y^{2} u \cdot|u|
$$

A 7-month smoothing routine was applied to these geostrophic wind stress data. $\rho_{a}=1.2 \mathrm{~kg} / \mathrm{m}^{3}$ is the air density, $\gamma^{2}=2 \times 10^{-3}$ the drag coefficient, and $u$, in $\mathrm{m} / \mathrm{sec}$, the zonal wind component.

A qualitative comparison of these diagrams lets us arrive at the following conclusions:

(i) The subarctic front (Roden, 1975) appears as the dominant feature in Fig. 41 somewhat north of $40^{\circ} \mathrm{N}$. The involvement of the subtropical front near $30^{\circ} \mathrm{N}$ in generating meridional SST gradients is confined to late winter and spring, but varies greatly from year to year (White et al., 1978). There is a large interannual variability in the magnitude and position of the meridional SST gradient within the zone of maximum gradients as delineated by the hatched areas of Fig. 41. Sometimes, as for instance in $1969 / 70$, the anomalous behavior of the oceanic fronts even tends to mask their seasonal variability. Another extended period of "unruly" behavior of the seasonal cycle of $\triangle S S T$ started towards the end of 1974 and became very pronounced in 1977, culminating in strong SST anomalies.

TABLE 3. Characteristics of North Pacific fronts, based on horizontal sampling at $30 \mathrm{~km}$ intervals. Al1 gradients are expressed in terms of the Nyquist sampling interval (from Roden, 1975).

\begin{tabular}{|c|c|c|c|c|c|}
\hline Characteristics* & Kuroshio & $\begin{array}{l}\text { North } \\
\text { Oyashio }\end{array}$ & $\begin{array}{l}\text { Pacific fronts } \\
\text { Subarctic }\end{array}$ & Subtropical & Doldrum \\
\hline Temperature gradient $\left({ }^{\circ} \mathrm{C}\right.$ per $\left.60 \mathrm{kgl}\right)$ & 6 & 9 & 8 & 4 & 1 \\
\hline Salinity gradient ( $\%$ per $60 \mathrm{~km}$ ) & 0.6 & 1.5 & 1.2 & 0.5 & 1.0 \\
\hline Sound velocity gradient (m $\mathrm{s}^{-1}$ per $60 \mathrm{~km}$ ) & n) 24 & 39 & 28 & 12 & 1 \\
\hline Density gradient $\left(\mathrm{kg} \mathrm{m}^{-3}\right.$ per $\left.60 \mathrm{~km}\right)$ & 0.8 & 0.2 & 0.2 & 0.8 & 0.7 \\
\hline Baroclinic current $\left(\mathrm{m} \mathrm{s}^{-1}\right)$ & 0.6 & 0.2 & 0.4 & 0.5 & 0.5 \\
\hline Baroclinic shear $\left(s^{-1}\right)$ & $2 \times 10^{-5}$ & $8 \times 10^{-6}$ & $7 \times 10^{-6}$ & $10^{-5}$ & $2 \times 10^{-5}$ \\
\hline
\end{tabular}

* Maximum values. 

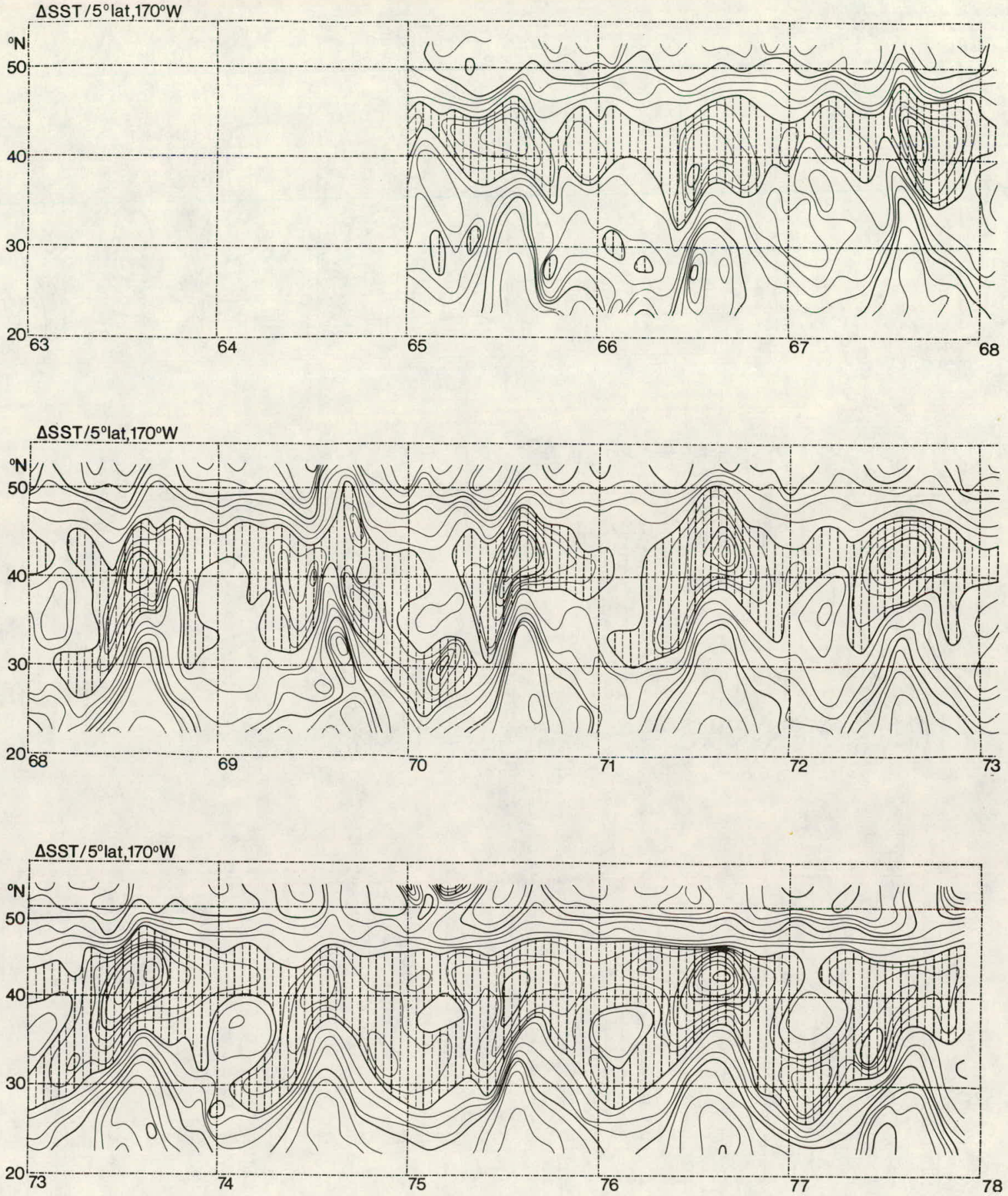

Fig. 41. Time section of meridional gradients of SST at $170^{\circ} \mathrm{W}$ (in ${ }^{\circ} \mathrm{C}$ per $5^{\circ}$ latitude interval) as a function of latitude. (Original data courtesy of U.S. Fleet Numerical Weather Central, Monterey, California.) Thin isolines are for each $0.5^{\circ} \mathrm{C}$ temperature difference, heavier isolines for each $2^{\circ} \mathrm{C}$ difference. Shaded areas indicate gradients larger than $4^{\circ} \mathrm{C} / 5^{\circ} 1$ atitude. The heavier vertical shading marks constitute reference marks for monthly anomaly values. Vertical dashed-dotted lines labelled with the calendar year indicate the month of January of that year. Unsmoothed monthly data were used for the analysis. 

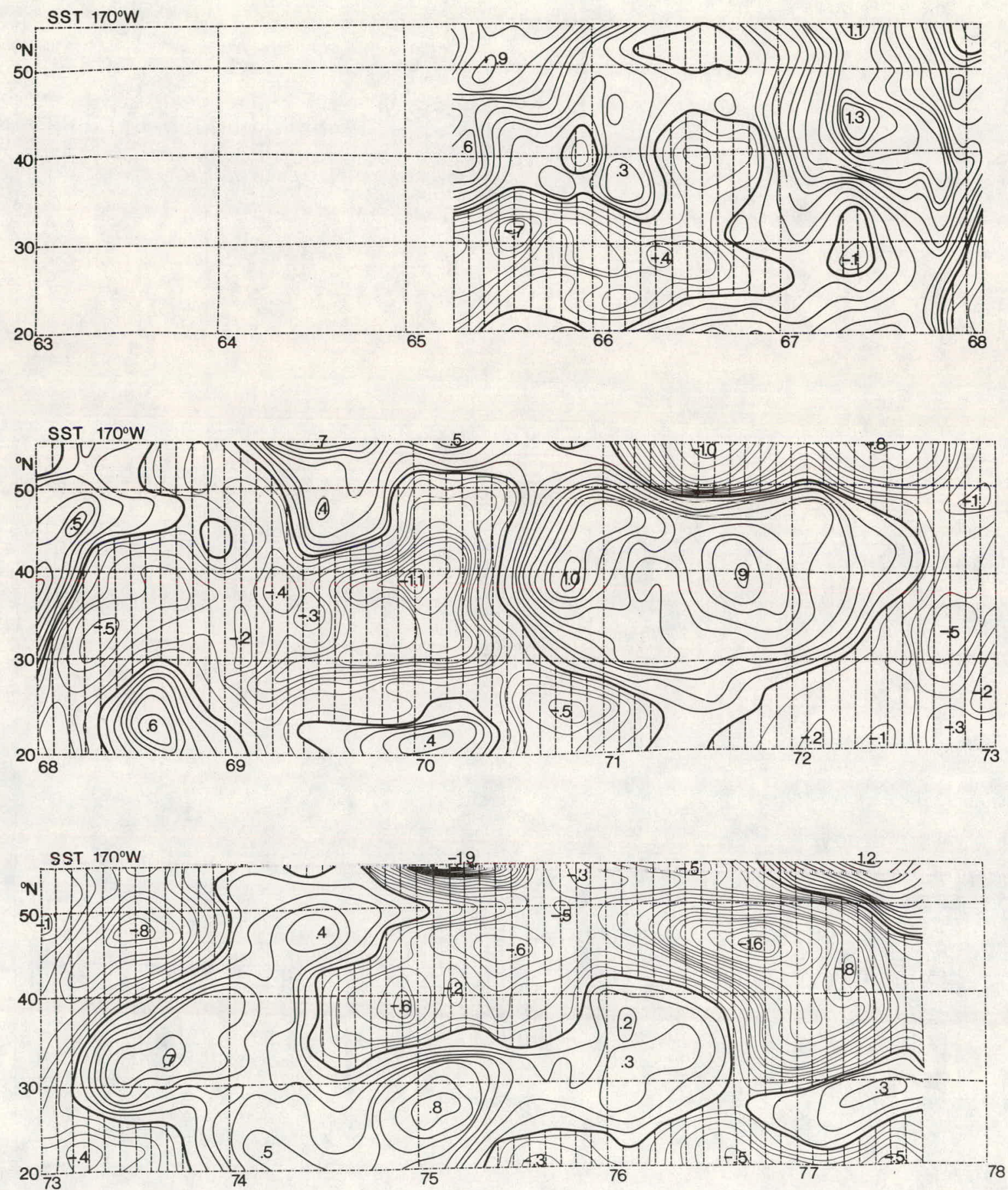

Fig. 42. Time section of SST anomalies at $170^{\circ} \mathrm{W}$. Isolines for each $0.1^{\circ} \mathrm{C}$. Areas with negative SST anomalies are shaded, whereby each shading line constitutes a monthly reference mark, similar to those in Fig. 41. The heavy lines mark zero SST anomalies. Long-term (13-year) monthly averages were removed from the record to compute departures. A 7-month running-mean filter was applied to the data to reduce highfrequency noise. 

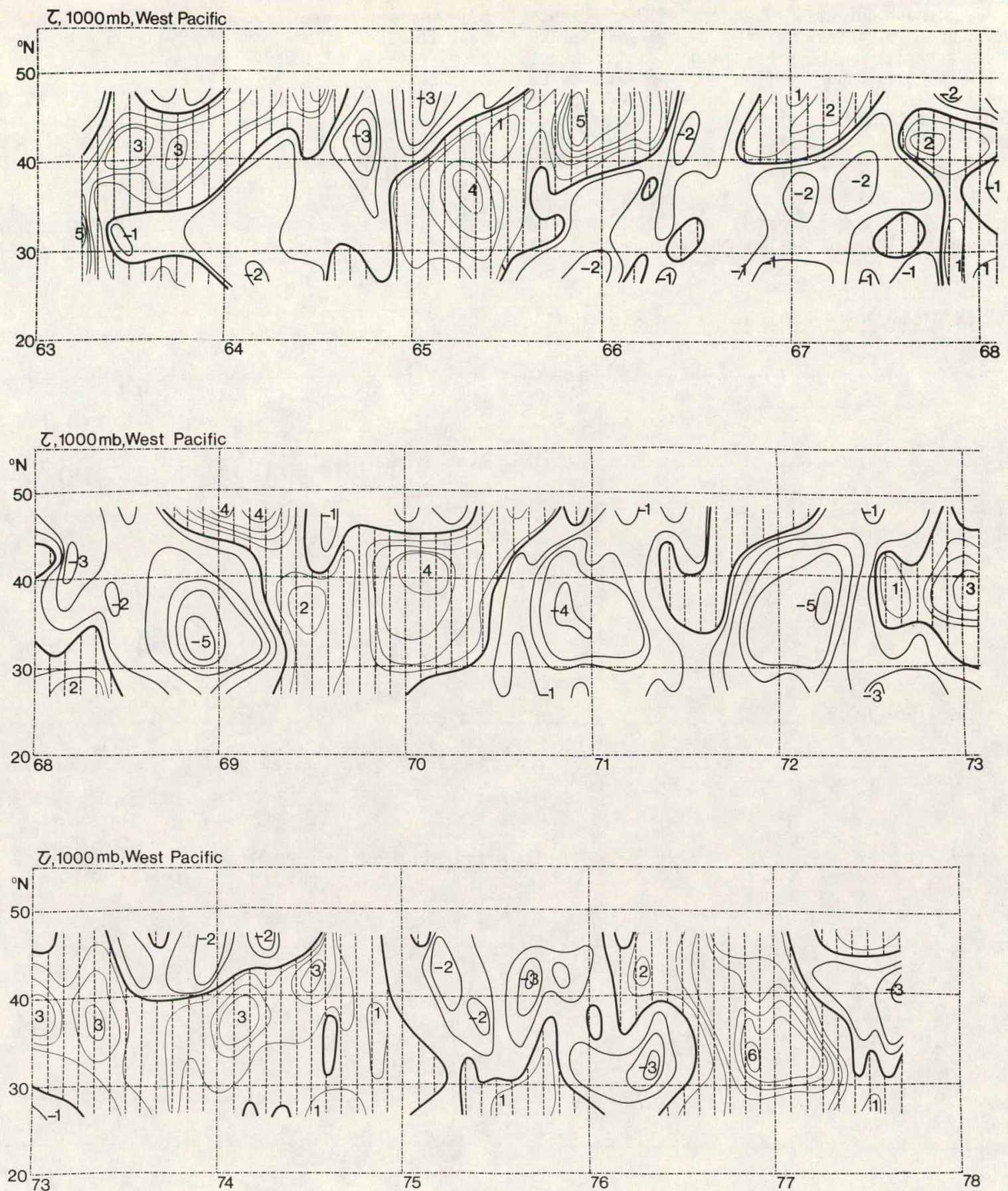

Fig. 43. Departures of the wind stress from the 15-year mean, computed from 1000-mb geostrophic winds between $150^{\circ} \mathrm{E}$ and $180^{\circ} \mathrm{W}$ (West Pacific) in units of $10^{-2} \mathrm{Kg} / \mathrm{m} \mathrm{sec}$. A 7 -month running-mean filter was applied to the monthly departure data. Hatching with monthly reference lines indicates above-normal stress. 
(ii) Figure 44 compares meridional SST gradients along the three meridians $170^{\circ} \mathrm{E}, 170^{\circ} \mathrm{W}$ and $150^{\circ} \mathrm{W}$. Whereas the oceanic fronts are strongest in the West Pacific, their interannual variability appears to be largest in the Central North Pacific, where SST anomaly patterns also tend to maximize. $150^{\circ} \mathrm{W}$ corresponds approximately to the longitude of the northernmost displacement of surface isotherms during winter (Kenyon, 1978).

(iii) As we compare Figs. 41 and 42 with each other we come to the conclusion that, indeed, large
SST anomalies are frequently, if not always, found near the zone of maximum meridional SST gradients (see also Weare et a1., 1976).

(iv) Large negative SST anomalies were observed near $40^{\circ} \mathrm{N}$ in 1968 , more so during the winter of $1969 / 70$, also in 1973, at the end of 1974, continuing into 1975, and especially in 1976-77. This latitude band of high negative SST anomalies falls into a "stability gap" described by Roden (1970). North of $43^{\circ} \mathrm{N}$, near $160^{\circ} \mathrm{W}$, there is a strongly developed halocline with high stabilities between 100 and $150 \mathrm{~m}$,
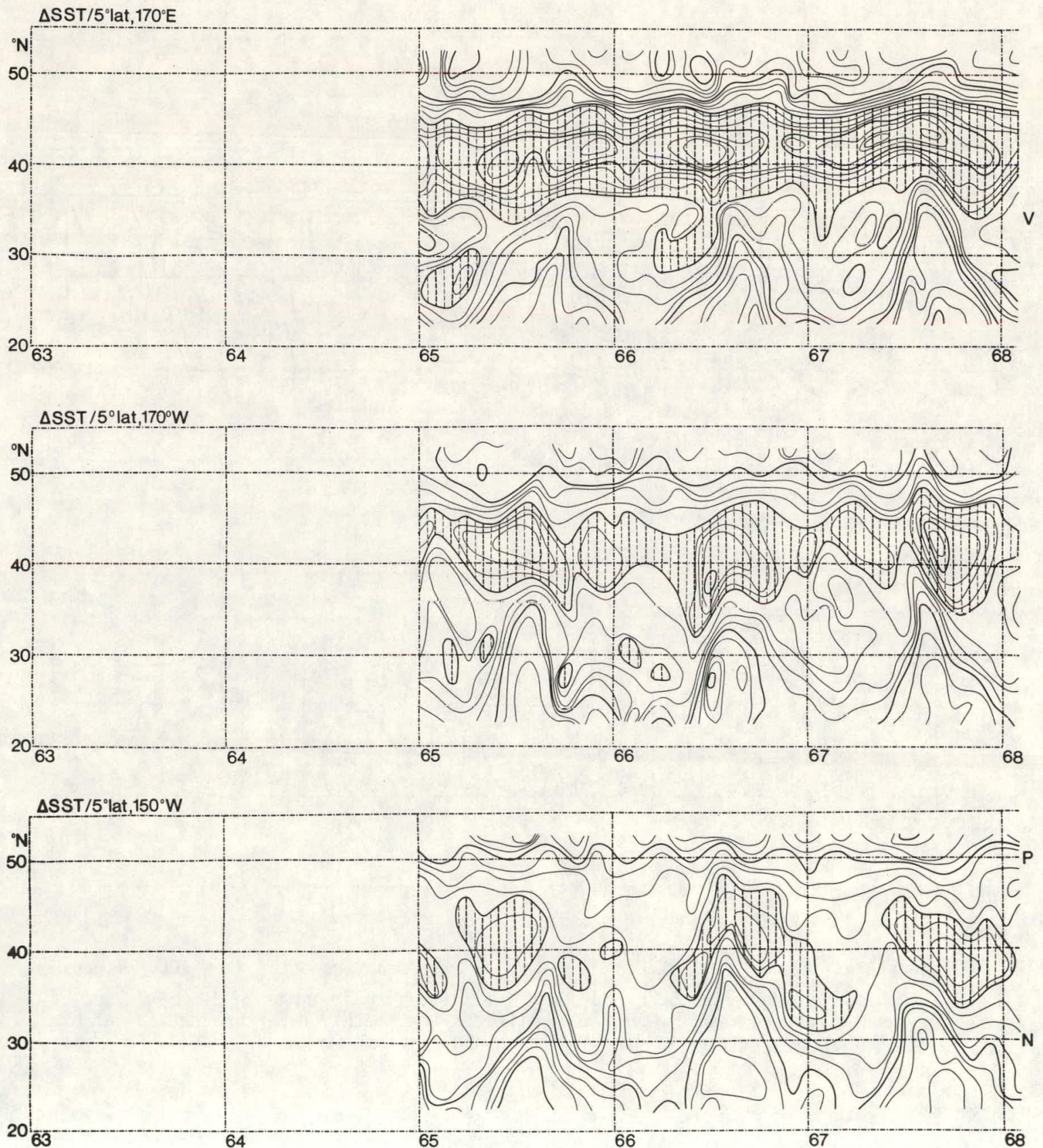

Fig. 44. Similar to Fig. 41, but showing time sections for three different meridians: $170^{\circ} \mathrm{E}, 170^{\circ} \mathrm{W}$ and $150^{\circ} \mathrm{W}$. 

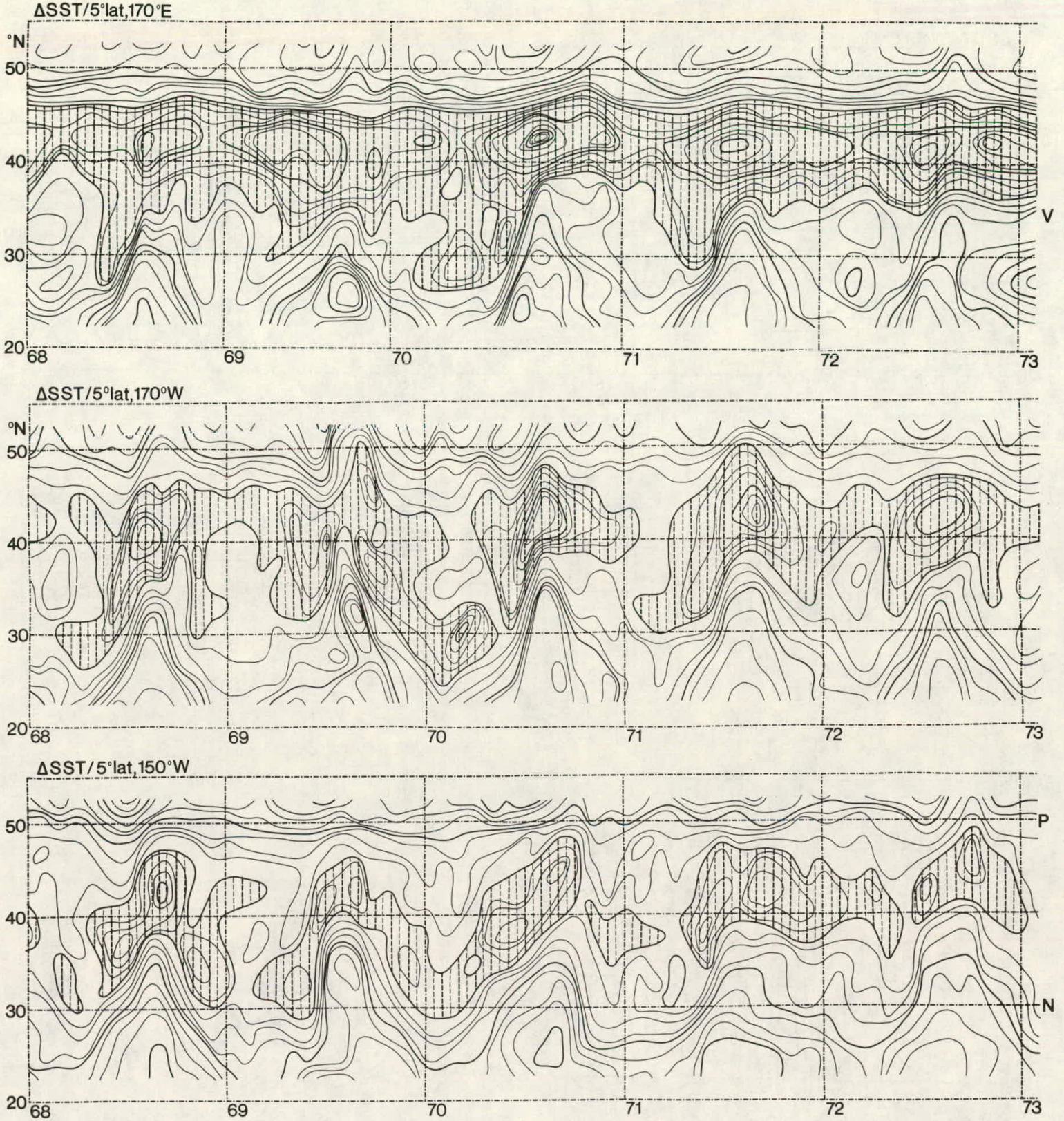

Fig. 44 (Continued)

whereas south of $37^{\circ} \mathrm{N}$ stabilities near $30 \mathrm{~m}$ are high due to combined effects of a thermocline and a halocline. Preceding each of the occurrences of negative SST anomalies mentioned above a region of abnormally strong $\triangle$ SST was found at relatively low latitudes. (The hatched areas in Fig. 41 are seen to dip below $30^{\circ} \mathrm{N}$ on these occasions.) This observation helps to confirm the earlier statement that a southward displacement of the oceanic fronts, and a delay in their northward migration, can have profound impacts on the SST anomaly patterns in the sense of generating large and persistent negative anomalies. It is furthermore of interest to note, that White et al. (1978) computed relatively low intensities of the subtropical front, as measured by the zonal relative geostrophic flow $0 / 200$ dbar, during some of the negative SST-anomaly periods mentioned above (Fig. 45). Similar intensity variations are reported for the subtropical countercurrent, the North Equatorial Current (Wyrtki, 1974) and the Kuroshio south of Japan (Nitani, 1972) (Fig. 46). Several relationships between current fluctuations and the North Pacific trade winds will be pointed out in section (d) below.

(v) If we include the wind-stress analyses of Fig. 43 in this comparison, we find that episodes of anomalous storminess in the West Pacific $\left(150^{\circ} \mathrm{E}-180^{\circ} \mathrm{W}\right)$ preceded, or coincided with, the odd behavior of the oceanic fronts described above and the resultant generation of large negative SST anomalies. Rhoden (1970) points out that variations in the convergence of the wind-induced Ekman flow might influence the positions of the subarctic and subtropical fronts (near $40^{\circ} \mathrm{N}$ and $30^{\circ} \mathrm{N}$, respectively) and of the transition zone in between. Ekman-flow convergence is strongest near these two fronts. A model, based on simple Ekman dynamics, provides reasonable agreement between frontogenetic and frontolytic regions and the 

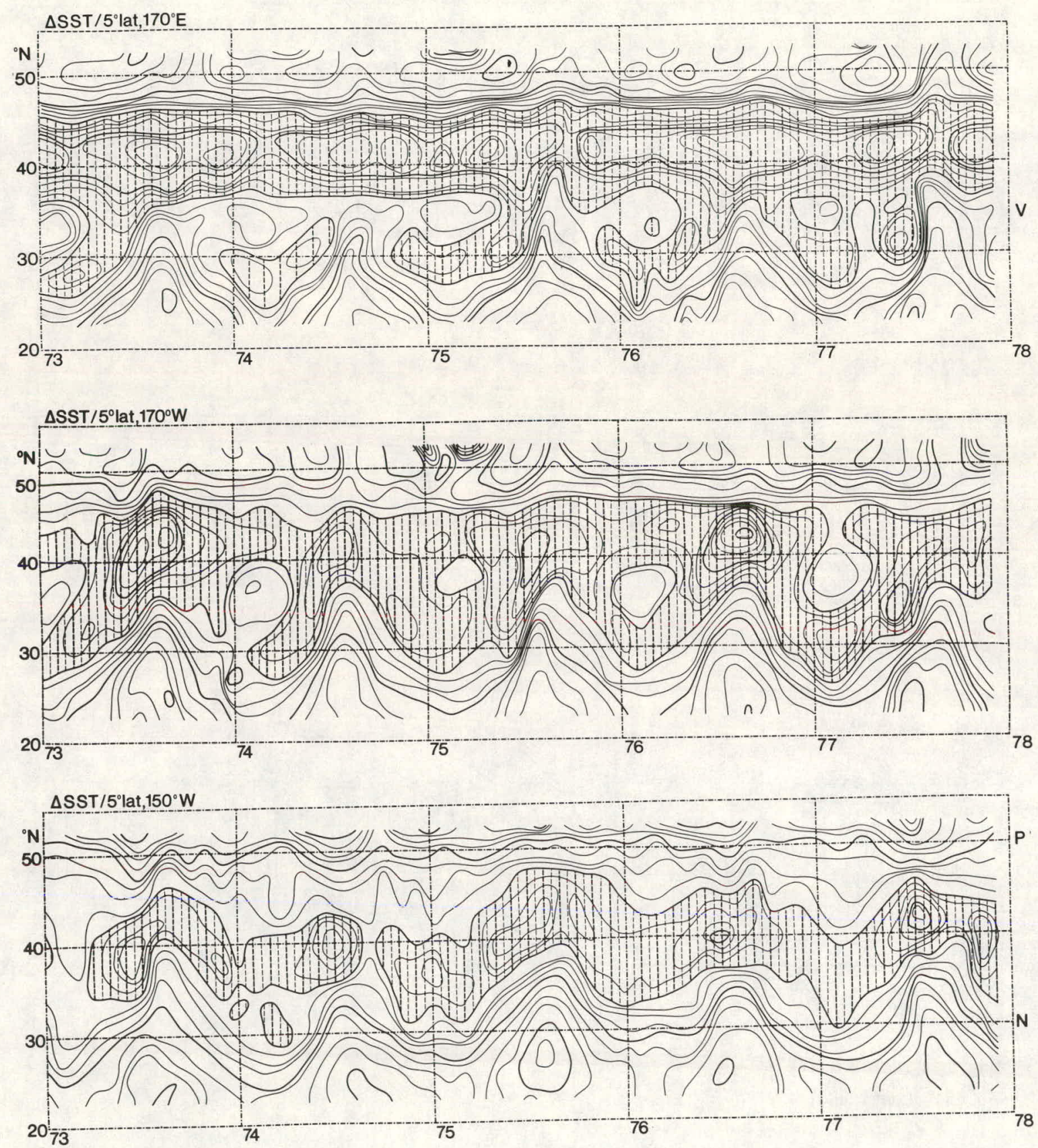

Fig. 44 (Continued)

time-variant wind-stress field (Roden and Paskausky, 1978). Experiments with drifters which lost their drogues indicated that Ekman theory might overpredict the angle by which the ocean surface currents depart from the direction of the wind $\left(45^{\circ}\right.$ cum sole, according to theory). Kirwan et al. (1979) find better agreement in the response of surface currents to wind stress by applying wave-induced Stokes drift in a fully developed sea, which is linear with wind speed

$$
\vec{v}_{s}=0.0158 \vec{V}_{a}
$$

where $\vec{V}_{s}$ is the drift vector of the surface layer of the ocean and $\vec{V}_{a}$ is the "surface" wind at $19.5 \mathrm{~m}$ (see also Barnett and Kenyon, 1975). A mixture between an Ekman and a Stokes response of the observed drifts to the wind field also yielded a reasonable interpretation of the data. With such a response the angle between the wind and the surface current is only $15^{\circ}$ cum sole.

Applying these findings to an estimate of the frontogenetic and frontolytic effects of wind stress it appears, that simple Ekman theory application might yield mis-estimates of developing SST anomalies depending on the orientation of temperature gradients in the ocean relative to those of the surface wind.

The lag-correlation between SST anomalies and geostrophic $1000-\mathrm{mb}$ wind anomalies, using seven-month smoothed data, is shown as a function of latitude in Figs. 47-49. A tendency is indicated that trends in $u$ slightly lead trends in SST. The same holds for 

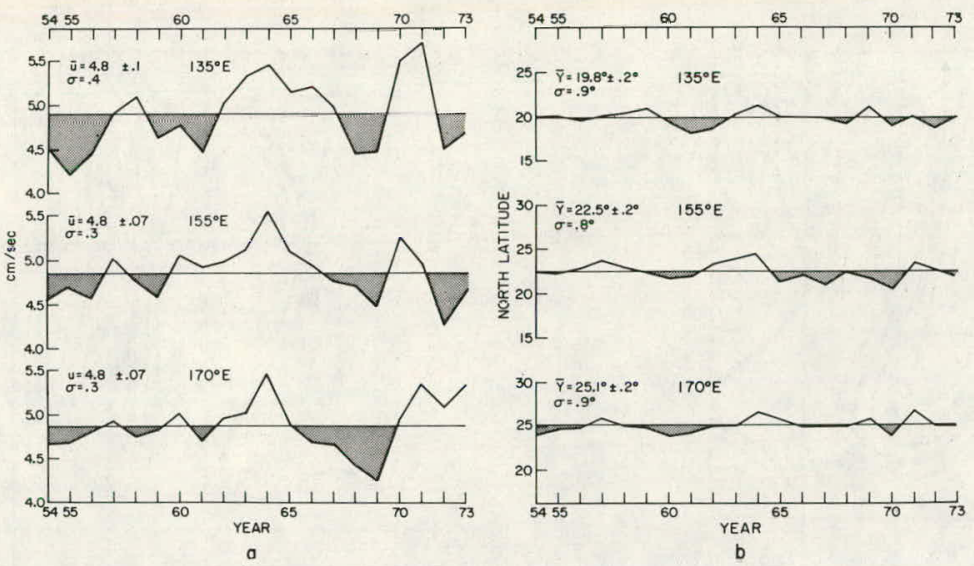

Fig. 45. (a) Intensity variations of North Pacific subtropical front, given as the speed of the zonal relative geostrophic flow $(0 / 200 \mathrm{dbar})$ in $\mathrm{cm} / \mathrm{sec}$. (b) Latitude variations of this front from 1954 to 1974 at the three longitudes $135^{\circ} \mathrm{E}, 155^{\circ} \mathrm{E}, 170^{\circ} \mathrm{E}$. (From White et al., 1978.)

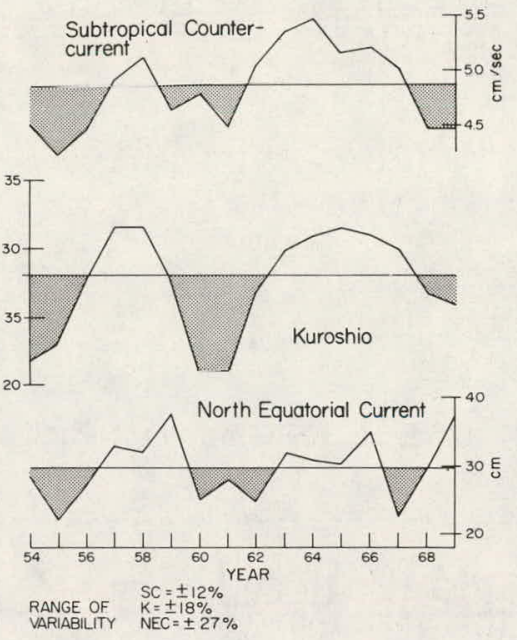

Fig. 46. Indices of the individual annual strenghts of the Subtropical Current, the North Equatorial Current (Wyrtki, 1974) and the Kuroshio south of Japan (Nitani, 1972) from 1954 to 1969 , a time period for which all three indices were available. (From White et al., 1978.)

lag-correlations between wind stress and SST (Figs. 50-52). Relatively high positive correlation coefficients of significance are found between the timeaveraged zonal wind stress and the meridional gradients, SSST (Figs. 53-55) in the central North Pacific $\left(170^{\circ} \mathrm{W}\right)$ in the realm of the subtropical front, and in the West Pacific $\left(170^{\circ} \mathrm{E}\right)$ in the vicinity of the subarctic front. In the East Pacific $\left(170^{\circ} \mathrm{W}\right)$ excessive wind stress may have a frontolytic effect, indicated by a negative correlation efficient in the region of the subarctic front. It should be stressed again, that high-frequency noise has been largely eliminated from these diagrams by application of a 7-month smoothing routine. Seasonal cycles have also been removed by considering monthly departure values, so have been linear trends. Because of these data manipulations we have to be cautious in the interpretation of some of the details of the correlation patterns shown in these diagrams.

We are, nevertheless, brought to the conclusion that one of the most powerful mechanisms in producing long-lasting SST anomalies lies in the anomalous behavior of the oceanic fronts that mark the North Pacific Drift. Local heat losses to the atmosphere in the middle latitudes of the North Pacific, most likely, play only a role secondary to that mechanism. Vertical mixing processes, stirred up by excessive wind stresses, are also controlled, to a large extent, by the position of such oceanic fronts.

Since the development of SST anomalies will, to a large extent, be controlled by this frontal behavior, processes of a scale much larger than just local air-sea interaction should be considered in tracking the history of SST anomalies. Waves and eddies propagating in the region of such frontal zones may provide a certain impact to seemingly advective features of SST anomalies. They also may provide a relatively long memory mechanism for SST behavior which allows such SST anomalies to feed their influence back into the atmospheric general circulation.

The changes in magnitudes and positions of zones with large $\triangle S S T$, evident from Fig. 44, suggest a rather strong variability in the drift velocities associated with the North Pacific Drift (see also White, 1975, 1977), as well as a variability in the position of its main channels (White et al., 1978).

Clearly a lot more research and better data are required before some of the mechanisms of SST anomaly formation implied above can be confirmed and quantified in a comprehensive mathematical model.

\section{c. Heat Flux to the Atmosphere.}

We still are in the process of evaluating shortperiod heat flux fluctuations over the North Pacific in order to assess the impact of SST anomalies on the energy exchange between ocean and atmosphere. We believe that the time scale of resolution of the analysis will influence the results to a certain extent. This tentative conclusion can be demonstrated in the following way: Figure 56 shows semiannual SST anomalies in Marsden square 163 , quadrant $1\left(40-45^{\circ} \mathrm{N}\right.$, $170-175^{\circ} \mathrm{E}$ ) as departures from 20-year means. Data were taken from Favorite and McLain (1973). Also 
SST 170E, u $1000 \mathrm{mb}$ West Pacific

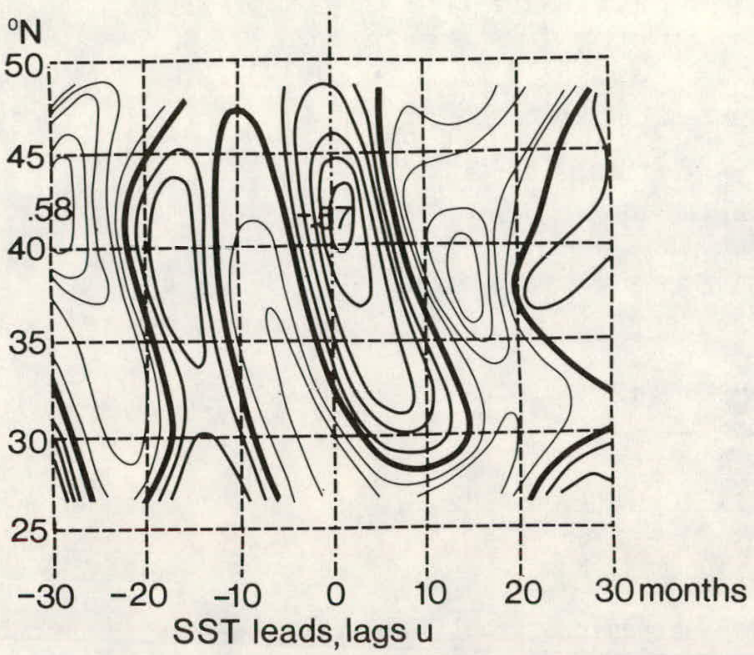

Fig. 47. Lag correlations, as a function of latitude, between 7-month smoothed data sets of SST anomalies at $170^{\circ} \mathrm{E}$ and the $1000-\mathrm{mb}$ geostrophic wind averaged over the longitude sector $150^{\circ} \mathrm{E}$ to $180^{\circ} \mathrm{W}$ (West Pacific). Thin lines indicate positive correlation coefficients analyzed at intervals of 0.1 , heavier lines are negative coefficients with the same analysis interval. Zero correlations are shown by an extra-heavy line. Time lags are given in months along the abscissa.

\section{SST $150 \mathrm{~W}$, u $1000 \mathrm{mb}$ East Pacific}

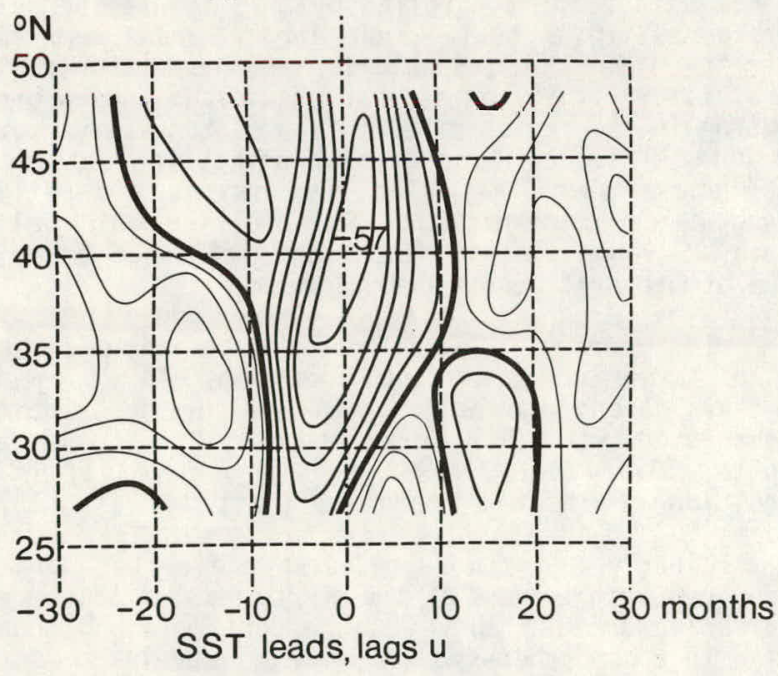

Fig. 49. Similar to Fig. 47, except SST anomalies at $150^{\circ} \mathrm{W}$ correlated with the geostrophic $1000-$ mb wind between $180^{\circ} \mathrm{W}$ and $140^{\circ} \mathrm{W}$ (East Pacific).
SST 170W, u $1000 \mathrm{mb}$ East Pacific

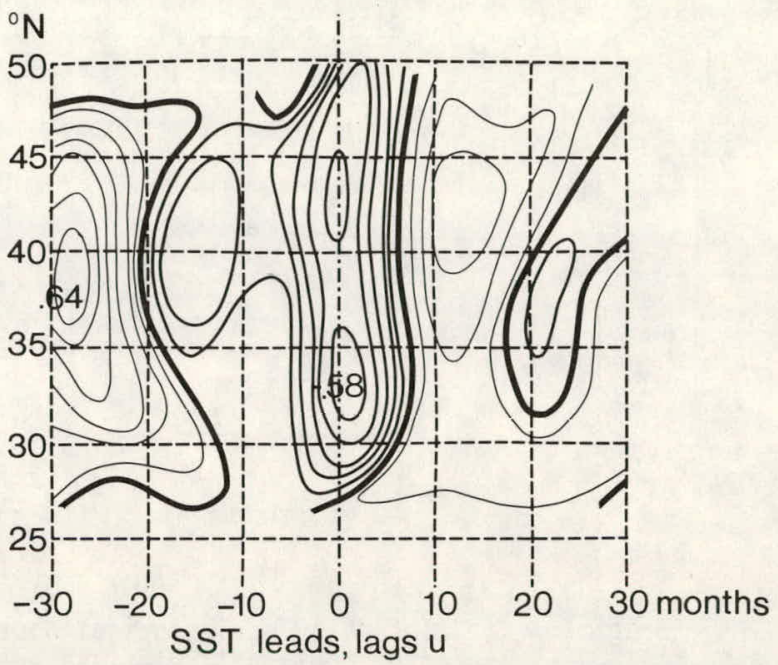

Fig. 48. Similar to Fig. 47, except SST anomalies at $170^{\circ} \mathrm{W}$ correlated with the geostrophic $1000^{-}$ $\mathrm{mb}$ wind between $180^{\circ} \mathrm{W}$ and $140^{\circ} \mathrm{W}$ (East Pacific).

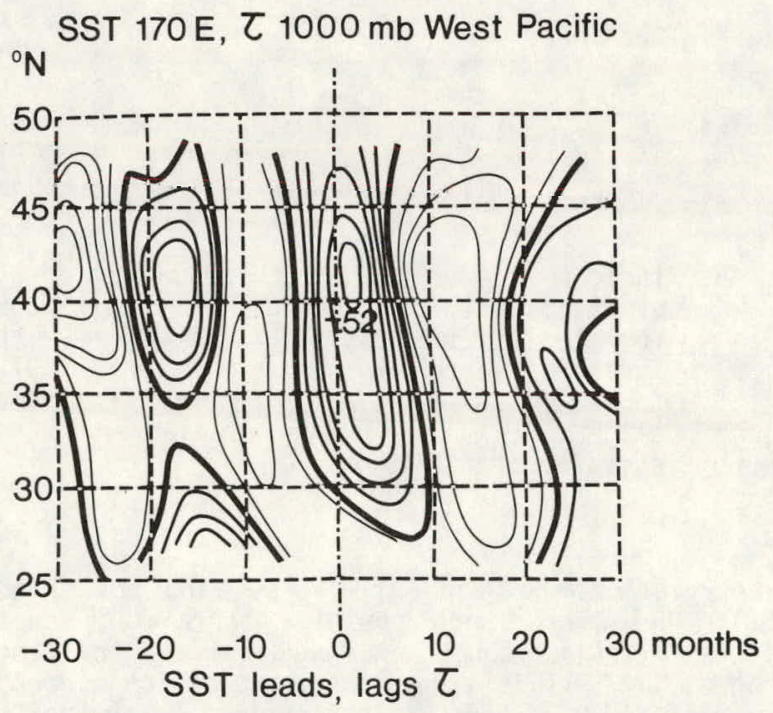

Fig. 50. Lag correlations, as a function of latitude, between 7-month smoothed data sets of SST anomalies at $170^{\circ} \mathrm{E}$ and the wind stress, computed from 1000-mb geostrophic winds, averaged over the longitude sector $150^{\circ} \mathrm{E}$ to $180^{\circ} \mathrm{W}$ (West Pacific). Thin lines indicate positive correlation coefficients, analyzed at intervals of 0.1 , heavier lines are negative coefficients with the same analysis interval. Zero correlations are shown by an extra-heavy line. Time lags are given in months along the abscissa. 
SST 150 W, $\tau 1000 \mathrm{mb}$ East Pacific

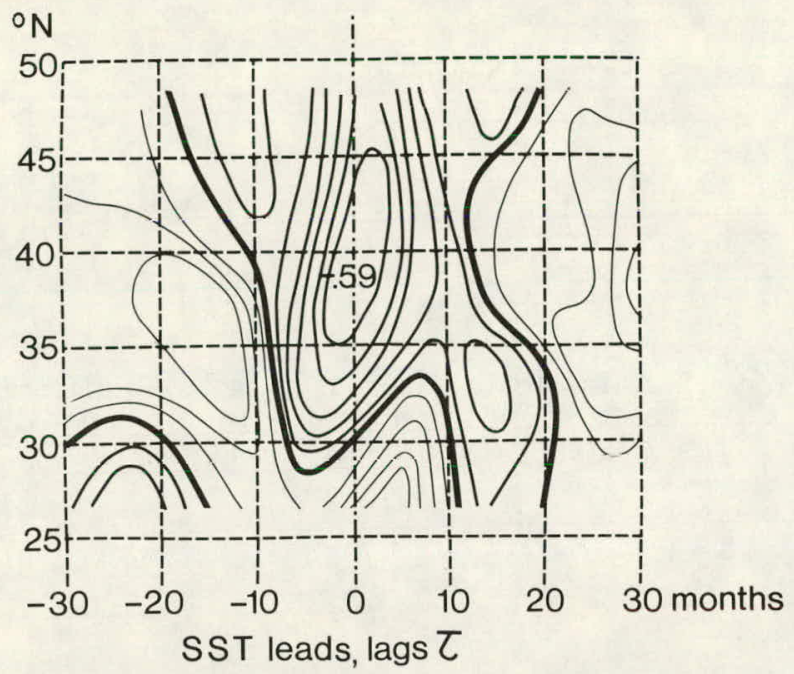

Fig. 51. Similar to Fig. 50, except SST anomalies at $170^{\circ} \mathrm{W}$ correlated with the wind stress between $180^{\circ} \mathrm{W}$ and $140^{\circ} \mathrm{W}$ (East Pacific).

\section{$\triangle S S T$ 170E, $\tau$ West Pacific}

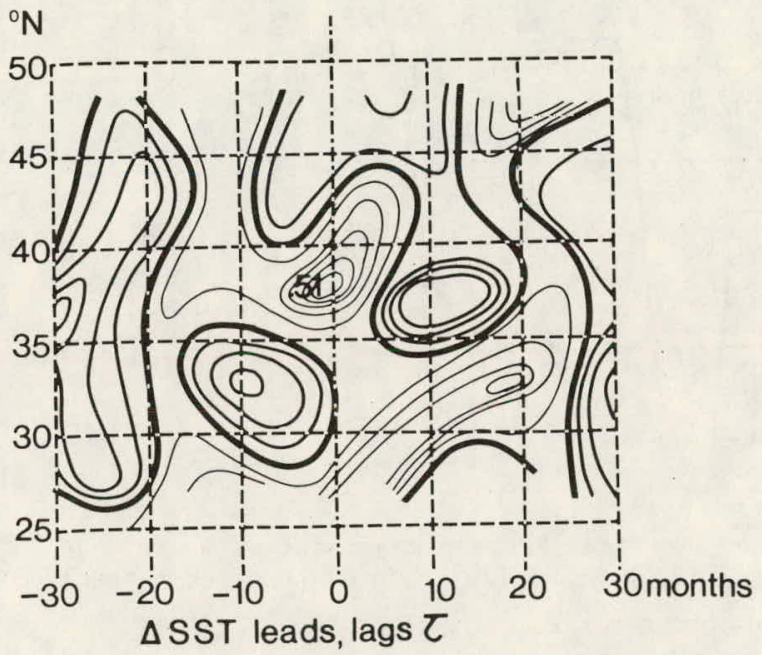

Fig. 53. Lag correlations, as a function of latitude, between 7 -month smoothed data sets of meridional SST differences (computed over $5^{\circ}$ latitude intervals) at $170^{\circ} \mathrm{E}$ and the wind stress, computed from 1000-mb geostrophic winds, averaged over the longitude sector $150^{\circ} \mathrm{E}$ to $180^{\circ} \mathrm{W}$ (West Pacific). Thin lines indicate positive correlation coefficients, analyzed at intervals of 0.1 , heavier lines are negative coefficients with the same analysis interval. Zero correlations are shown by an extra-heavy line. Time lags are given in months along the abscissa.
SST $170 \mathrm{~W}, \tau 1000 \mathrm{mb}$ East Pacific

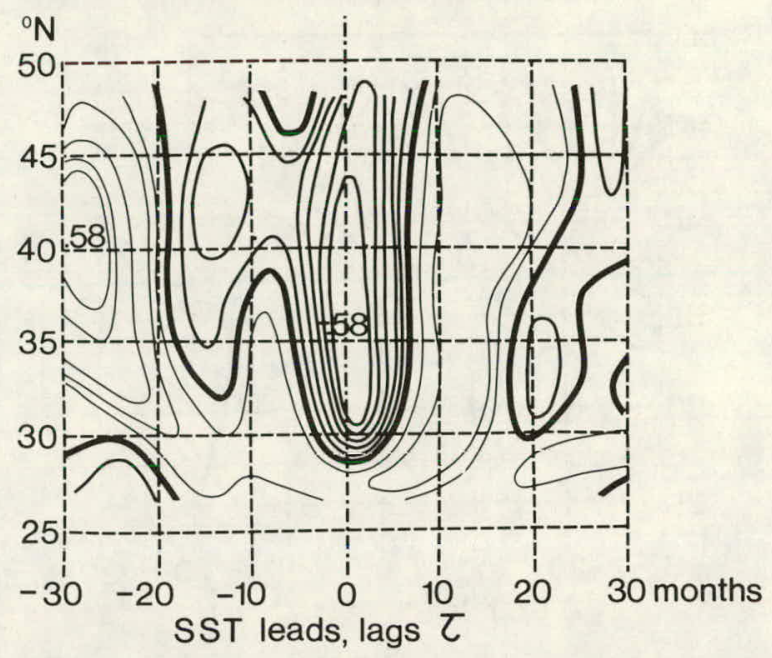

Fig. 52. Similar to Fig. 50, except SST anomalies at $150^{\circ} \mathrm{W}$ correlated with the wind stress between $180^{\circ} \mathrm{W}$ and $140^{\circ} \mathrm{W}$ (East Pacific).

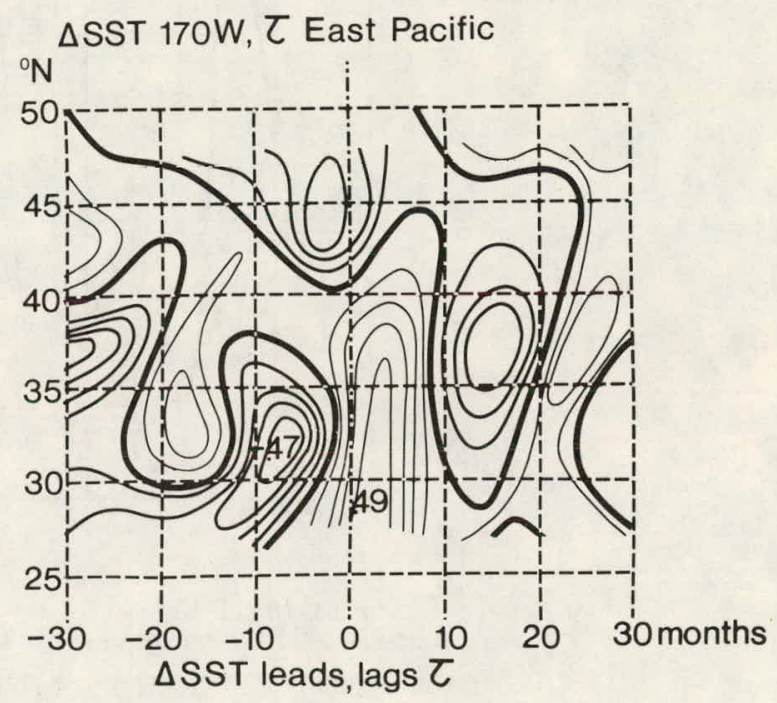

Fig. 54. Similar to Fig. 53, except SST differences at $170^{\circ} \mathrm{W}$ correlated with wind stress between $180^{\circ} \mathrm{W}$ and $140^{\circ} \mathrm{W}$ (East Pacific). 


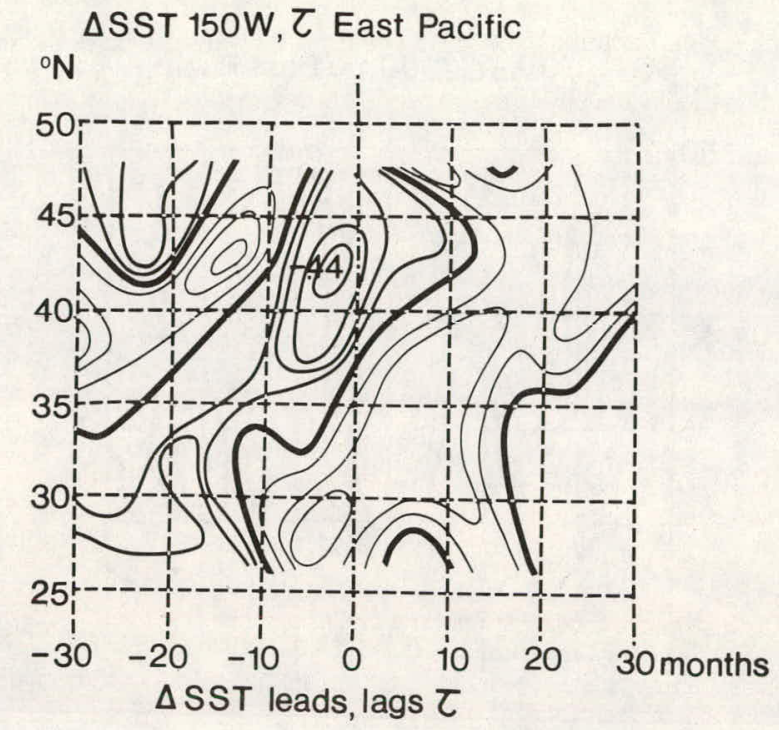

Fig. 55. Similar to Fig. 53, except SST differences at $150^{\circ} \mathrm{W}$ correlated with wind stress between $180^{\circ} \mathrm{W}$ and $140^{\circ} \mathrm{W}$ (East Pacific).

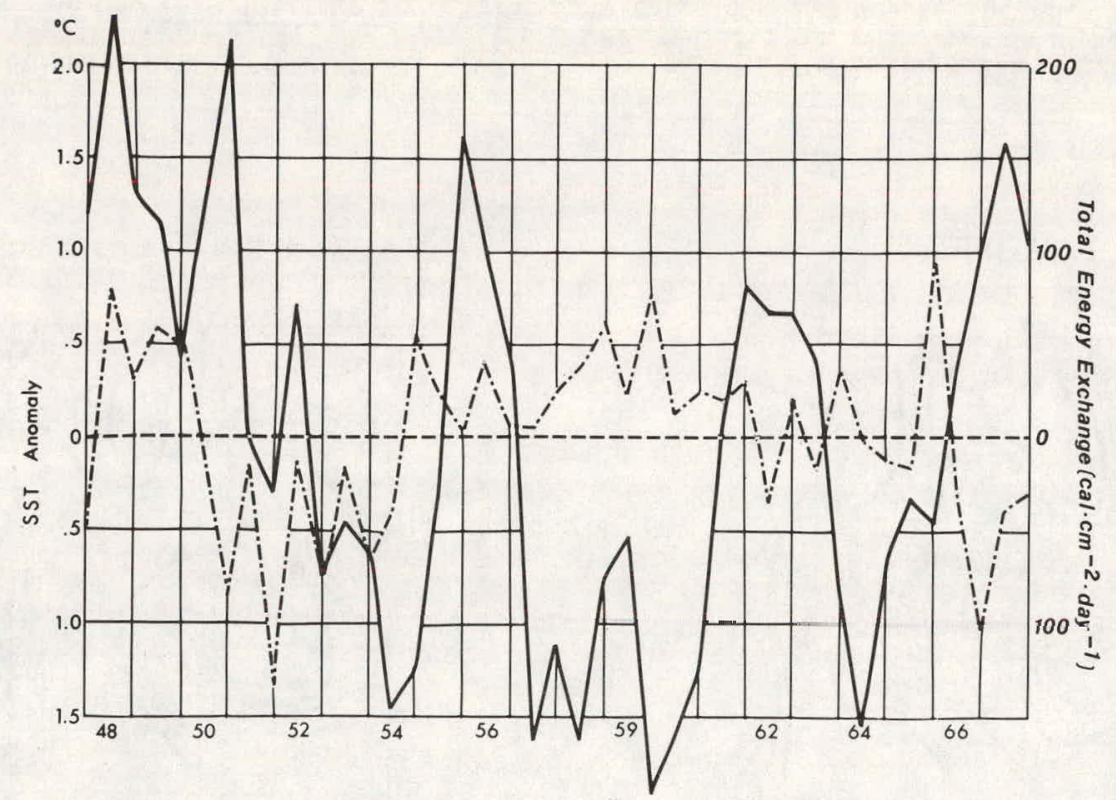

Fig. 56: SST anomalies $\left({ }^{\circ} \mathrm{C}\right.$, solid line) as departures from 20-year means for warm and cold seasons in Marsden Square 163 , Quadrant $1\left(40^{\circ} \mathrm{N}-45^{\circ} \mathrm{N}, 170^{\circ} \mathrm{E}-175^{\circ} \mathrm{E}\right)$, and semi-annual total anomalies of the total energy flux between ocean and atmosphere $\left(\mathrm{cal} \mathrm{cm}^{-2} \mathrm{~d}^{-1}\right)$. (Data from Favorite and McLain, 1973.)

given in this diagram are the semiannual anomalies of total energy exchange between ocean and atmosphere (in cal $\mathrm{cm}^{-2} \mathrm{~d}^{-1}$ ). The mean energy exchange from 0ctober to March was $-213 \mathrm{cal} \mathrm{cm}^{-2} \mathrm{~d}^{-1}$ for the period 1948-67, and $73 \mathrm{cal} \mathrm{cm} \mathrm{cm}^{-2} \mathrm{~d}^{-1}$ from April to September. These energy exchange values include the effects of incoming, back and reflected radiation, evaporation and sensible heat transfer at the ocean surface. There appears to be no obvious connection between SST anomalies and mean energy exchange between ocean and atmosphere on time scales of half a year. This conclusion should not be surprising, since Husby and Seckel (1975), analyzing Weather Station $V$ data in the main heat-loss region of the North Pacific, note that the major heat loss occurs by evaporation which, in turn, is mainly controlled by anomalous differences in the saturation vapor pressure at the sea surface and the vapor pressure of air, and by anomalous wind speeds.

Yet, on the other hand, we have to agree with Namias (1978), Barnett and Preisendorfer (1978), and others who have identified SST anomalies in, or near, the North Pacific region mentioned above as having a major impact on weather phenomena "downstream", i.e. over the United States. We envision such an impact to come through a certain effect of air-sea interaction on long planetary waves in the atmosphere.

In this context it is of interest to note that Seigel (1977) found largest amplitudes of a 24- and a 7-day cycle in sensible and latent heat fluxes from the ocean to the atmosphere in the vicinity of pronounced SST anomalies. McGuirk and Reiter (1976) 
ascribed a vacillation in available potential energy of the atmosphere with a quasi-periodicity of 22 to 26 days or 0.038 to 0.045 cycles per day (see Fig. 57) to be a consequence of baroclinic energy transformations. This vacillation appears in the amplitudes, and sometimes also in the phase angles (i.e. positions) of planetary waves (Figs. 58 and 59). It is conceivable that the vacillatory behavior of planetary long waves and that of heat transfer between ocean and atmosphere on time scales of a few weeks are interrelated -contrary to what Fig. 56 indicated for the longer time scales of half a year.

More research is required to understand the effects of heat fluxes between ocean and atmosphere on the dynamic coupling between the two systems as a function of time and space scales.

\section{d. Advection Effects by Longitudinal Current} Transport Variations.

Even though a large number of systematic measurements of current velocities in various branches of the Kuroshio are available (Stommel and Yoshida, 1972) they are difficult to relate to mass transport and SST anomalies because of the changes in meander configurations. The life span of some of these meanders is 3 to 10 years (Shoji, 1972) hence could have a significant impact. on regional SST anomalies. Especially the oceanic surface currents in Areas 2 and 1 (Fig. 60) appear to meander in some years and not in others. Current velocities for these regions are shown in Fig. 61. Trends in the volume transport of the Kuroshio southeast of Yakushima Island and south of $\mathrm{Kii}$ Peninsula reported by Nitani (1972) for the period 1956 and 1968 agree reasonably we11 with trends in the current velocities of Area 2. Water transport and current speed appear to have reached a minimum in 1962, with maxima before and after. The u-component in the equatorial Pacific (Fig. 62) reveals similar long-term trends, suggesting a certain forcing of the Kuroshio flow on relatively long time scales by wind stresses in the trade-wind region (wind data, courtesy of Dr. G. Meyers, University of Hawaii). Unfortunate$1 y$, we are not yet in a position to quantify this possible forcing connection between trade wind fluctuations and changes in the Kuroshio current system, mainly because we don't know what the characteristic time and space scales of such a postulated response would be and because of the dubious quality of data.

The possible relations between SST anomalies and current behavior in the North Pacific are also, at this time, difficult to document with data. In Fig. 63 we show SST anomalies in Areas C and D after a 7-month running-mean filter had been applied. These temperature anomalies are compared with current velocities measured in Areas 1 and 2. A gradual rising trend of SST in Area D is noted between 1962 and 1967, followed by a declining trend until about 1970, and a rising trend thereafter. These smoothed trends, however, are frequently interrupted by large positive and negative excursions of a duration of approximately 6 months to 2 years. The smoothed trends of SST anomalies in Area $D$ are, to a certain extent, reflected by the speed trends in Area 2, high current velocities having a tendency to occur with warm-water regimes. A similar agreement is found between SST anomalies in Area $C$ and current trends in Area 1 . The shorter-term SST variations, however, are not. reflected in the current speeds. We believe that these SST anomalies might be associated with the meandering characteristics of the Kuroshio (Wilson and Dugan, 1978; Reiter, 1978a).
The temperature differences between Areas $D$ and $C$ might serve as a crude indicator of geostrophic flow variations in the upper ocean in that region. In Fig. 64 they are compared with the trade-wind u-component anomalies in the North Pacific. Again an agreement in the long-term variability, but not in the short-term modulations can be pointed out in these data sets. Favorite and McLain (1973) have pointed out a quasiperiodicity of 5 to 6 years in SST anomalies observed in the region $40-45^{\circ} \mathrm{N}$ and $170-175^{\circ} \mathrm{E}$ (Fig. 56) which led them to the conclusion that large SST anomalies are advected around the subtropical North Pacific gyre which shows a similar revolution period.

Tentatively, we might offer Fig. 65 as a display of feedback mechanisms working in the North Pacific. The "loop" which involves the Hadley cell intensity,
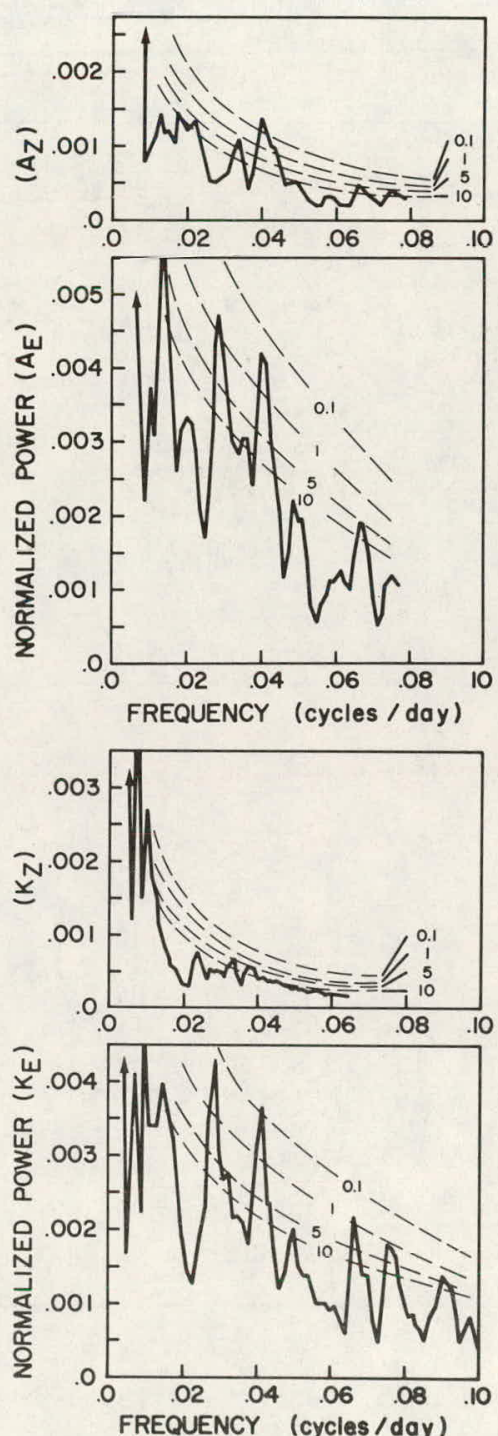

Fig. 57. Periodograms of normalized variance per unit bandwidth for 9.5-year series of daily atmospheric energy by mode. High-frequency spectra not shown. Dashed lines show 90, $95,96,99$ and $99.9 \%$ chi-squared confidence limits for assumed background spectra (McGuirk and Reiter, 1976). 

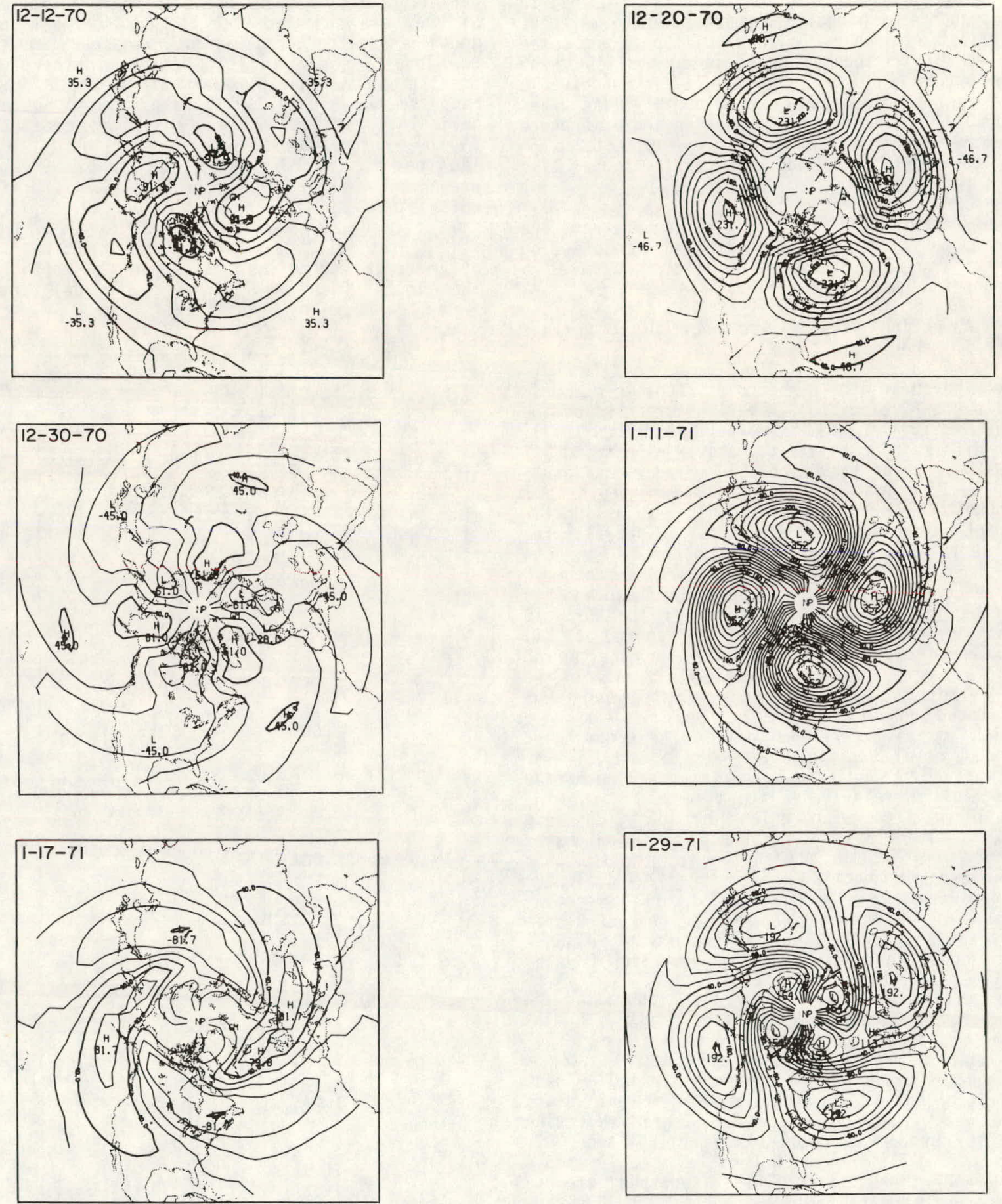

Fig. 58. Fourier-analyzed 500-mb synoptic patterns for three successive $A_{E}$ minima (left) and maxima (right), wavenumber two. Units in geopotential meters. The amplitude variations are typical (McGuirk and Reiter, 1976). 

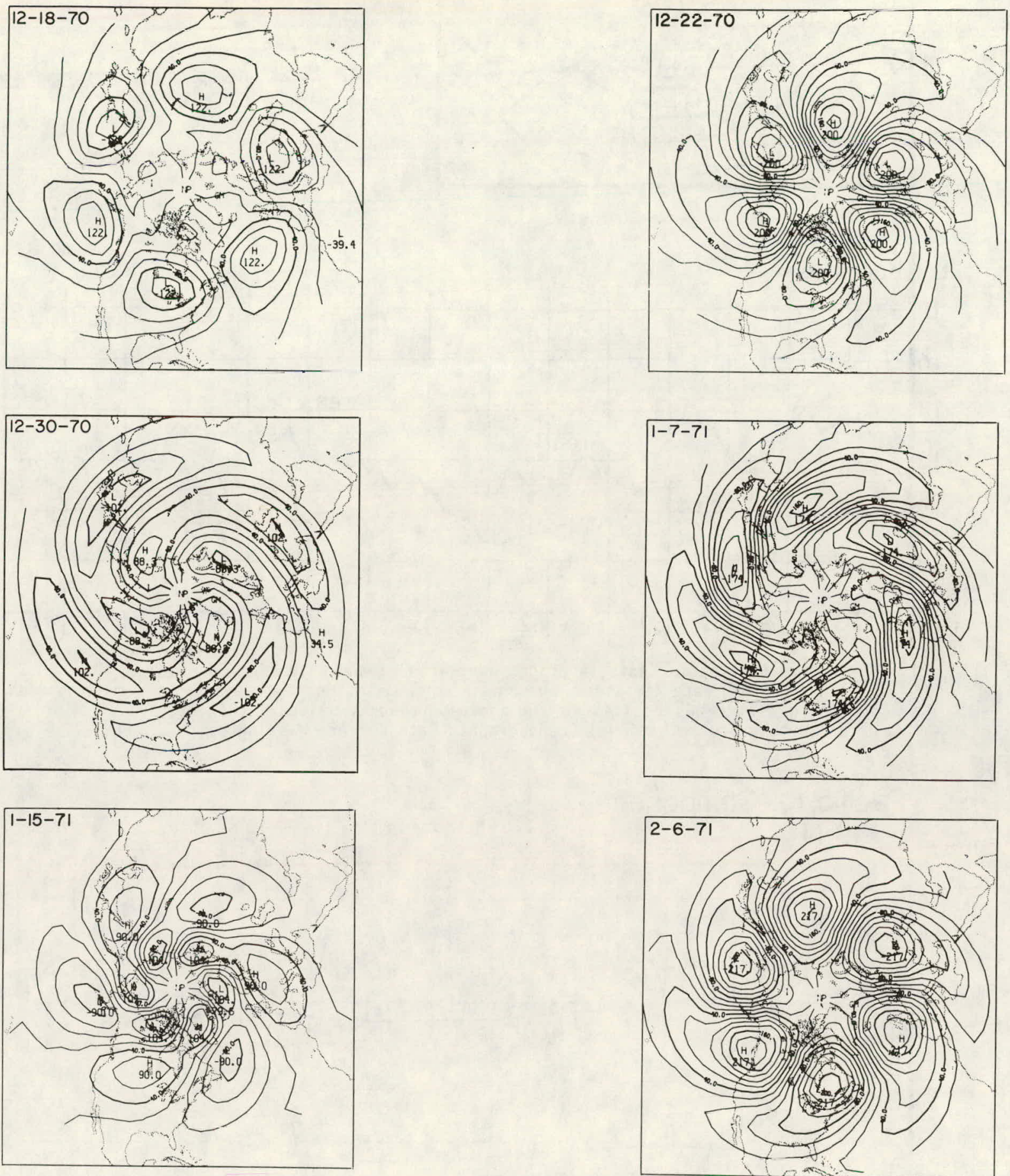

Fig. 59. Fourier-analyzed 500-mb synoptic patterns for three successive $A_{E}$ minima (1eft) and maxima (right), wavenumber three. Units in geopotential meters. The amplitude variations are typical (McGuirk and Reiter, 1976). 


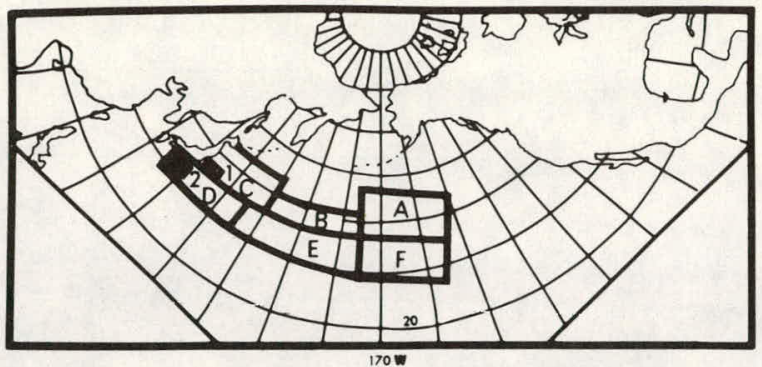

Fig. 60. Location map of oceanic areas used for averaging purposes.

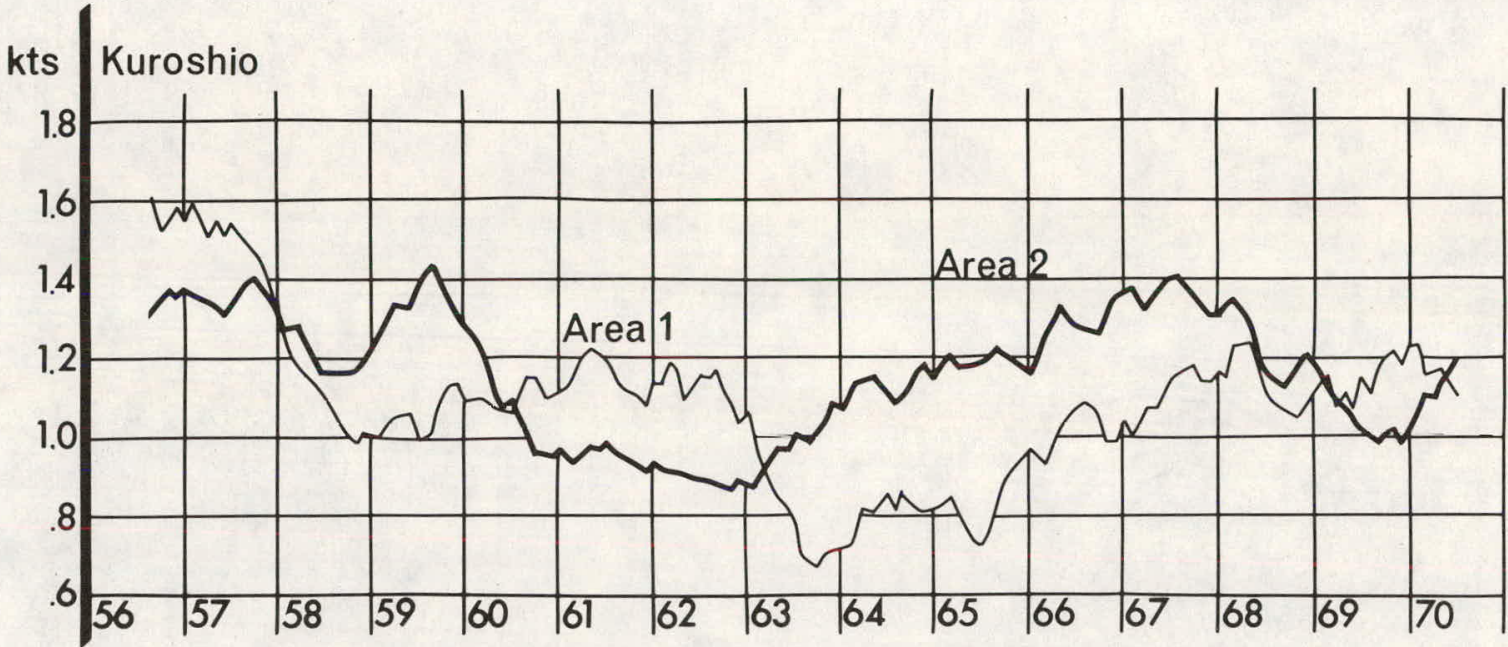

Fig. 61. Current velocities in knots, averaged over Areas 1 and 2 in Fig. 60. Values for missing months were obtained by linear interpolation. A seven-month running-mean smoothing filter was applied to the monthly velocity values. (Reiter, 1979b; original data courtesy of the National Oceanographic Data Center, Washington, D.C.)

Pacific, u-Component

$5-19^{\circ} \mathrm{N}$

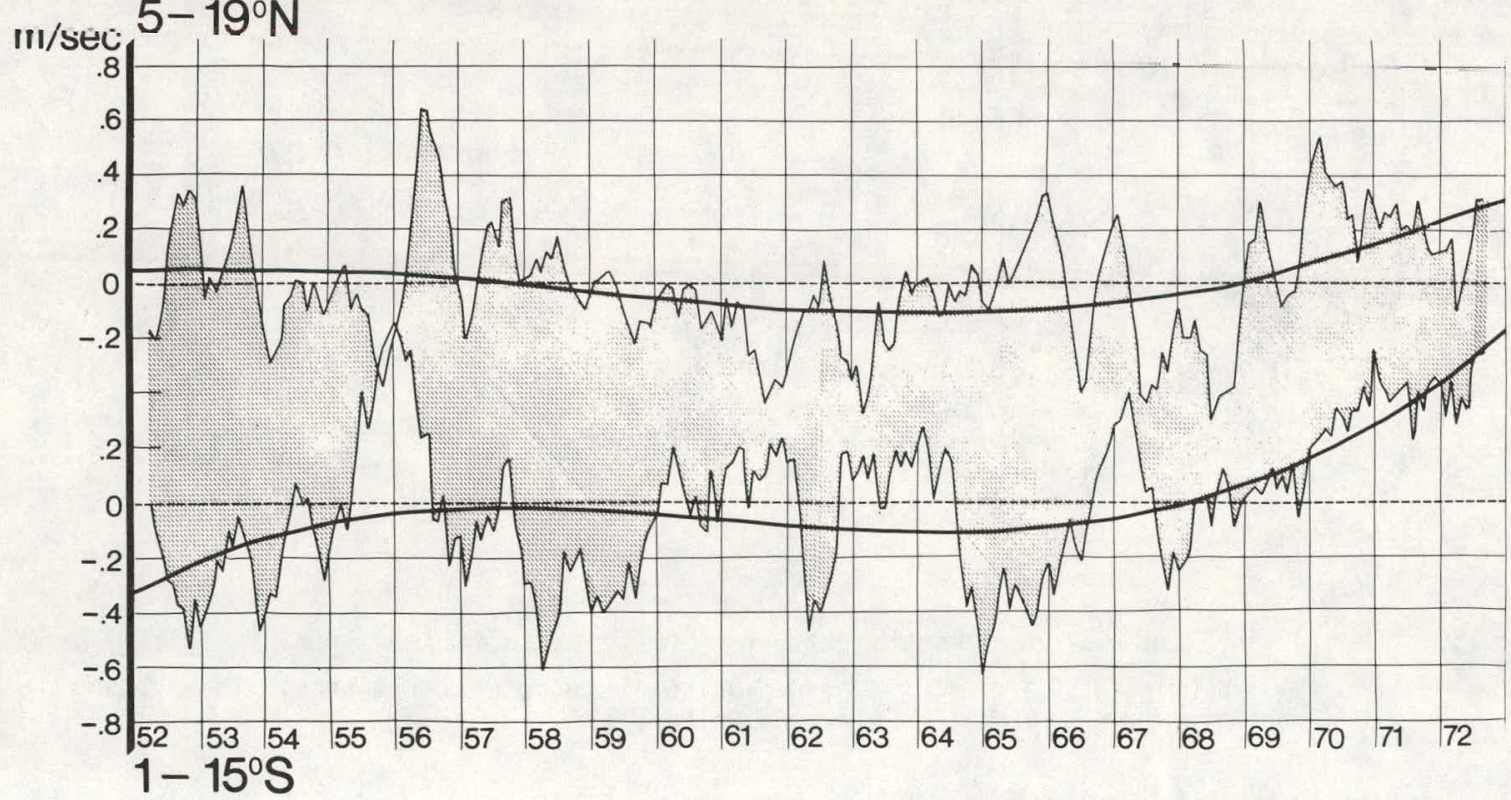

Fig. 62. Monthly departures of the surface trade-wind $u$-components $(\mathrm{m} / \mathrm{sec})$ from the "1ong-term" monthly means (a) in the North Pacific "box" $5^{\circ} \mathrm{N}-19^{\circ} \mathrm{N}, 125^{\circ} \mathrm{E}-95^{\circ} \mathrm{W}$, upper curve (land masses excluded) and (b) the u-component anomalies of the South Pacific trades in the "box" $1^{\circ} \mathrm{S}-15^{\circ} \mathrm{S}, 125^{\circ} \mathrm{E}-75^{\circ} \mathrm{W}$, lower curve, seven-month running averaging applied to data. Positive values indicate stronger-than-normal east wind. Vertical lines indicate January of each respective year. Heavy solid lines are least-squares fitted thirdorder polynomial curves (Reiter, 1979b). 


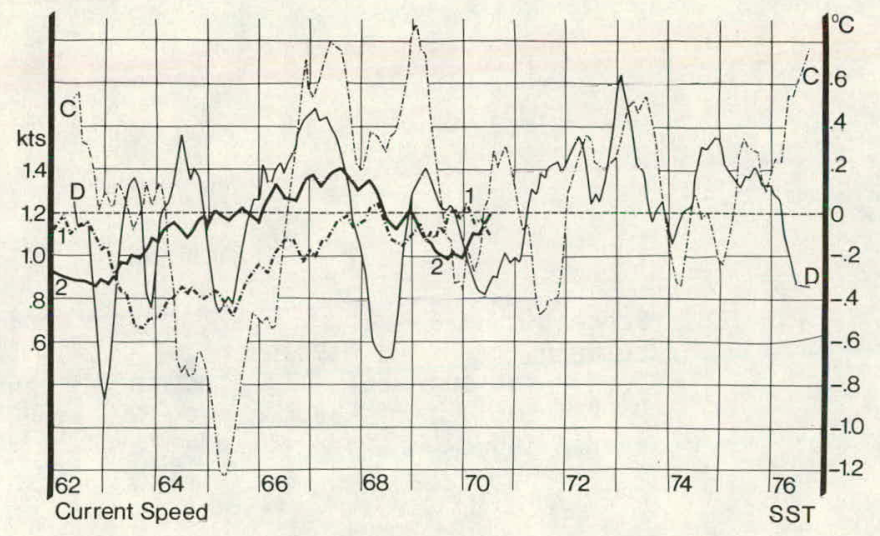

Fig. 63. SST anomalies in Areas $C$ and $D$ in ${ }^{\circ} \mathrm{C}$ (thin dashed-dotted and solid lines, areas are identified in Fig. 60), and current speeds in Areas 1 and 2 in knots (heavy dashed-dotted and solid lines). A11 data sets were subjected to a 7-month, running-mean smoothing routine (Reiter, 1979b).

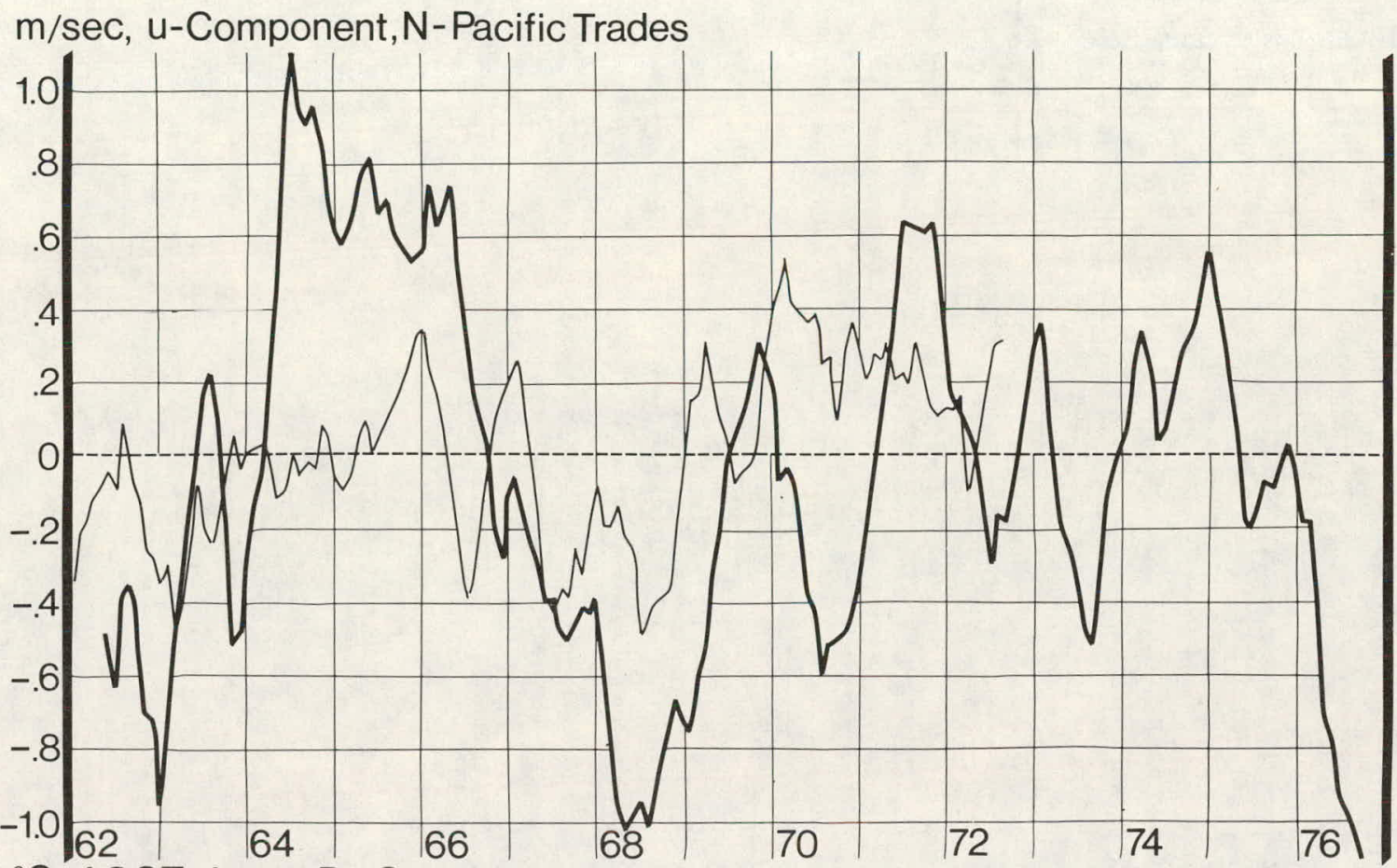

${ }^{\circ} \mathrm{C}, \Delta \mathrm{SST}$, Areas D-C

Fig. 64. Anomalies in the u-component in $\mathrm{m} / \mathrm{sec}$ of the North Pacific trade winds, averaged over the region $5^{\circ}-19^{\circ} \mathrm{N}, 125^{\circ} \mathrm{E}-95^{\circ} \mathrm{W}$ (thin line) and SST anomaly differences between Areas D and C ( ${ }^{\circ} \mathrm{C}$; heavy 1 ine). Both data sets have been subjected to a 7 -month running-mean filter (Reiter, 1979b).

the water transport in the Kuroshio and SST anomalies in mid-latitudes has a time scale of 20-35 months, thus could lead to quasi-periodicities in SST-anomaly formation of 4 to 6 years. A11 other loops involve local processes and have shorter time scales. The feedback loops with asterisks will be described more closely in Fig. 70.

Over the Atlantic there also exist long-term trends in the trade-wind $u$-components which are of similar magnitude as those over the Pacific (Fig. 66; data courtesy of $S$. Hastenrath, University of Wisconsin). A trend of increasing trade-wind intensity is noticeable in both hemispheres after 1968 . The temperature differences between Areas 1 and 2 (see Fig. 67) also have seen a rather sharp increase since the middle 1960 's suggesting an increase in geostrophic transport in the current east of Newfoundland (Fig. 68 ). It would be premature to relate these two events in a cause-effect relationship, however, especially since individual peaks in the two sets of curves are difficult to match.

\subsection{Trade Wind Surges, Precipitation Anomalies and \\ El Niño Events}

In an earlier paper (Reiter, 1978b) it was noted that an excellent correlation exists between precipitation in the so-called equatorial Pacific dry region and the convergence between the North and South Pacific trade-wind systems as measured by $\left(-v_{N} H_{+}+\right.$ $\left.v_{S . H .}\right) / 2$. These $v$-components had been averaged over the trade-wind "boxes" $5^{\circ}-19^{\circ} \mathrm{N}$ and $1^{\circ}-15^{\circ} \mathrm{S}$ and over the full longitudinal width of the Pacific. Representative precipitation data had been obtained for the 


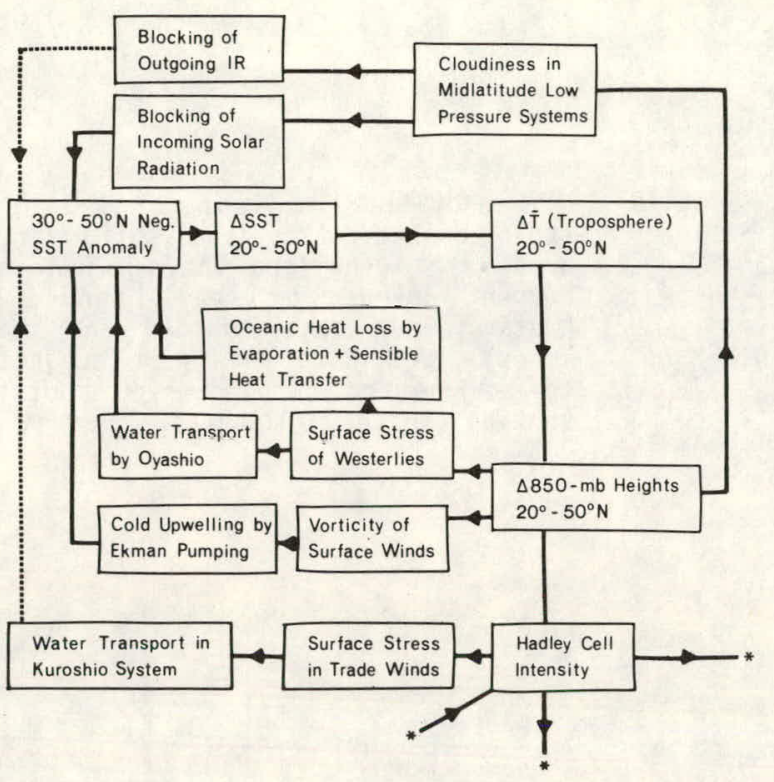

Fig. 65. Schematic diagram of feedback mechanisms between ocean and atmosphere affecting temperate-latitude SST anomalies in the North Pacific. Asterisks connect to feedback loops shown in Fig. 70 (Reiter, 1979b).

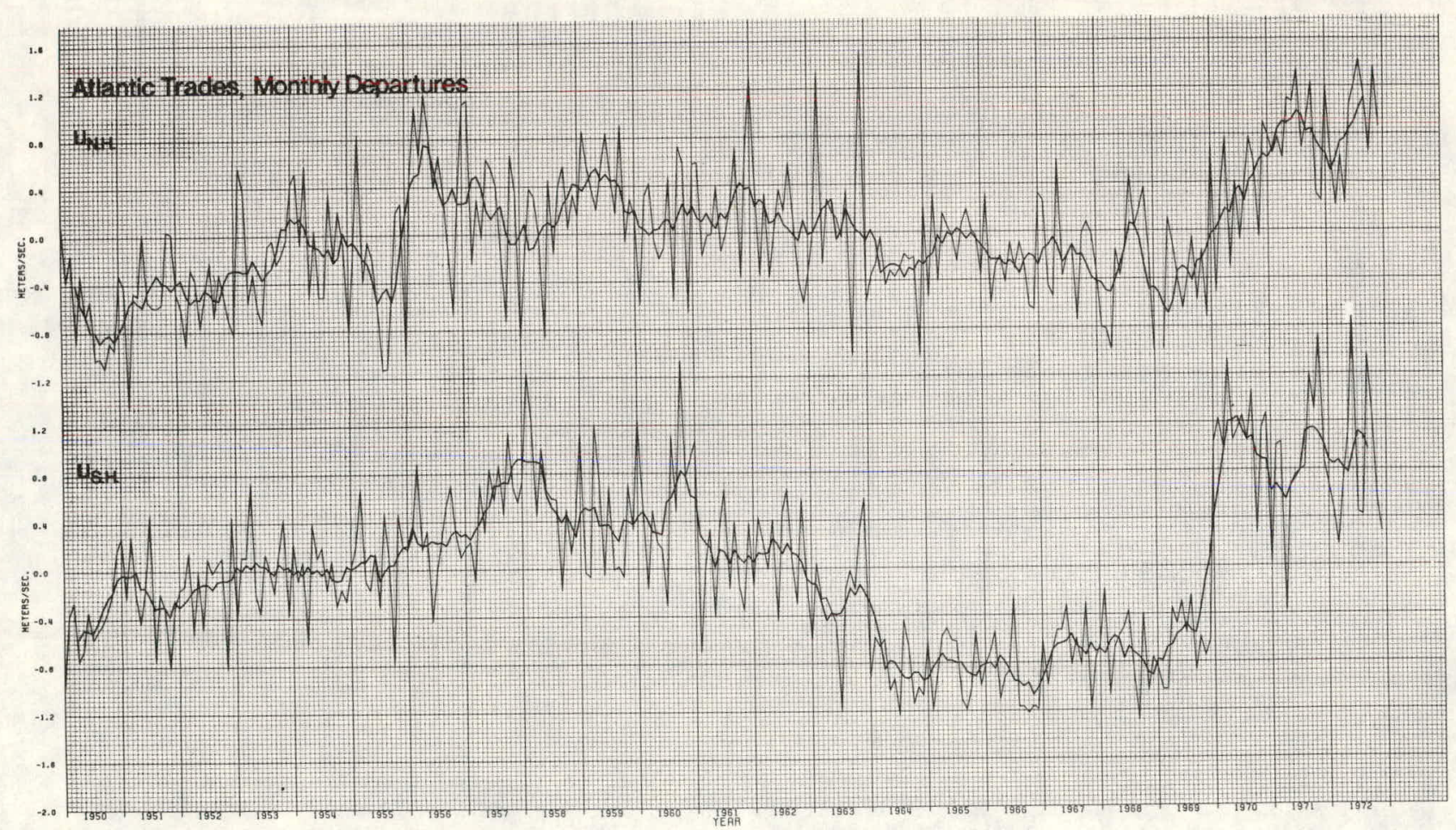

Fig. 66. Monthly anomalies of the zonal components $(\mathrm{m} / \mathrm{sec})$ of North and South Atlantic tradewinds, averaged over the regions $5^{\circ} \mathrm{N}-19^{\circ} \mathrm{N}, 89^{\circ} \mathrm{W}-10^{\circ} \mathrm{W}\left(\mathrm{U}_{\mathrm{N} . \mathrm{H} .}\right)$ and $1^{\circ} \mathrm{S}-15^{\circ} \mathrm{S}, 40^{\circ} \mathrm{W}-13^{\circ} \mathrm{E}$ ( $\mathrm{u}_{\mathrm{S} . \mathrm{H}_{\mathrm{S}}}$ ), land areas excluded. Positive anomalies indicate stronger-than-normal easterlies. Thin lines are monthly values, heavier lines represent 7 -month smoothed values. 


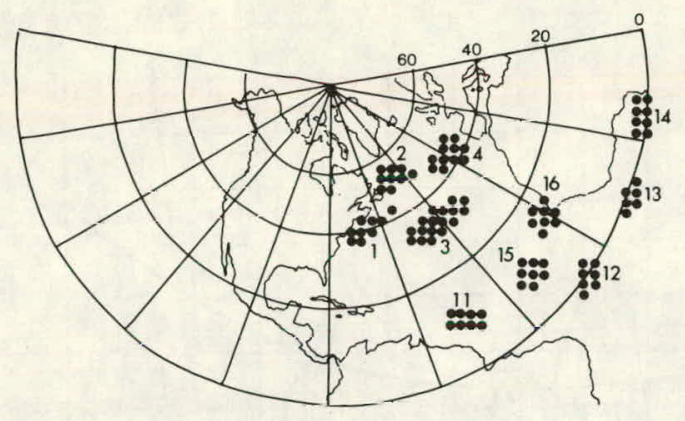

Fig. 67: Identification of areas in the Atlantic used for SST-anomaly computations.

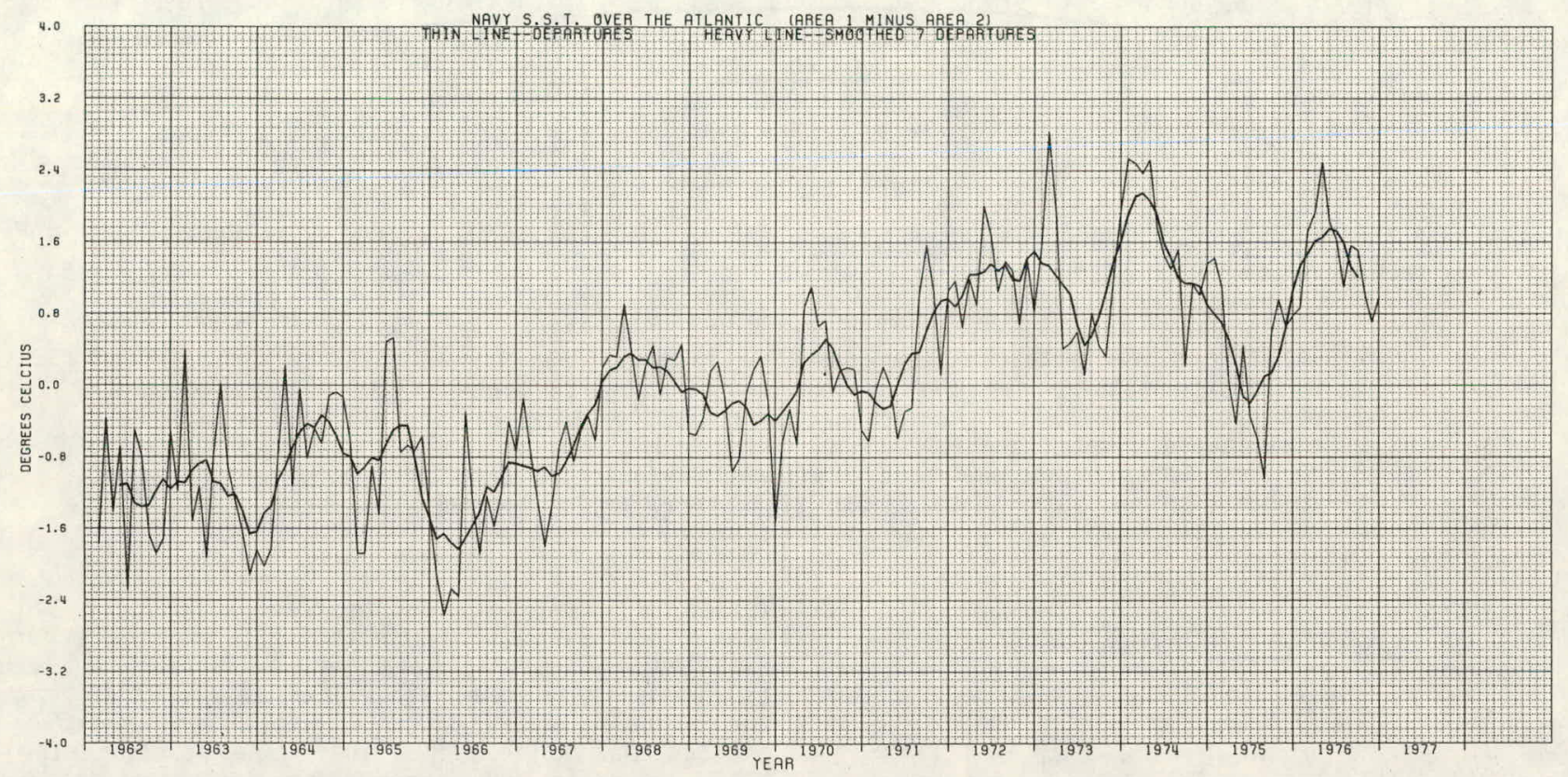

Fig. 68. Difference in SST anomalies between Area 1 and Area 2 (see Fig. 67) in ${ }^{\circ} \mathrm{C}$. The thin line represents monthly difference anomalies, the heavy line shows a 7 -month running-mean filter application.

Line Islands (Meisner, 1976). Results of this comparison are shown in Fig. 69. We postulated at that time the existence of a feedback mechanism between the moisture convergence caused by the trade-wind convergence, the release of latent heat in the region of the Intertropical Convergence Zone (ITCZ) and the strength of the Hadley cell (Fig. 70) (see also Ming and Lau, 1979). A warming of the tropical troposphere, indeed, takes place during the major precipitation surges (Newe11 and Weare, 1976a).

Julian and Chervin (1978), from experiments with the NCAR General Circulation Model, showed that such an intensification of the Hadley cel1, indeed, might take place with precipitation surges and might reveal itself in an intensification of the subtropical jet stream. Model experiments by Rowntree (1976) in the Atlantic sector favor a similar conclusion.

Reiter (1978b) also indicated that surges in the trade-wind convergence and precipitation over the equatorial Pacific tend to culminate with an "El Niño" event. Such events are characterized by the appearance of relatively warm water off the coast of Peru where normally cold upwelling water is found. In Fig. 70 we have presumed that a slight reduction of evaporation with the appearance of cold upwelling water in equatorial regions might be the first trigger that brings about the culmination of a surge in trade-wind convergence. A rapid decrease in the trade wind intensity would then set in motion the processes which have been modelled by McCreary (1976) and Hulburt et al. (1976) and which give rise to El Niñno events as described by Wyrtki (1975) and Wyrtki et al. (1976).

Ramage (1977) criticizes the notion by Ichiye and Petersen (1963) and Bjerknes (1966, 1969) that positive SST anomalies coincide with above-normal rainfal1, using data from Canton Island. We should not be surprised to find, off and on, poor matches on a relatively short-term basis between these two parameters in a given locality because, after a11, the moisture contained in precipitation may have traveled over great distances before it is removed from the atmosphere within a precipitation system. Figure 71 shows the SST near Christmas Island, one of the Line Islands (Seckel and Yong, 1977). Curve B in this diagram reveals the long-term variation, using the harmonics $n=1$ to 19 . The major peaks in this curve agree excellently with the positive precipitation anomalies shown in Fig. 69. Model calculations by Wells (1979) also suggest that over longer time periods ( 80 days in the case of his calculations) positive tropical SST anomalies are correlated with enhanced precipitation. 


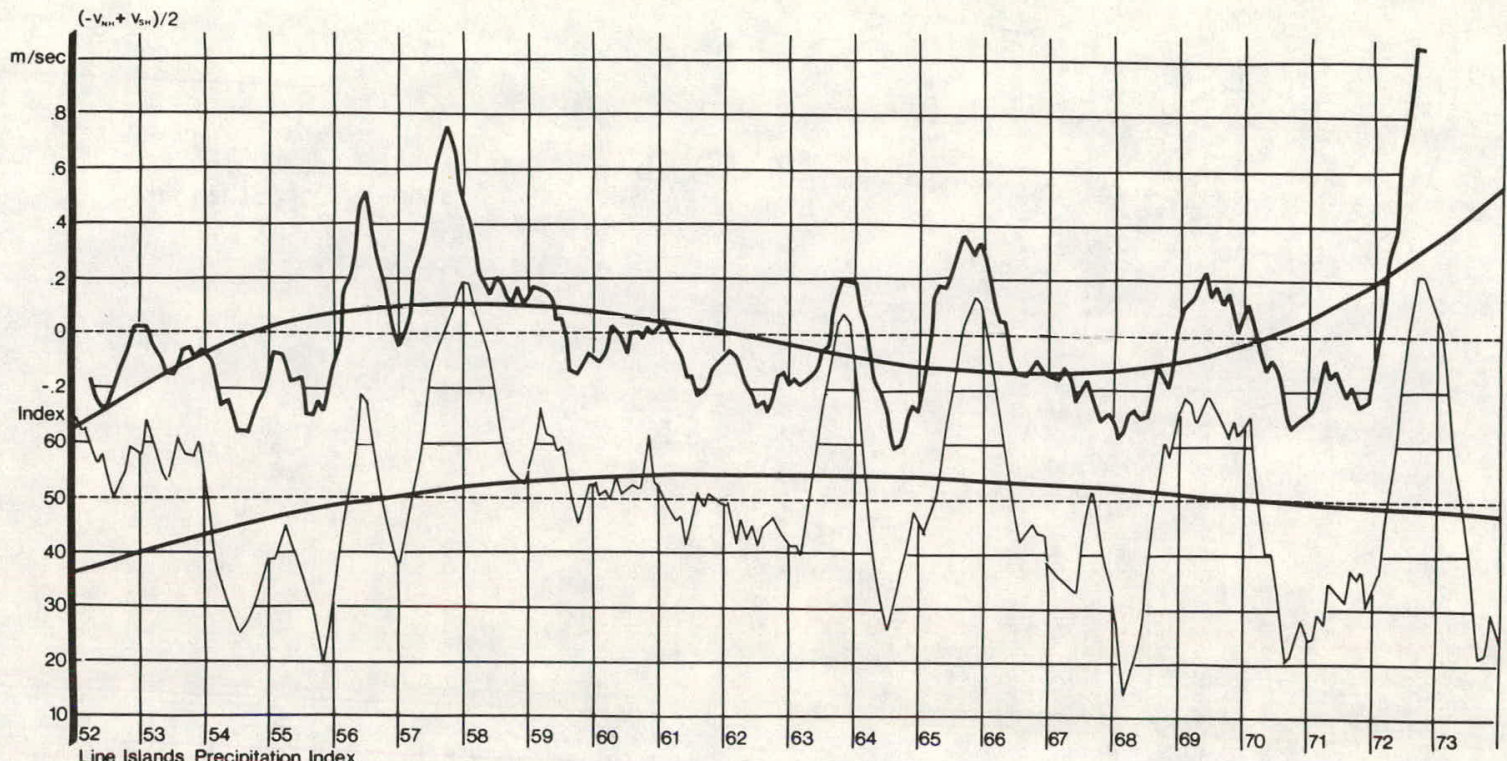

Fig. 69. Mean Pacific trade-wind v-component anomalies $\left(-v_{N} . H .+v_{S} . H.\right) / 2$ in m/sec (heavy line), and precipitation index for Line Islands (thin line). This index is obtained by assigning the value 100 to the largest positive monthly anomaly at the station, and the value 0 to the largest negative anomaly. The remainder of the anomalies are distributed proportionally between 0 and 100 . This procedure gives equal weight to dry and wet stations and to dry and wet seasons. Seven-month smoothing was applied to both curves. The heavy smooth lines represent a least-squares, third-order polynomial fit.

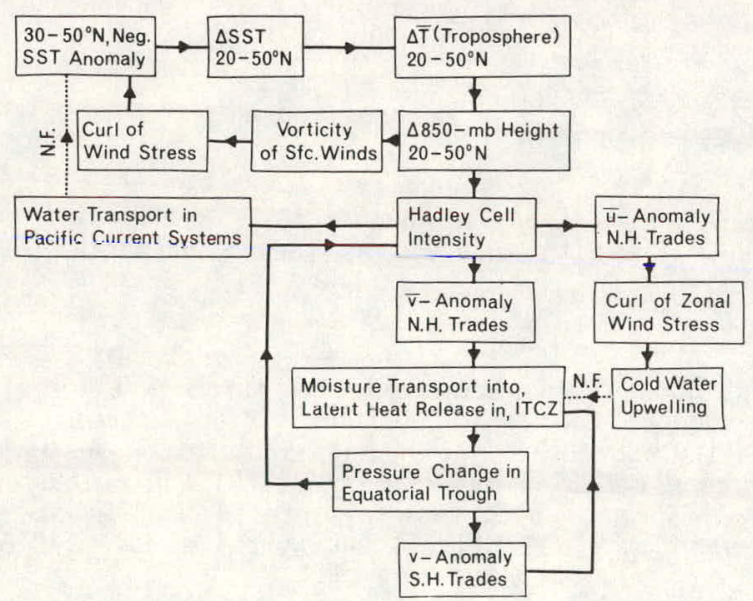

Fig. 70. Schematic diagram of feedback mechanisms involving oceanic and atmospheric anomalies in the Pacific region. Positive feedbacks are indicated by solid lines with arrows between "boxes", negative feedbacks by dotted lines and "N. F"

J. Middleton (work to be published) analyzed SST trends at the San Diego pier and also in the region of the cold California current. Results of the latter analyses, after application of a low-pass filter with a cut-off frequency of $0.065 /$ month, are shown in Fig. 72. For comparison, the Line Island precipitation data are also shown in this diagram. Even though the match between the SST and precipitation curves is not perfect, a certain trend resemblance cannot be denied. Most precipitation peaks at the Line Islands are preceded slightly by a peak in SST's in the entrance region of the North Pacific trade winds, i.e. in a region where most of the moisture uptake occurs. Detailed SST -anomaly analyses by Dorman and Saur (1978; see also Saur, 1978; Saur et al., 1979) along the shipping route Honolulu-San Francisco give a similar indication. Numerical model experiments by Wells and Puri (1979) suggest that increases of SST in the southern hemisphere as far south as $30-40^{\circ} \mathrm{S}$ can enhance the equatorward moisture transport. Albrecht et al. (1979) find from their model calculations that the water vapor mixing ratio in the trade-wind subcloud layer is positively correlated with, and quite sensitive too, SST anomalies and surface wind-speed anomalies, thus corroborating the feedback mechanisms postulated in Fig. 70 .

At this point of our investigation it would be difficult to decide if the SST decrease past each peak in Fig. 72 is caused by increased heat loss to the atmosphere, by intensified upwelling, or by the obliteration of an El-Niño-type event. We are presently in the process of calculating the evaporation rate in the region of the California current from the somewhat deficient data on hand, to see if trends in this rate, which also depend on atmospheric moisture and wind speed trends, provide a better match to equatorial precipitation fluctuations than sea-surface temperatures alone.

We have pointed out in an earlier publication (Reiter, 1979a) that surges in the Pacific trade-wind convergence and in Line Island precipitation are also reflected in positive pressure anomalies over Jakarta. These anomalies provide a convenient index to the state of the "southern oscillation" (Walker, 1924; Berlage, 1966). Figure 15 shows a time series of surface pressure anomalies at Jakarta. Since in the southern oscillation the South Pacific pressure anomalies are out of phase with those in the South Atlantic and Indian Oceans (for which Jakarta is a representative indicator), it is not surprising that Covey and 

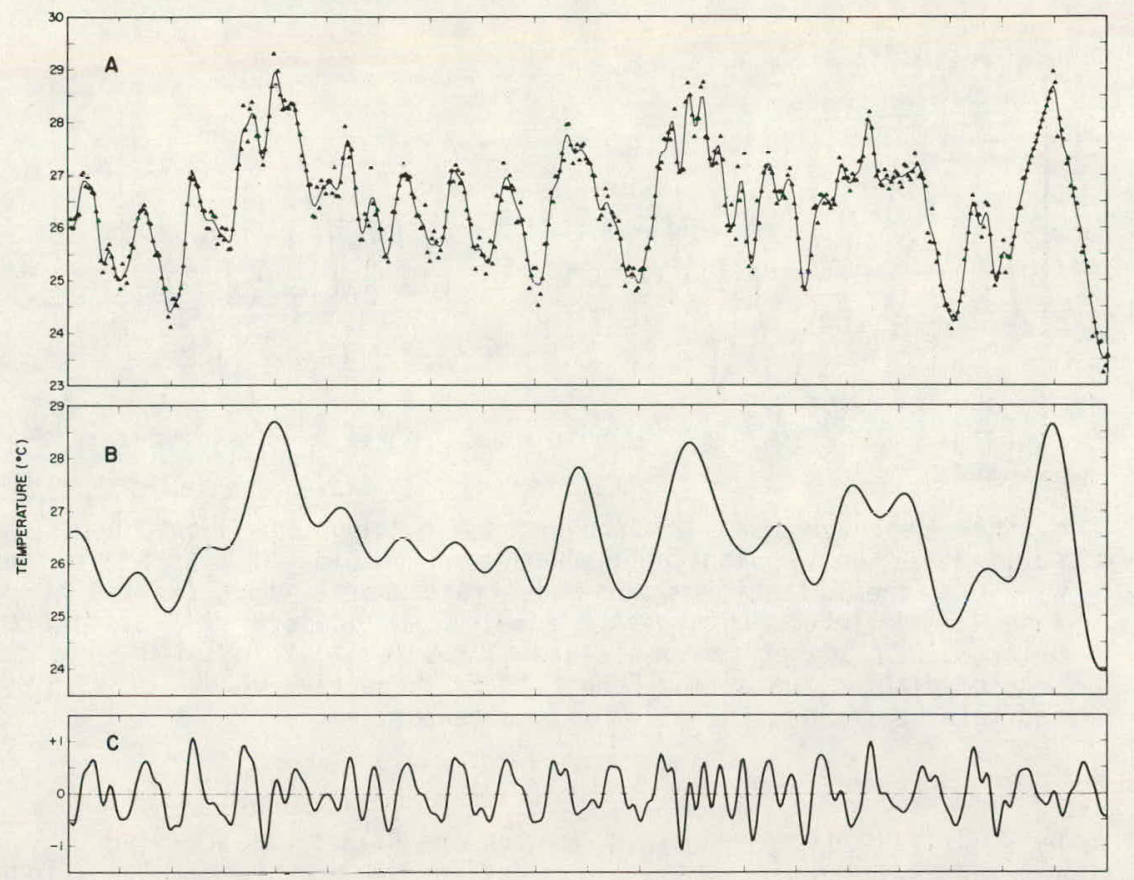

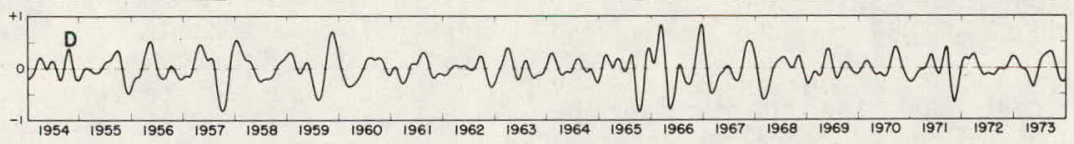

Fig. 71. Christmas Island SST, 1954-1973. A: Data fitted with a harmonic curve of 3-month resolution ( $\mathrm{n}-1$ to 80 ); $\mathrm{B}$ : Long-term variation ( $\mathrm{n}-1-19)$; C: Short-term variation $(n=20-80) ; D$ : Residual variation $(n=21,39,41-59,61-79)$. (From Seckel and Yong, 1977.)

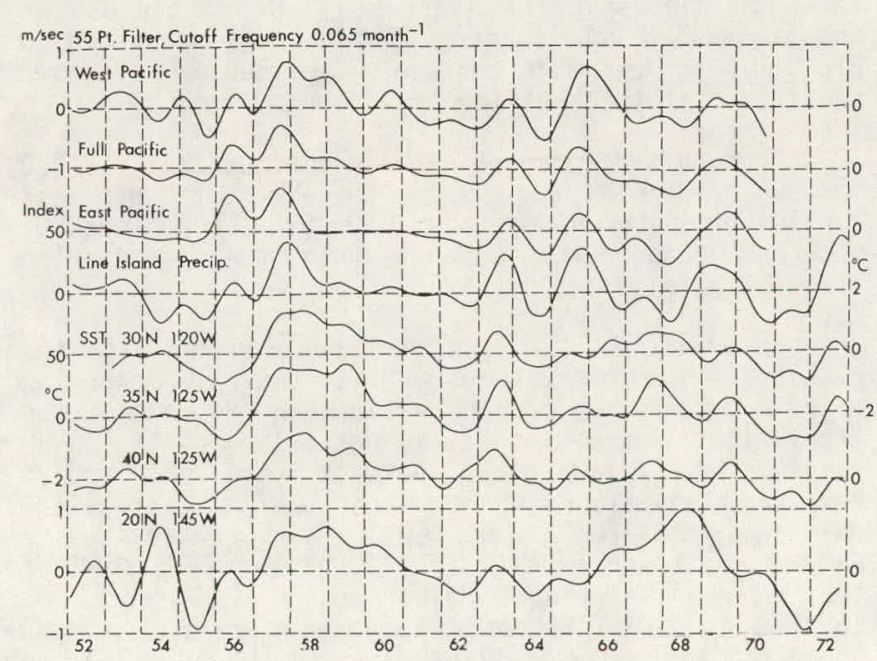

Fig. 72. Filtered time series (cut-off period ca. 15 months) of the trade wind convergence $\left(-v_{\text {N.H. }}+v_{\text {S.H. }}\right) / 2$ in $\mathrm{m} / \mathrm{sec}$ in the West Pacific $\left(5^{\circ} \mathrm{N}-19^{\circ} \mathrm{N}, 1^{\circ} \mathrm{S}-15^{\circ} \mathrm{S}\right.$; west of $\left.160^{\circ} \mathrm{W}\right)$, the full Pacific (same latitude bands), and the East Pacific (same latitude bands, east of $\left.160^{\circ} \mathrm{W}\right)$; filtered series of the Line Island Precipitation Index expressed.as ranging from -50 (dry) to +50 (wet), and of SST anomalies $\left({ }^{\circ} \mathrm{C}\right)$ at various grid points as indicated. Years are plotted along the abscissa. (Filter design and computations by J. Middleton. )
Hastenrath (1978) find positive pressure anomalies for March/April in the equatorial and subtropical Atlantic during El Niño years, negative anomalies during counter-E1 Niño years.

That the southern oscillation and its inherent "Walker circulation" depend on the release of latent heat and seem to be tied to SST anomalies in low latitudes has been demonstrated by several authors (e.g. Cornejo-Garrido and Stone, 1977; McWilliams and Gent, 1978; Ming and Lau, 1979).

\subsection{The Atlantic Quasi-Biennial 0scillation}

In a previous publication (Reiter, 1979a) it was shown that the convergence between the North and South Atlantic trade-wind systems, as measured by $\left(-v_{N}\right.$. H. $\left.v_{S . H .}\right) / 2$, undergoes a rather regular quasi-biennial oscillation (QBO) that seems to be correlated with the stratospheric $Q \mathrm{BO}$ as evident from the Canton Island or Balboa winds. The $v$-components of the two trade-wind systems, $v_{N} . H$. and $V_{S . H}$, were averaged in these computations over the longitudinal width of the Atlantic between $5^{\circ} \mathrm{N}$ and $19^{\circ} \mathrm{N}$, and between $1^{\circ} \mathrm{S}$ and $15^{\circ} \mathrm{S}$, respectively. These earlier results are repeated in Fig. 73 in terms of anomalies from long-term monthly means, with a seven-month running-mean filter applied to the anomaly data of $\left(-v_{N . H}+{ }^{+} v_{S . H .}\right) / 2$.

Several additional factors have emerged recently from our analysis work which help to shed some light on this yet unexplained $\mathrm{QBO}$ in the Atlantic trade-wind convergence. 


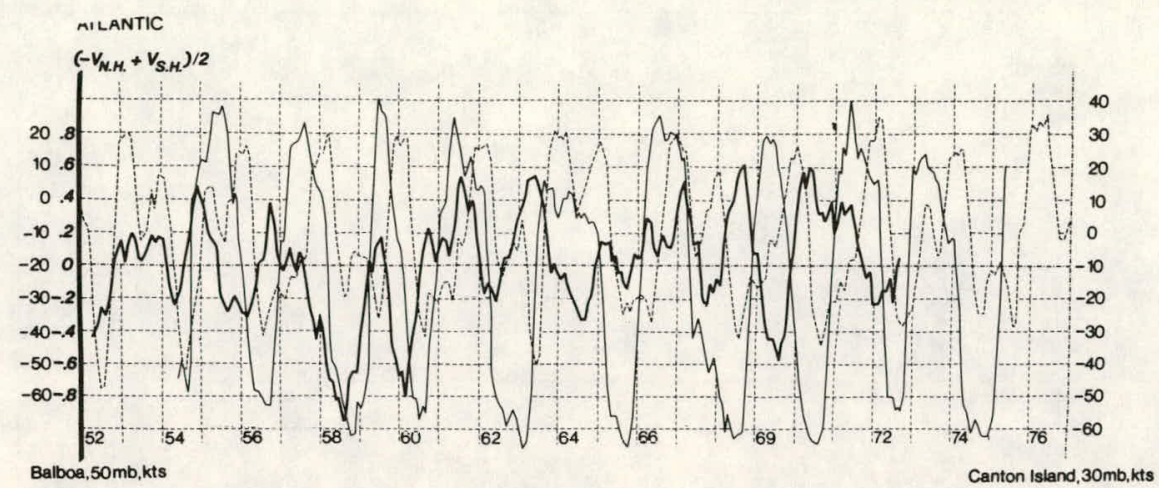

Fig. 73. Monthly departures of the convergence between the $v$-components (knots, heavy solid line, heavy slanting numbers on left side of diagram) of surface tradewinds in the Atlantic sector and stratospheric winds (knots) at Balboa, Canal Zone (50-mb level, thin dashed line, scale on left side of diagram; data from Brier, 1978) and at Canton Island (30-mb level, thin solid line, scale on right side of diagram; data from Ebdon, 1975). Positive values of stratospheric winds indicate westerlies, negative values easterlies.

As has been shown by Reiter (1979a) in a display of the appropriate time series, the contribution of $V_{N}$.H. towards the observed QBO in the trade-wind convergence over the Atlantic sector appears to be somewhat more significant than the contribution by $\mathrm{v}_{\mathrm{S} . \mathrm{H}}$. (Fig. 74). In Fig. 75 the non-nomalized spectra of $v_{S . H .}, v_{N . H .}$, and $\left(-v_{N . H .}+v_{S . H .}\right) / 2$ are shown, revealing their relative contributions to a $Q B O$ in the trade-wind systems.

Figure 76 displays the non-normalized spectrum of the trade-wind convergence over the Pacific. The Pacific spectrum does not have a significant peak at frequencies characteristic of a QBO. Neither do the spectra for trade-wind convergences when computed separatcly for Eact. and West Pacific (Fig. 77). These computational results prompted us to the speculatiun that the Atlantic trade-wind convergence, perhaps through a yet to be specified ocean-atmosphere feedback mechanism, has a characteristic eigenfrequency corresponding to a period of approximately 26 months, whereas the Pacific -- most likely due to its different size and time scales of its current systems -does not share this frequency domain in a significant way. One is tempted to conclude that the stratospheric $Q B O$, evident from the reversal of equatorial winds, is mainly tied to tropospheric flow behavior over the Atlantic sector, but not over the Pacific.

To test this hypothesis $J$. Middleton, in yet unpublished work, subjected both, the Balboa stratospheric wind data and the Atlantic trade-wind convergence data, to a low-pass filter with a cut-off frequency at 0.065 months $^{-1}$ (corresponding to a period of 15 months).

The two filtered time series are shown in Fig. 78. There is an indication from this diagram that the QBO in the Atlantic trade-wind convergence and the stratospheric $Q B O$ might be correlated, especially prior to 1964. After that year drastic phase changes occurred mainly in the stratospheric QBO.

To investigate the possible connection between the tropospheric and the stratospheric OBO more closely we examined their seasonal behavior. Taking the low-pass filtered time series of $\left(-v_{N} . H .+v_{S . H .}\right) / 2$ for the Atlantic trade-wind reqions (Table 4), one can define the monthly mean amplitude of the QBO as follows: For each month the interannual differences of these values are assigned positive values if they follow a "see-saw" pattern (e.g. January 1953 has a relatively low value, January 1954 a higher one, January 1955 a lower one again, etc.). A negative value is given to such differences if they fall out of step with a quasi-biennial oscillation. A phase shift of the QBO by one year was assumed between 1966 and 1970, depending on the season. The pattern of these interannual differences is shown in Fig. 79. The mean-monthly interannual differences thus defined are taken to represent the mean amplitude of the $\mathrm{QBO}$ in the trade-wind convergence. Results are presented in Fig. 80, which also contains the monthly standard deviations of these difference values.

From this diagram it becumes obvious that the $Q B O$ in the trade-wind convergence is strongest and most consistent between March and July. It is weakest between October and January when the oscillation frequently falls out of step.

The foregoing analyses can be compared with the results of a recent study by Brier (1978). According to his Fig. 4, reproduced here as Fig. 81 most of the transitions from easterlies to westerlies at the $50-\mathrm{mb}$ level over Balboa occur between April and July. Reverse transitions, from westerlies to easterlies, reveal a preference for the period January-August. Figure 82, taken from Brier (1978), shows the QBO of the seasonally-averaged Balboa winds at $50 \mathrm{mb}$. $\mathrm{Ac}^{-}$ cording to this diagram a three-year persistence of summer (N-season) westerlies occurred between 1957 and 1959. Figure 79 indicates that the QBO of the Atlantic trade winds during summer and autumn fell out of step thrice in a row between 1956 and 1958. A phase shift of the stratospheric QBO in the $\mathrm{N}$-season occurred in 1962 (Fig. 82); in the autumn trade-wind QBO a shift was observed in 1961. The $\mathrm{N}$-season stratospheric QBO decisively fell out of step in 1967 (Fig. 82). We note from Fig. 79 that the trade-wind QBO changed phase during summer and fall of 1966 . This phase shift continued into spring and summer of 1967.

Focussing our attention to the $S$-season in Fig. 82 we find that the phase-shift in the winter of 


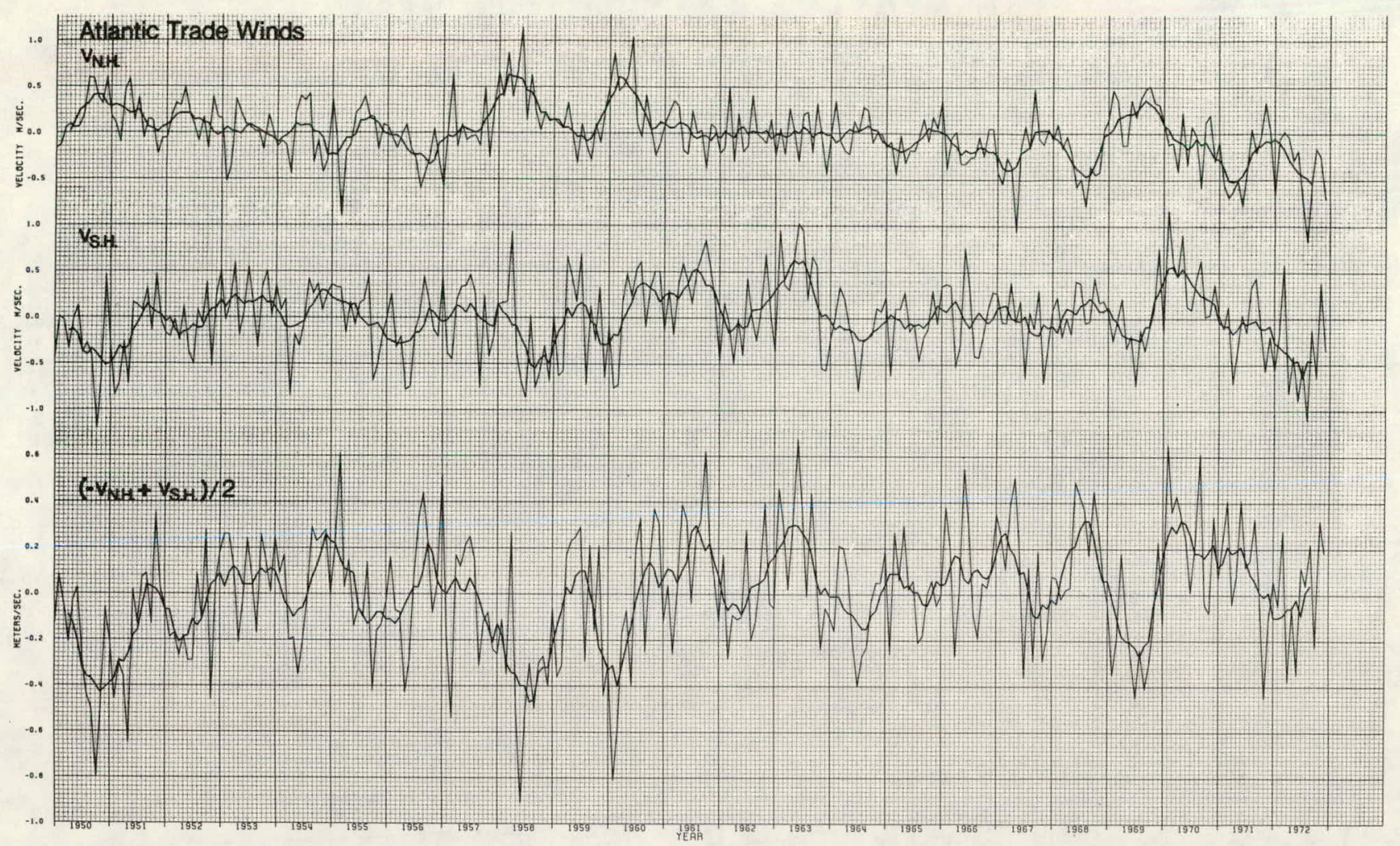

Fig. 74. Monthly anomalies of meridional component of Atlantic trade-winds ( $\mathrm{m} / \mathrm{sec})$ averaged over the regions $5^{\circ} \mathrm{N}-19^{\circ} \mathrm{N}, 89^{\circ} \mathrm{W}-10^{\circ} \mathrm{W}\left(\mathrm{v}_{\mathrm{N} . \mathrm{H} .}\right)$ and $1^{\circ} \mathrm{S}-15^{\circ} \mathrm{S}, 40^{\circ} \mathrm{W}-13^{\circ} \mathrm{E}\left(\mathrm{v}_{\mathrm{S} . \mathrm{H} .}\right)$, land areas excluded. The lower set of curves gives the anomalies of convergence (positive values) and divergence (negative values), computed as $\left(-v_{N} . H_{.}+v_{S . H .}\right) / 2$. Thin lines represent monthly departure values, heavy. lines indicate 7 -month smoothing.

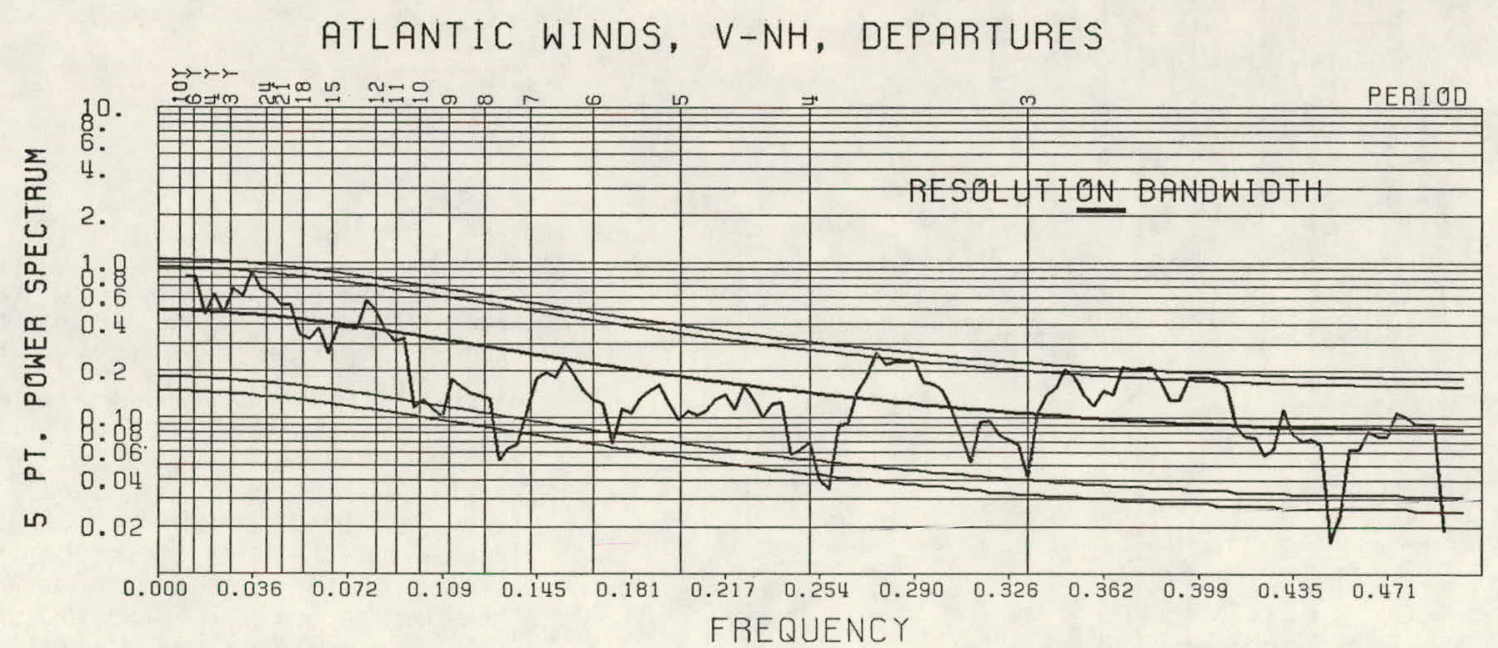

ig. 75. 5-point smoothed power spectra (non-normalized) of monthly anomalies of the Atlantic tradewind $v$-components averaged over the regions $5^{\circ} \mathrm{N}-19^{\circ} \mathrm{N}, 89^{\circ} \mathrm{W}-10^{\circ} \mathrm{W}$ (N.H.) and $1^{\circ} \mathrm{S}-15^{\circ} \mathrm{S}, 40^{\circ} \mathrm{W}-$ $13^{\circ} \mathrm{E}$ (S.H.), land areas excluded. The third diagram shows the spectrum of the convergence between the northern and southern hemisphere trade-wind components. The spectra have been obtained by Fast Fourier Transformation after cosine-tapering of ten percent of the data points at each end of the time series. The smooth curves represent the "red-noise" null hypothesis (center curve) and the 90 and 95 percent confidence limits on either side. The resolution bandwidth for five-point smoothing is given graphically by the length of a heavy dash in each diagram. 
ATLANTIC WINDS, V-SH, DEPARTURES

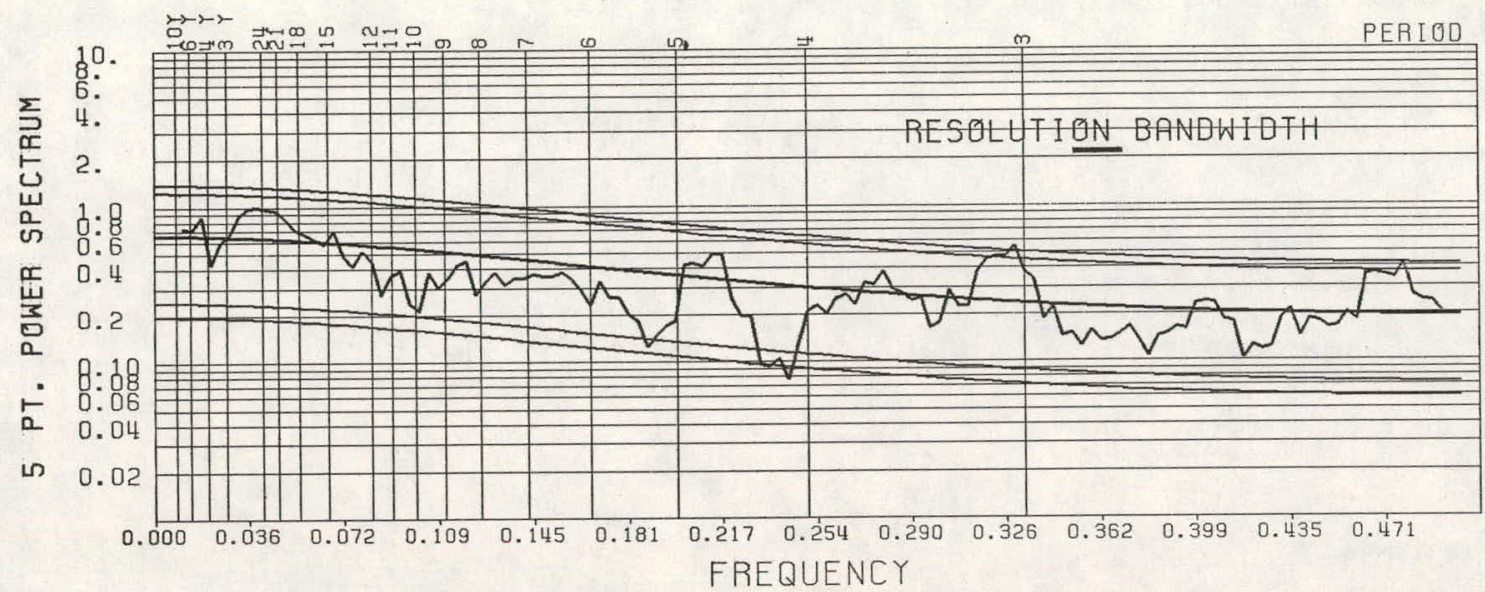

ATLANTIC WINDS, (-VNH $+V S H) / 2$, DEPARTURES

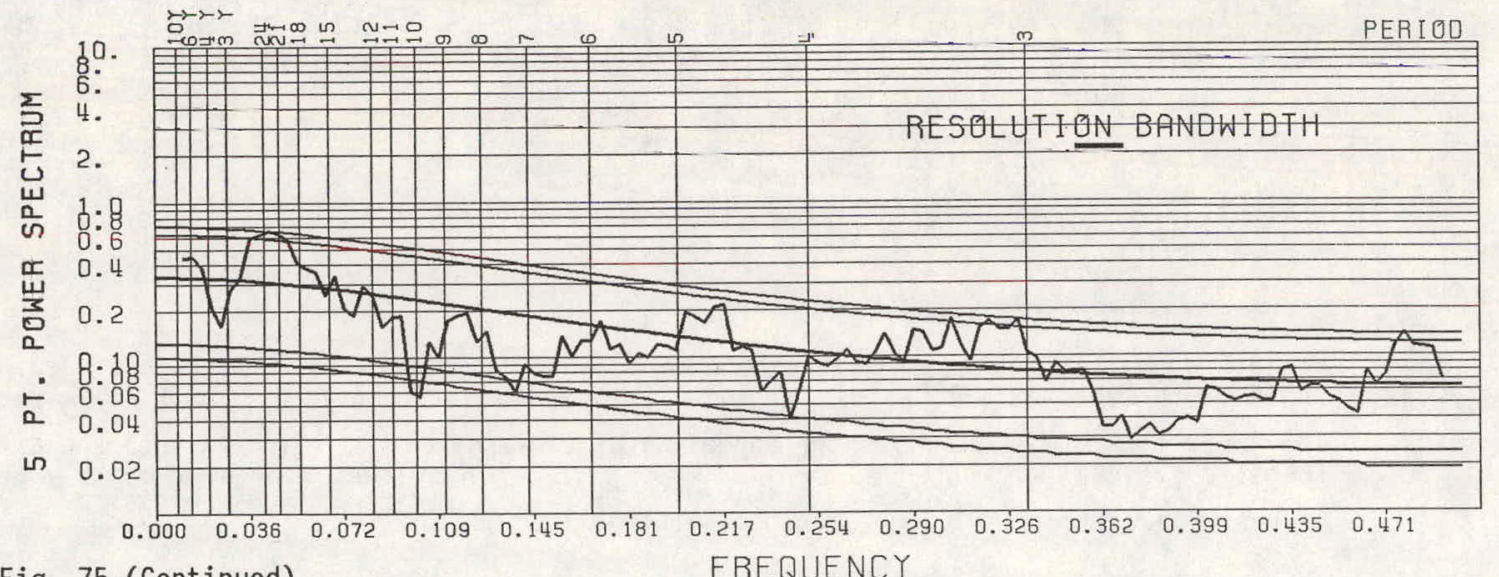

Fig. 75 (Continued)

FREQUENCY

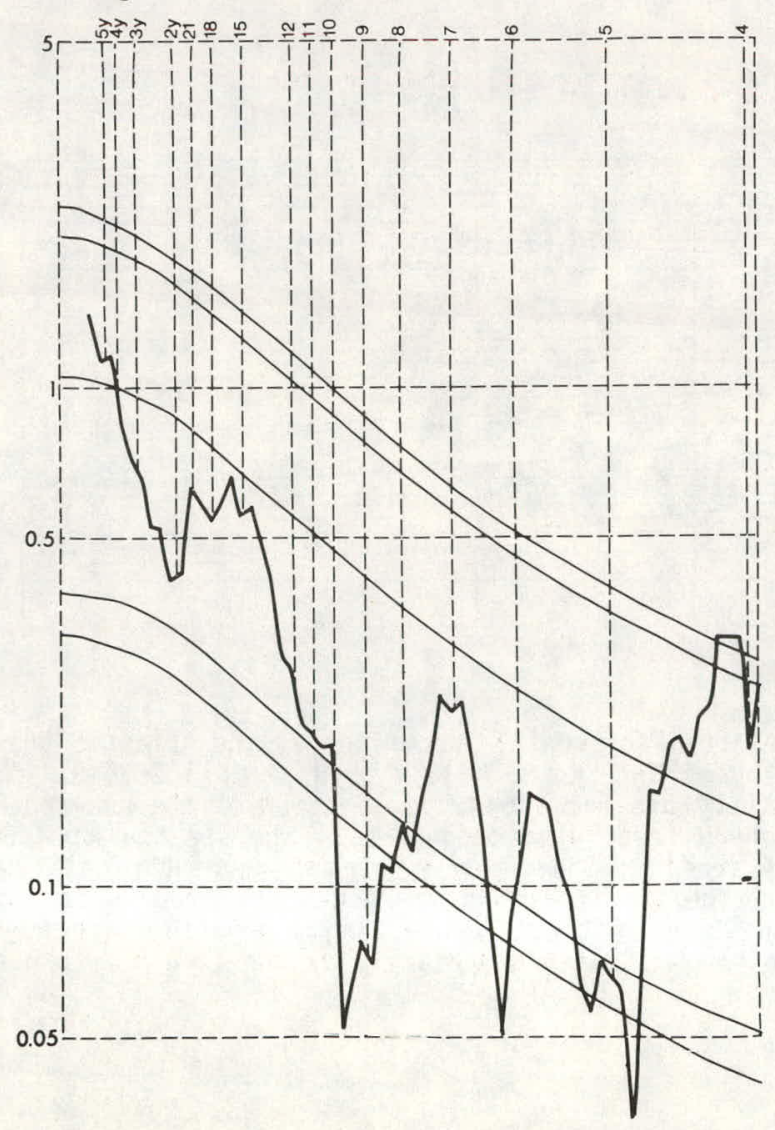

Fig. 76. 5-point smoothed power spectrum (non-normalized) of monthly anomalies of the Pacific trade-wind convergence, $\left(-v_{\text {N.H. }}+\right.$ v $\left._{\text {S.H. }}\right) / 2$, computed from monthly wind values for the latitude bands $5^{\circ} \mathrm{N}-19^{\circ} \mathrm{N}$ and $1^{\circ} \mathrm{S}-15^{\circ} \mathrm{S}$, averaged over the full longitudinal width of the Pacific, land masses excluded. The spectrum has been obtained by Fast Fourier Transformation after cosine-tapering of ten percent of the data points at each end of the time series. The smooth curves represent the "red-noise" null hypothesis (center curve) and the 90 and 95 percent confidence limits on either side. 


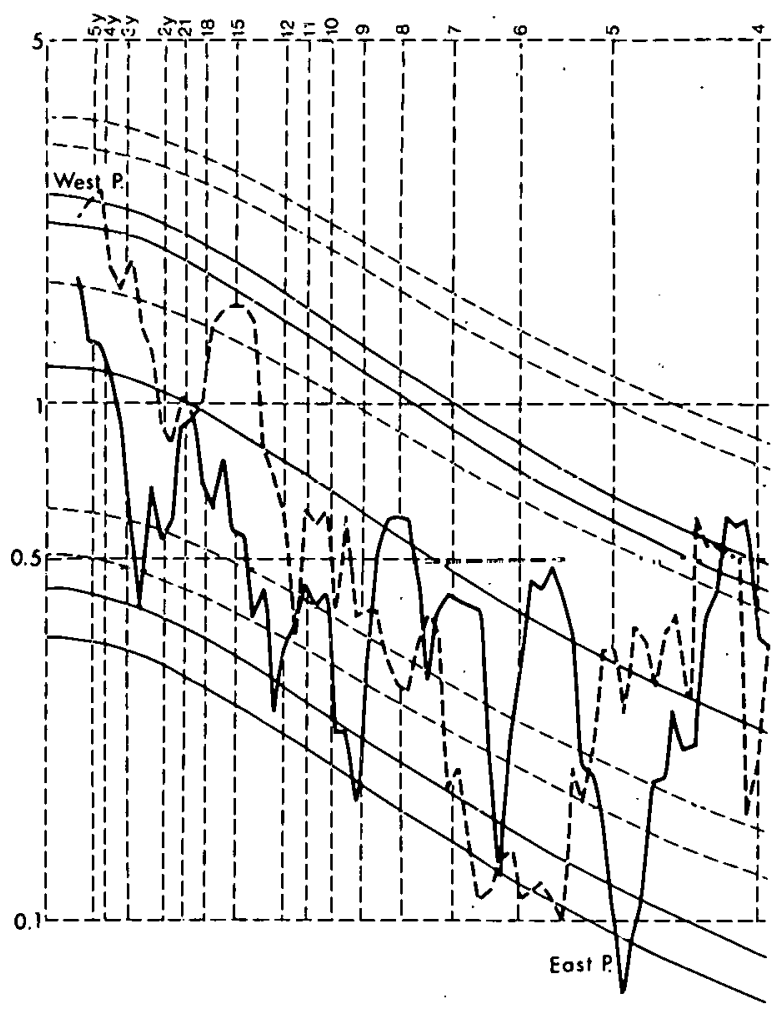

Fig. 77, Similar to Fig. 76, except for separate spectral presentations of the trade-wind convergence in the West Pacific (west of $16 n^{\circ} \mathrm{W}$ : dashen spectrum and confidence limits curves) and in the East Pacific (east of $160^{\circ} \mathrm{W}$; full spectrum and confidence limits curves).

55 Term Filter, 0.065 month ${ }^{-1}$ Culoff Frequency

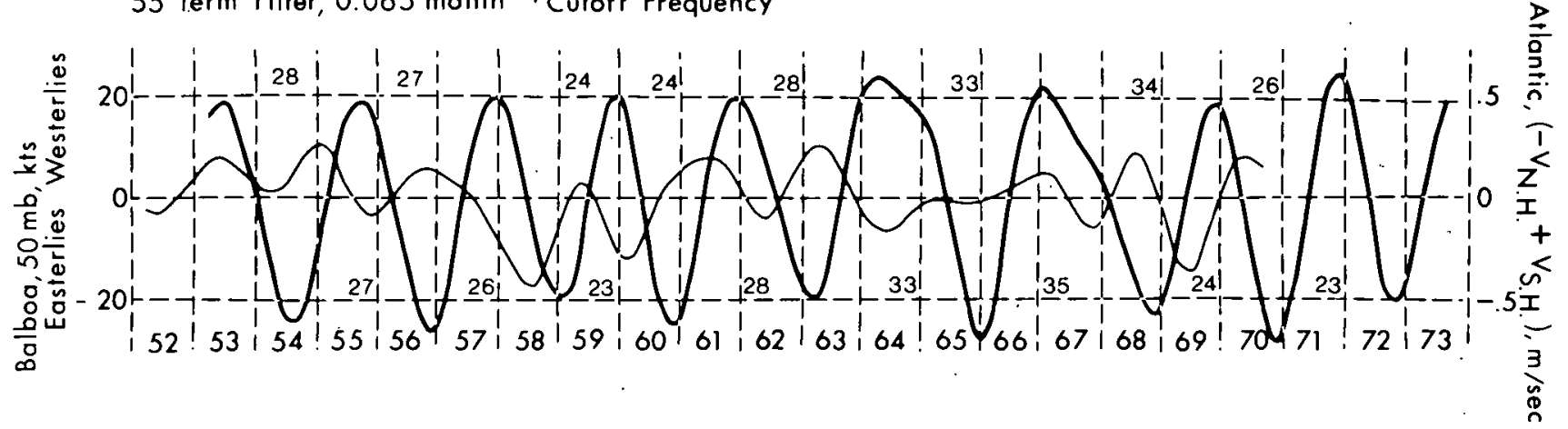

Fig. 78. Filtered time series (cutoff period ca. 15 months) of Balboa winds at 50 mb (in knots, heavy line) and the convergence between the two Atlantic trade-wind systems ( $\mathrm{m} / \mathrm{sec}$, thin line). Numerical values indicate the time intervals, in months, between extremes of the $\mathrm{QBO}$ in the Balboa winds. (Filter computations by J: Middleton.)

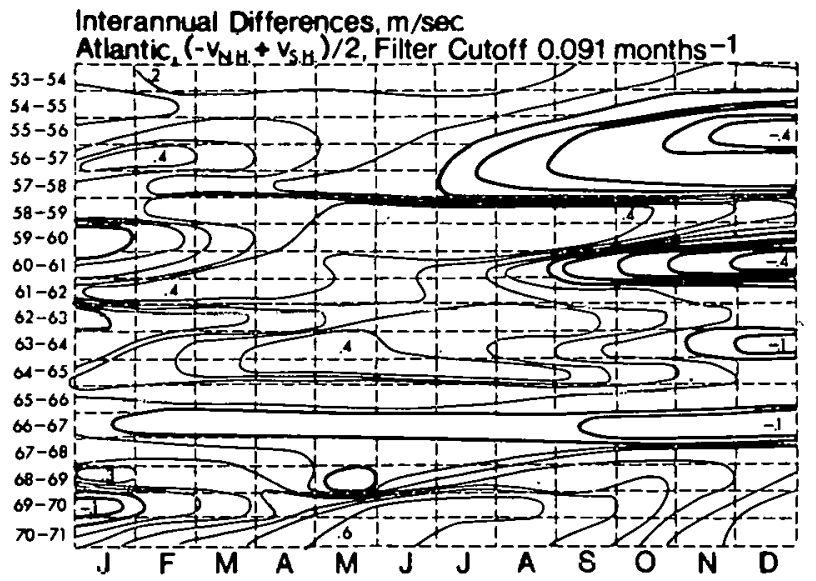

Fig. 79. Interannual differences of filtered Atlantic trade-wind convergence data (iso-lines for each $0.1 \mathrm{~m} / \mathrm{sec}$ ). Thin lines indicate inphase, heavy lines out-of-phase behavior of QBO. Data from Table 4. 
TABLE 4. Atlantic trade wind convergence $\left(-v_{N} . H .+v_{S . H .}\right) / 2$, departures from monthly means, using a low-pass filter with cutoff frequency at 0.09100 months $^{-1}$. The horizontal lines indicate phase shifts of the QBO, allowed for in Fig. 79 (After J. Middleton, unpublished work).

$\begin{array}{rrrrrrrrrrrrr}\text { Year } & \text { Jan. } & \text { Feb. } & \text { Mar. } & \text { April } & \text { May } & \text { June } & \text { July } & \text { Aug. } & \text { Sept. } & \text { Oct. } & \text { Nov. } & \text { Dec. } \\ & & & & & & & & & & & & \\ 1953 & 0.06 & -0.01 & -0.07 & -0.12 & -0.15 & -0.15 & -0.12 & -0.06 & 0.00 & 0.07 & 0.13 & 0.17 \\ 1954 & 0.19 & 0.19 & 0.17 & 0.15 & 0.13 & 0.12 & 0.13 & 0.15 & 0.17 & 0.19 & 0.20 & 0.19 \\ 1955 & 0.16 & 0.10 & 0.04 & -0.01 & -0.05 & -0.06 & -0.03 & 0.03 & 0.11 & 0.20 & 0.28 & 0.34 \\ 1956 & 0.35 & 0.34 & 0.29 & 0.22 & 0.14 & 0.07 & 0.01 & -0.03 & -0.06 & -0.07 & -0.08 & -0.08 \\ 1957 & -0.09 & -0.08 & -0.07 & -0.04 & 0.00 & 0.05 & 0.10 & 0.15 & 0.17 & 0.18 & 0.18 & 0.15 \\ 1958 & 0.13 & 0.10 & 0.08 & 0.06 & 0.06 & 0.06 & 0.06 & 0.05 & 0.03 & -0.00 & -0.05 & -0.10 \\ 1959 & -0.15 & -0.20 & -0.26 & -0.31 & -0.35 & -0.39 & -0.42 & -0.44 & -0.44 & -0.41 & -0.37 & -0.31 \\ 1960 & -0.22 & -0.12 & -0.02 & 0.07 & 0.15 & 0.18 & 0.18 & 0.14 & 0.05 & -0.06 & -0.19 & -0.31 \\ 1961 & -0.39 & -0.43 & -0.42 & -0.35 & -0.24 & -0.12 & 0.00 & 0.10 & 0.15 & 0.17 & 0.15 & 0.11 \\ 1962 & 0.07 & 0.04 & 0.03 & 0.06 & 0.11 & 0.18 & 0.24 & 0.29 & 0.30 & 0.28 & 0.23 & 0.15 \\ 1963 & 0.07 & -0.01 & -0.07 & -0.11 & -0.12 & -0.10 & -0.08 & -0.04 & -0.00 & 0.04 & 0.08 & 0.12 \\ 1964 & 0.17 & 0.22 & 0.27 & 0.30 & 0.31 & 0.29 & 0.26 & 0.21 & 0.14 & 0.08 & 0.03 & -0.01 \\ 1965 & -0.04 & -0.06 & -0.08 & -0.10 & -0.12 & -0.15 & -0.18 & -0.19 & -0.18 & -0.15 & -0.10 & -0.04 \\ 1966 & 0.02 & 0.06 & 0.09 & 0.08 & 0.05 & 0.00 & -0.04 & -0.09 & -0.11 & -0.10 & -0.07 & -0.03 \\ 1967 & 0.02 & 0.07 & 0.10 & 0.10 & 0.09 & 0.06 & 0.03 & 0.00 & -0.01 & 0.01 & 0.04 & 0.09 \\ 1968 & 0.15 & 0.19 & 0.21 & 0.20 & 0.17 & 0.10 & 0.02 & -0.07 & -0.14 & -0.19 & -0.22 & -0.20 \\ 1969 & -0.16 & -0.09 & -0.01 & 0.08 & 0.17 & 0.23 & 0.26 & 0.27 & 0.25 & 0.21 & 0.14 & 0.06 \\ 1970 & -0.02 & -0.11 & -0.20 & -0.28 & -0.34 & -0.39 & -0.40 & -0.39 & -0.34 & -0.26 & -0.15 & -0.03 \\ 1971 & \mathbf{0 . 0 9} & 0.19 & 0.25 & 0.29 & 0.28 & 0.24 & 0.19 & 0.13 & 0.08 & 0.04 & 0.03 & 0.04\end{array}$

$\begin{array}{ll}\mathrm{QBO},\left(-\mathrm{v}_{\mathrm{N} . \mathrm{H} .}+\mathrm{v}_{\mathrm{S.H} . \mathrm{H}}\right) / 2, & \text { Atlantic Trades } \\ \mathrm{m} / \mathrm{seC} & \text { Filter Cutoff } 0.091 \mathrm{months}^{-1}\end{array}$

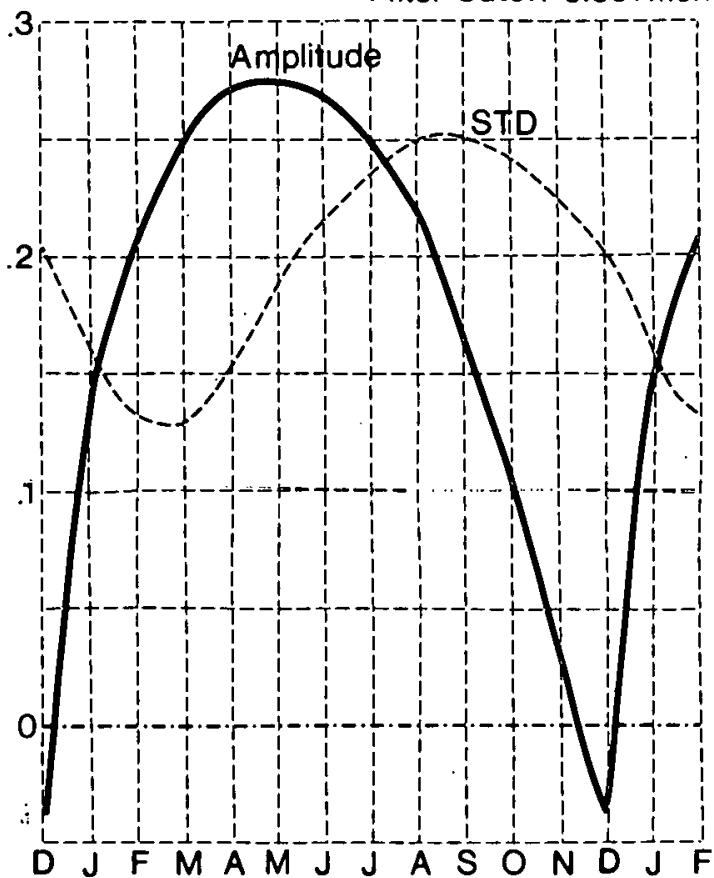

Fig. 80. Mean amplitude of the QBO of the Atlantic trade-wind convergence, $\mathrm{m} / \mathrm{sec}$ (solid line) and standard deviation (dashed), obtained from the filtered data of Table 4 .

$1967 / 68$ followed a prolonged phase-shift in the tradewind QBO lasting from July 1966 through June 1967 (Fig. 79). A similar phase shift in the S-season stratospheric 080 was noted by Brier (1978) in the winter of 1964/65 (Fig. 82). The Atlantic trade-wind QBO in Fig. 79 indicates a phase anomaly in November and December of 1964. After the general phase shifts in stratospheric $Q B O$ of the $\mathrm{N}^{-}$and $\mathrm{S}$-seasons during $1967 / 68$ there occured a phase shift in the trade-wind QBO early in 1970. This shift did not seem to be reflected in the stratosphere.

The foregoing discussion leads us to the conclusion that phase anomalies in the $Q B O$ of the Atlantic trade-wind convergence occurring in summer and

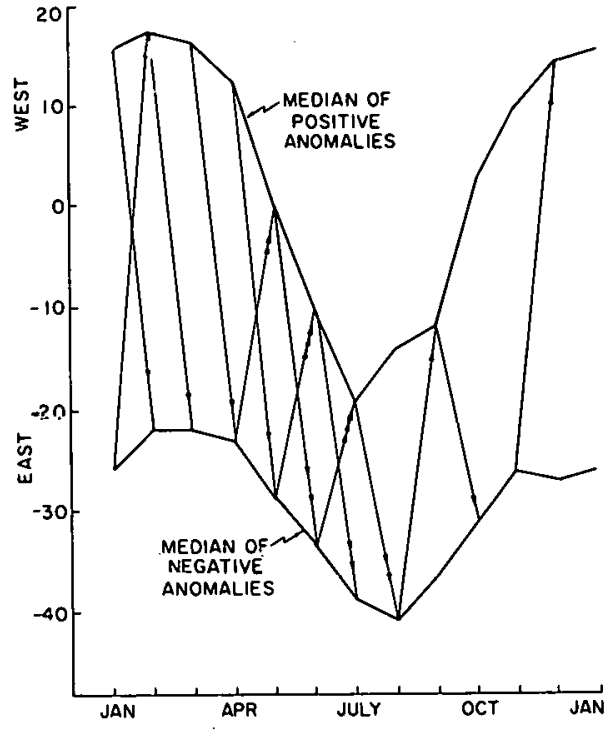

Fig. 81. Months of transition from positive to negative anomalies in the $50-\mathrm{mb}$ Balboa winds. Directions of change and frequencies of that transition are represented by the arrow heads. (From Brier, 1978.)

fall presage phase shifts in the stratospheric QBO. Brier (1978) suspected that the stratospheric $Q B O$ is forced by, perhaps seasonably dependent, feedback processes from outside the stratosphere. Our data seem to provide the answer to Brier's quest: The forcing of the stratospheric $Q B O$ seems to originate in the trade-wind regimes of the Atlantic longitude sectors and, more specifically, in the convergence between these regimes which affects the rising branch of the Hadley cell.

$A$ QBO is barely indicated in the u-component of the North Atlantic trade winds (Fig. 83), but is "swamped" by lower frequencies in the smoothed 


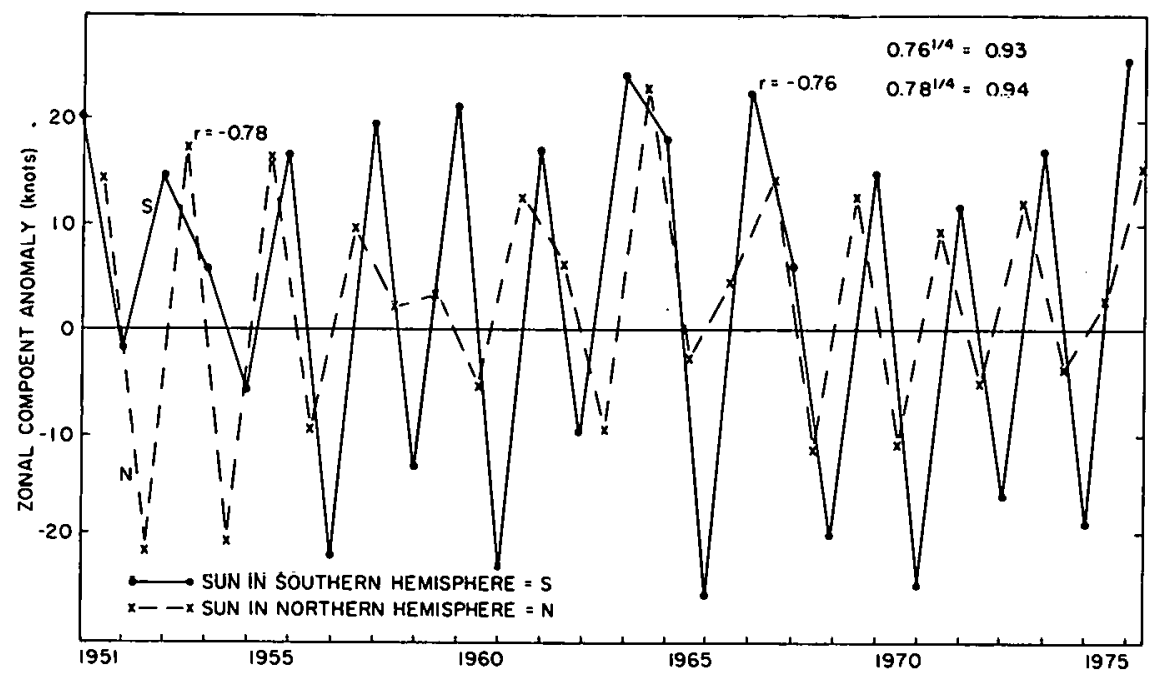

Fig. 82. Seasonal averages of mean monthly zonal wind anomalies at $50 \mathrm{mb}$, Balboa, Canal Zone, 1950-76. The season November-April is designated as $S$, the season May-October as $N$. The lag-one correlation for the $\mathrm{S}$-season values is $\mathrm{r}=-0.76$, that for the $\mathrm{N}$-season values is $r=-0.78$. If these correlations were the results of a feedback mechanism with four links in the chain, the individual links must have correlations near $0.76^{1 / 4}=0.93$. (From Brier, 1978.)

a

ATLANTIC WINDS, U-NH, DEPARTURES, M/SEC

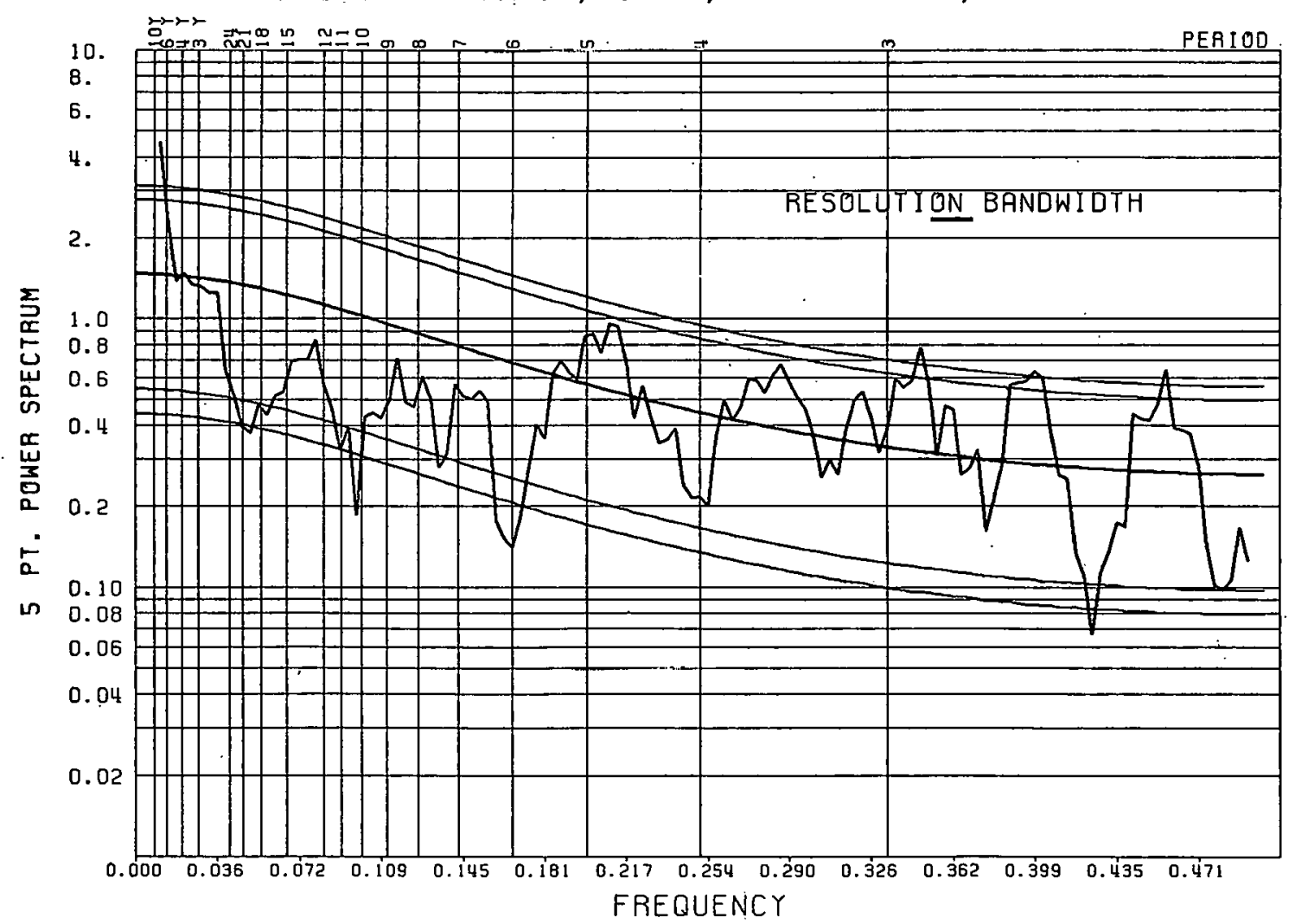

Fig. 83. 5-point smoothed power spectra (non-normalized) of the Atlantic trade-wind u-components, (a) northern hemisphere; (b) southern hemisphere; (c) average of northern and southern hemisphere. For further details see legend of Fig. 75. 


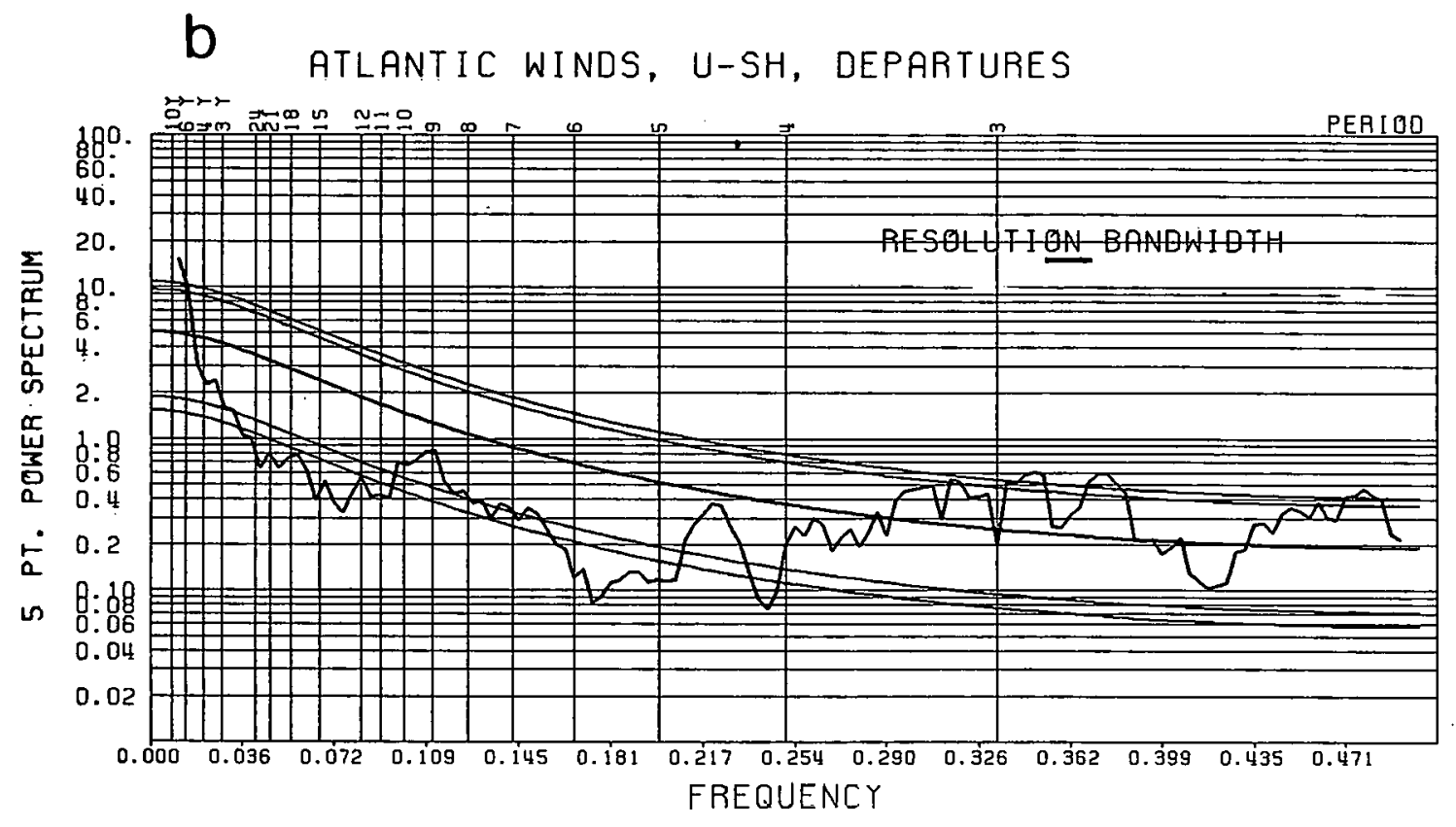

\section{C atlantic winds, (UNH + USH) $/ 2$, Departures}

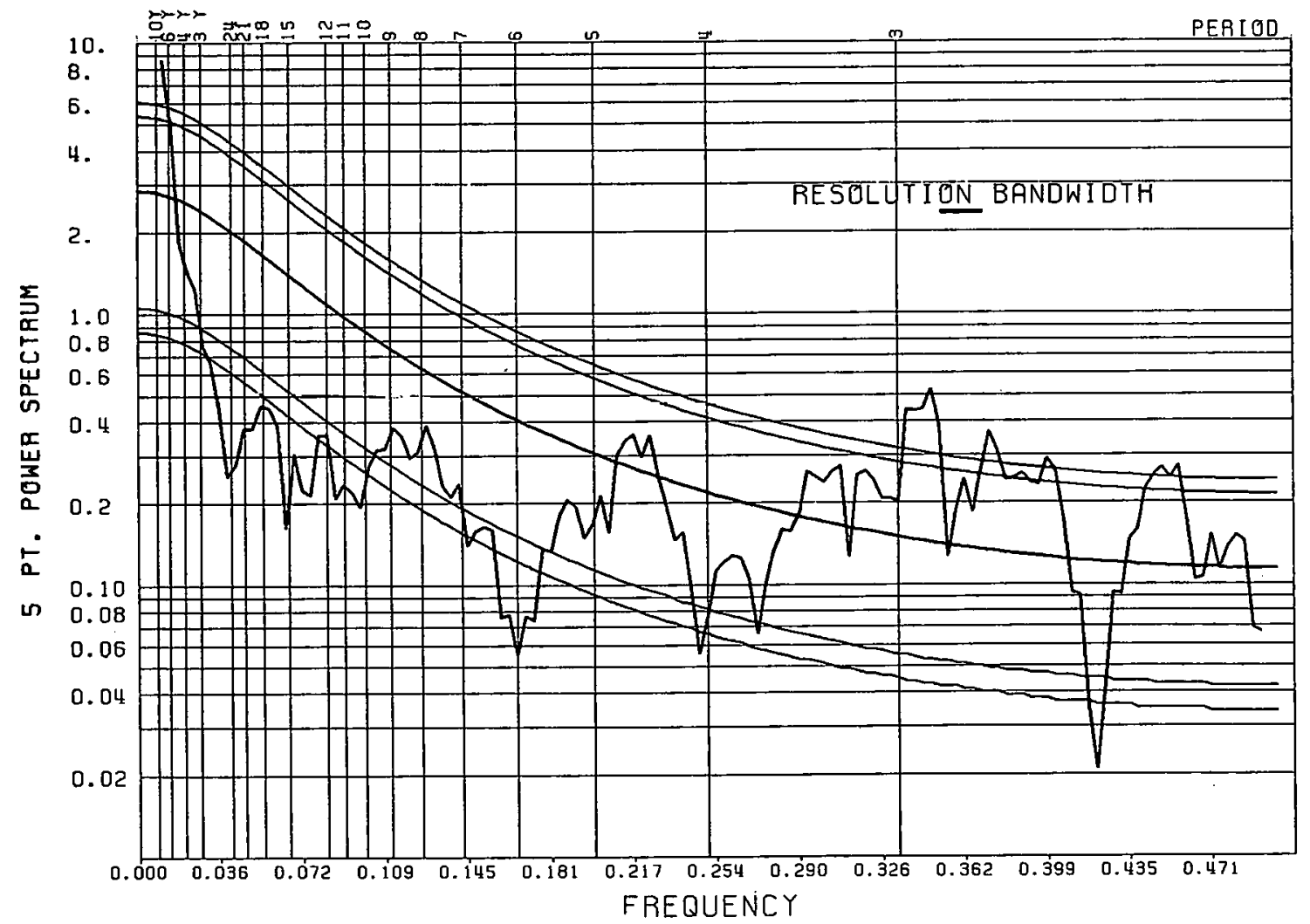

Fig. 83 (Continued)

spectra. Neither $u_{S . H}$ nor $\left(u_{N . H .}+u_{S . H .}\right) / 2$ reveal a QBO in their spectra (Fig. 83). One should expect this result, because $v_{N} . H$. and $u_{N} . H$. are moderately well correlated, better in the Pacific than in the Atlantic (Fig. 84a,b). For some yet unexplained reason this correlation is better expressed for the trade-wind components in the northern hemisphere than for those in the southern hemisphere (Fig. 84c,d).
Furthermore, we find a significant negative correlation in the Pacific between $v_{S} . H$. and $v_{N} . H$. with $v_{N} . H$. leading by approximately one month (Fig. 84f). This means that surges in the equatorward $v$-component in one hemisphere tend to induce a similar surge in the other hemisphere. In the Atlantic such interaction between the two trade-wind systems does not appear to be indicated (Fig. 84e). On the other hand, a correlation with a lag of about 12 months appears in the 
trade-wind u-components of the Atlantic, especially in the 7-month smoothed data, with $u_{S . H}$. leading $u_{N . H}$. (Fig. $84 \mathrm{~g}$ ). No such currelation is indicated over the Pacific (Fig. 84h). The u-component behavior shown in Fig. $84 \mathrm{~g}$ is in agreement with the quasi-biennial modulation of the trade winds described earlier: Significant positive correlations are encountered at lags from 0 to -12 months.

In reviewing the low-pass filtered wind data from the 50-mb level over Balboa (Fig. 78) we notice that the periods between peaks of westerlies and easterlies are not varying at random but appear to be at a minimum of 23 to 24 months in the late $1950^{\prime} \mathrm{s}$, at a maximum of 35 months in the late $1960^{\prime} \mathrm{s}$, followed by a rapid decrease to 24 months in the earlv 1970's. We think that it is more than just a curious coincidence that the variability in the QBO periodicity matches, with a negative correlation, the long-term trends in the u-components of the Atlantic trade-wind systems (Fig. 85).

If, indeed, a feedback mechanism with the ocean were responsible for the variability in trade-wind convergence, as postulated in Fig. 70, the difference in characteristic times involved in such feedbacks over the Pacific and Atlantic areas might provide an explanation for the observational fact that the Atlantic trade-wind convergence shows $a$ QBO and the Pacific trade convergence does not (Fig. 76). In the search for possible feedback mechanisms that have characteristic times of a year or longer we should recall our earlier discussion concerning trends in the Kuroshio current velocities and their possible relation to trends in the North Pacific trade-wind velocilies. From a crude evaluation of oceanographic charts Reiter (1978c) estimated that the half-period for the North Pacific subtropical gyre rotation (i.e. the time required for a water mass to travel from the equatorial Central Pacific through the Kuroshio into the Central North Pacific) is of the order of 20 months (Fig. 86). Reiter's evaluation involves only the fast-traveling "half" of the subtropical Pacific gyre. For the whole gyre Favorite and McLain (1973) arrived at a period of 5 to 6 years, which is within the range of values indicated by Fig. 86 . SST fluctuations in the region $40-45^{\circ} \mathrm{N}$ and $170-175^{\circ} \mathrm{E}$, indeed, reveal a quasi-periodicity of 5 to 6 years (Fig. 56 ). A similar evaluation for the North Atlantic yields a half period of the subtropical gyre of the order of one year (Fig. 87).

If the Pacific and Atlantic Hadley cells, indeed, were modulated by an extratropical feedback mechanism as postulated in Fig. 65, involving trade-wind variability, water mass transport through the western boundary current systems, advective effects on SST anomalies in mid-latitudes, their influence on atmospheric temperatures and meridional temperature gradients, we might expect a response of the Atlantic trade-wind systems to interact strongly with the annual cycle, resulting in a QBO, whereas the Pacific trades would be more inclined towards a quasi-periodicity near 40 months, i.e. 3 to 4 years, or longer. Direct evidence for such a spectral peak in the Pacific trade-wind convergence (Figs. 76 and 77 ) is weak, perhaps because of the relative shortness of the record. The Line-Island precipitation, for which a record of 66 years has been compiled by Meisner (1976) shows such a spectral peak very prominently, approaching the 95 percent confidence level (Fig. 88).

The current velocity estimates shown in Figs. 86 and 87 , admittedly, are very crude. They do not take
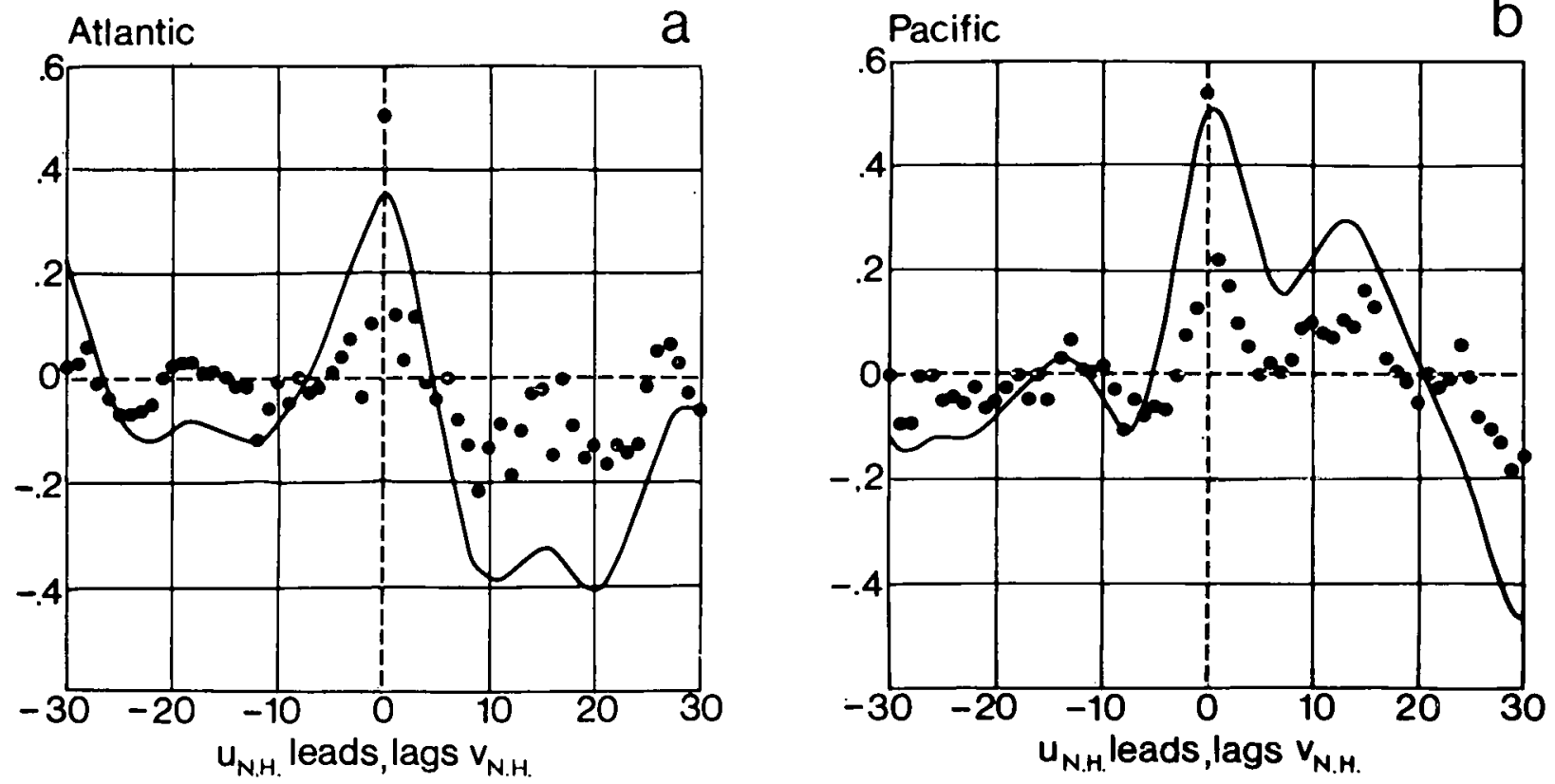

Fig. 84. Lag correlations between monthly anomalies of the zonal and meridional components of surface winds averayed over the Atlantic and Pacific trade-wind regions $\left(5^{\circ} \mathrm{N}-19^{\circ} \mathrm{N}, 89^{\circ} \mathrm{W}-\right.$ $10^{\circ} \mathrm{W} ; 1^{\circ} \mathrm{S}-15^{\circ} \mathrm{S}, 40^{\circ} \mathrm{W}-13^{\circ} \mathrm{E} ; 5^{\circ} \mathrm{N}-19^{\circ} \mathrm{N}, 125^{\circ} \mathrm{E}-95^{\circ} \mathrm{W} ; 1^{\circ} \mathrm{S}-15^{\circ} \mathrm{S}, 125^{\circ} \mathrm{E}-75^{\circ} \mathrm{W}$ ). West winds and south winds are considered as positive. Correlation coefficients are labelled along the ordinates, time lags along the abscissas of each diagram. Dots indicate correlations obtained from individual monthly anomaly values, the solid curves give correlations between seven-month smoothed data sets. 

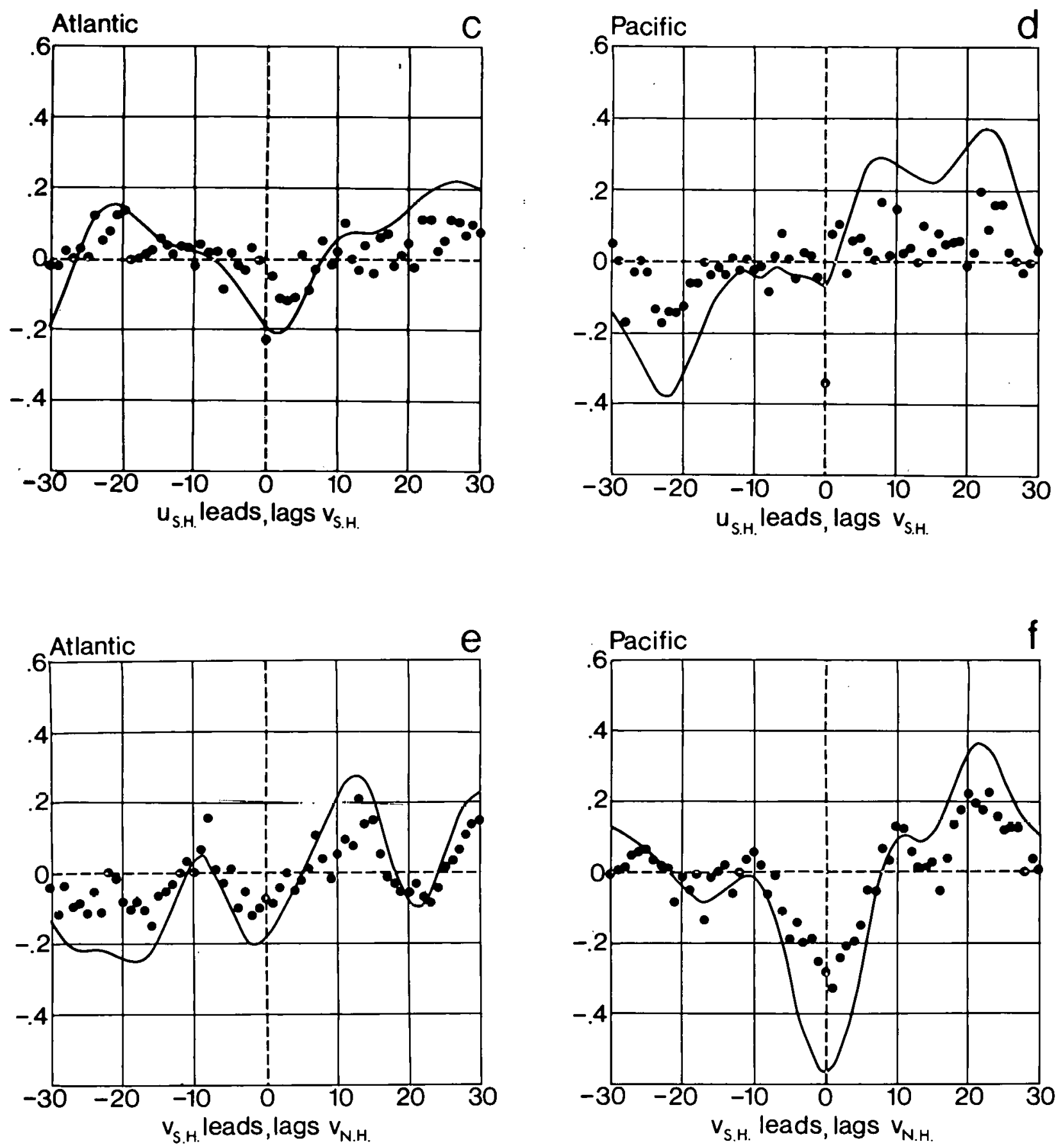

Fig. 84 (Continued) 

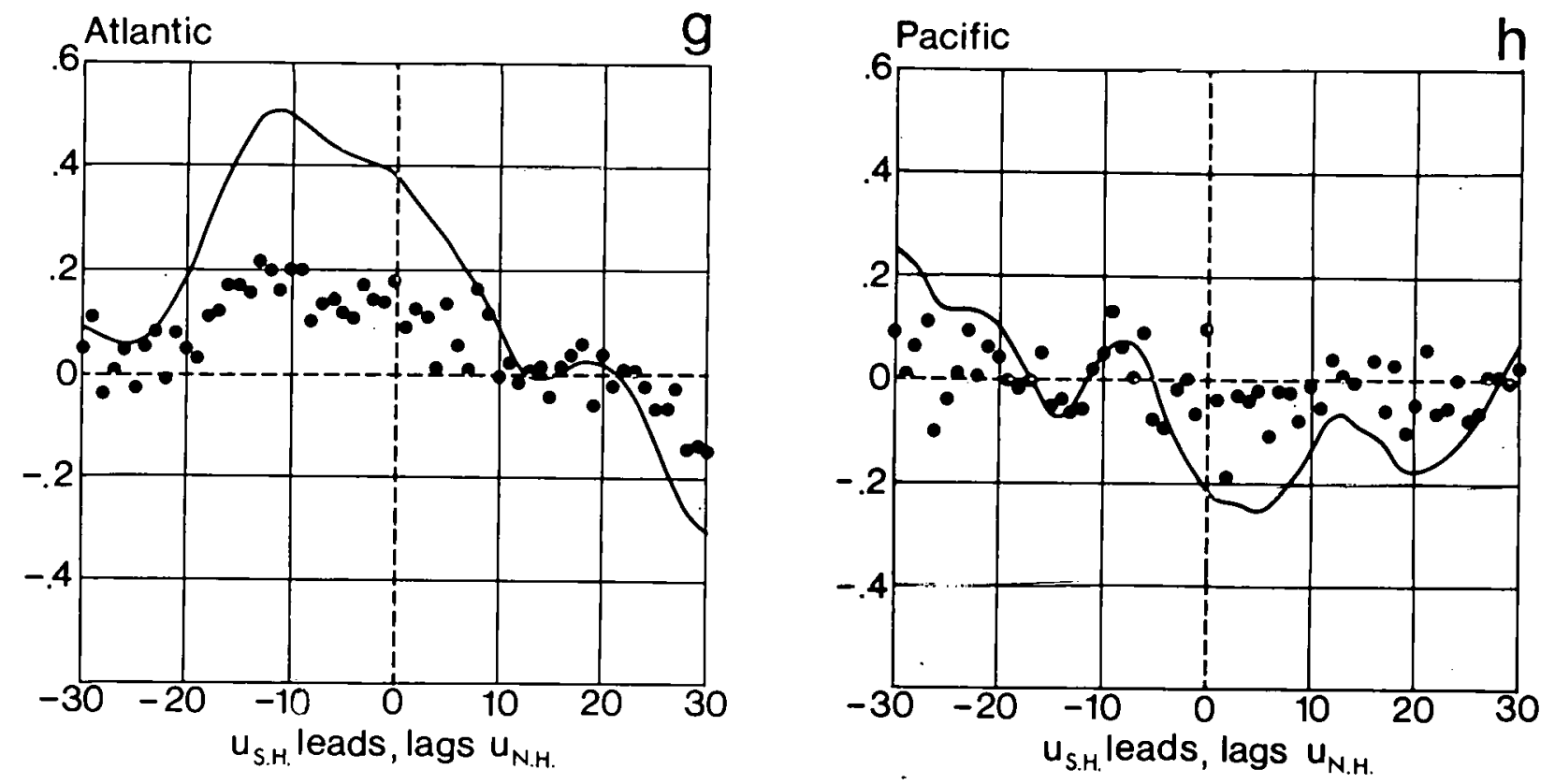

Fig. 84 (Continued)

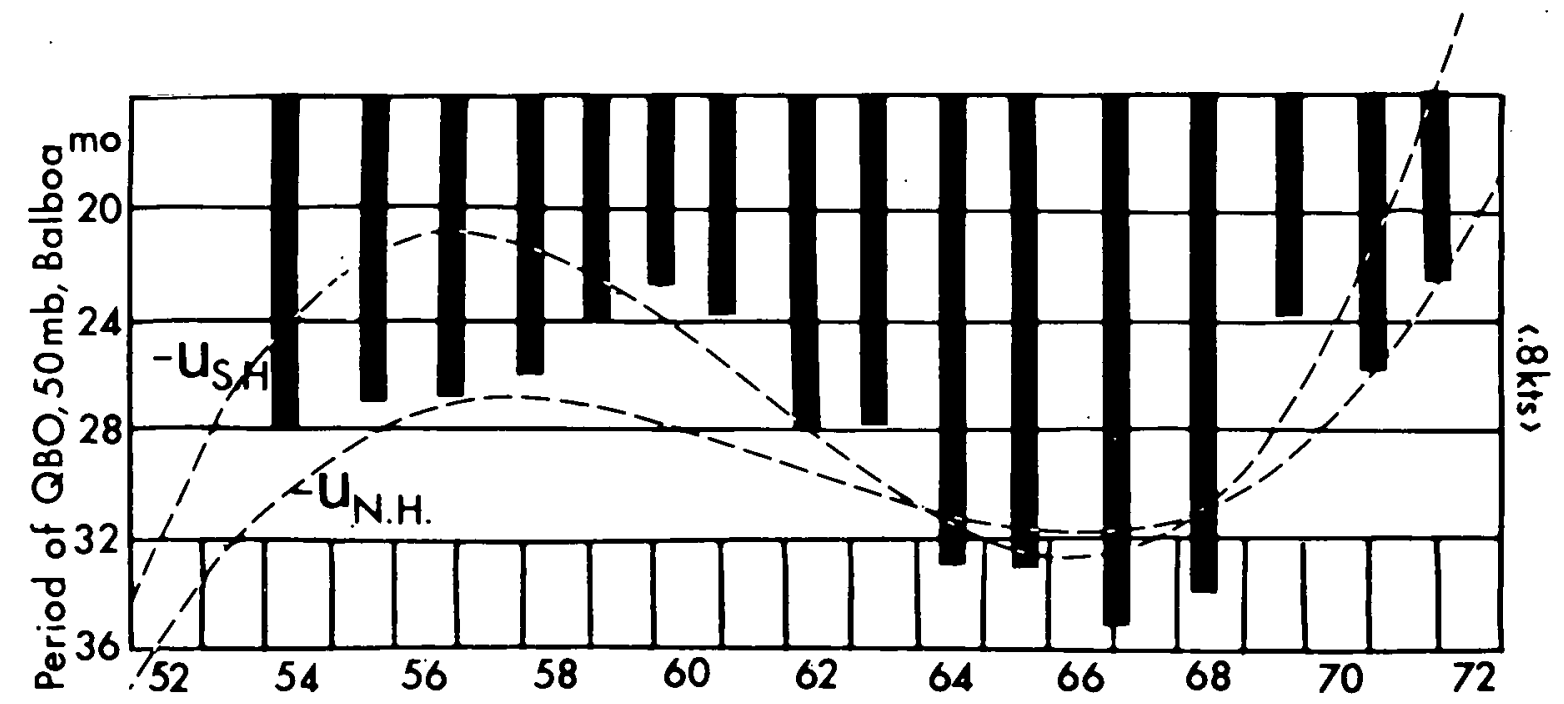

Fig. 85. The hodograph gives the period (in months, labelled on left side of diagram) of the QBO of the 50-mb winds at Balboa, smoothed by low-pass filter as indicated in Fig. 78. The two dashed lines are the North and South Atlantic zonal wind component anomalies (see Fig. 66), approximated by a third-order polynomial, plotted with respect to arbitrary zeroreference lines. Stronger-than-normal easterlies are expressed as positive departures. The distance between two ordinate scale lines corresponds to 0.8 knots. 


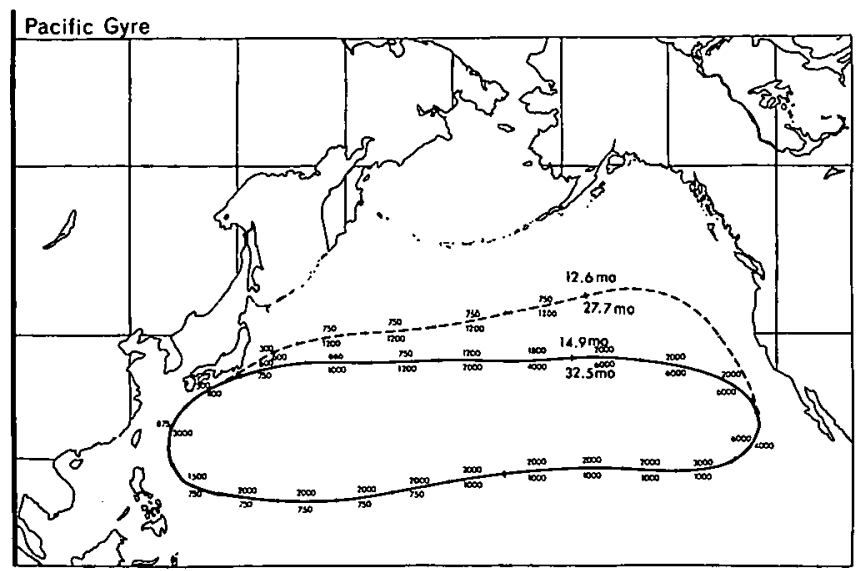

Fig. 86. Streamlines around Pacific gyre for winter (full line) and summer (dashed line) current conditions. Small numbers indicate the maximum and minimum hours required to traverse a 600-n mi segment of the streamlines. Heavy marks along streamlines indicate the starting and end points of the segment of the gyre used in computing half-revolution times (maximum and minimum values indicated in months). (Data from Office of Climatology, 1961.)

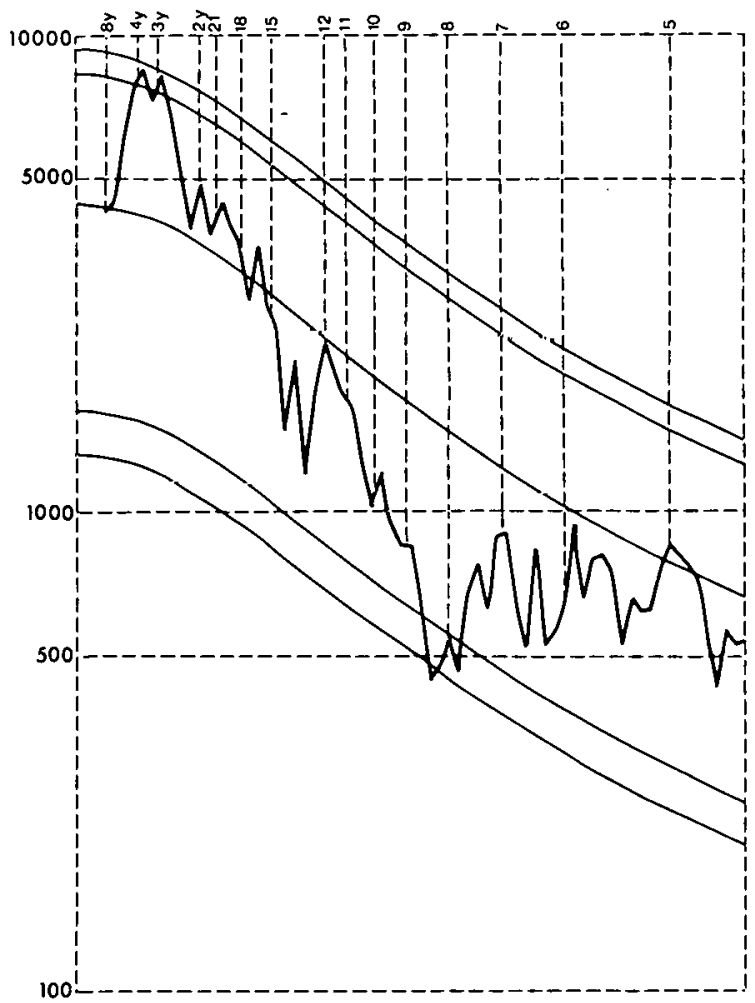

Fig. 88. 5-point smoothed power spectrum (non-normalized) of Line Island precipitation index (data after Meisner, 1976). The smooth curves represent the "red noise" null hypothesis (center curve) and the 90 and 95 percent confidence limits on either side.

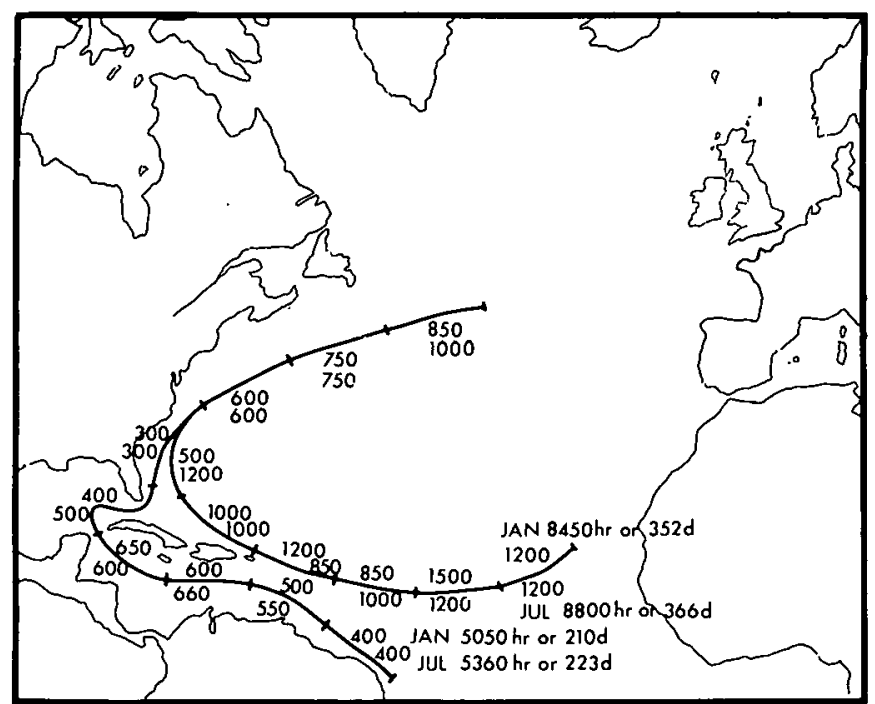

Fig. 87. Streamlines around Atlantic gyre. The numbers indicate the time required to traverse a $600^{-n} \mathrm{mi}$ streamline segment in January (upper number) and July (lower number). Total times required are indicated at the starting points of each streamline. (Data from office of Climatology, 1959.)

into account the rather strong variability of the velocities in the subtropical gyre, or at least in parts thereof, that we have to suspect from the interannual and longer-term trend variability of meridional SST gradients in the North Pacific and North Atlantic described earlier, and from trends in the wind stress exerted by the trade winds. A variability in this wind stress, and a resultant modification in the gyre velocity and period, might perhaps be the reason for the correspondence between trade-wind velocity trends and QBO periods, shown in Fig. 85.

Let us assume that a spectral peak near 40 to 44 months characterized some of the Pacific circulation anomalies in the ocean as well as in the atmosphere. The interference of a 40 or 44 month cycle with the 12-month annual cycle would produce a "beating" frequency of 10 to 11 years. One could also argue, in a similar vein, that a subtropical gyre periodicity of 5 to 6 years, pointed out by Favorite and McLain (1973) from SST anomaly trends in the region $40-45^{\circ} \mathrm{N}$ and $170-175^{\circ} \mathrm{E}$ (Fig. 56), might interfere with the annual cycle to yield similar harmonic variations. In view of the possibility that geophysical feedback mechanisms might produce quasi-periodicities within those frequencies ascribed to the sunspot cycle, we have to agree with the cautionary remarks voiced by Pittock (1978) as to the significance of some so-called solarterrestrial effects. There is a distinct possibility that the atmosphere-ocean system in the Pacific region contains a set of feedback mechanisms that provides energy to the variance spectrum of the general circulation in the same approximate frequency range as that characteristic of the sun-spot cycle. Such a feedback, involving 11- and 22-year cycles might have a conceivable impact on the "downstream" weather over North America (see e.g. Fig. 26), but also on the monsoon circulation over Asia because of the coherence between Pacific trade wind and precipitation regimes with the southern oscillation. 
If a QBO of an average cycle length of 26 months can be assumed for the Atlantic trade-wind convergence, we should hope to find the imprint of such a cycle in the influence region of these wind systems. Indeed, we find a 13- and 26-year cycle in the rainfall at Fortaleza, Cereá, northeastern Brazil (Markham, 1974; Strang, 1979; Girardi and Teixeira, 1978). That station and others in the dry region of northeastern Brazil are characterized by a very sharply defined rainy season which peaks in March-April (Fig. 89), (Strang, 1972). The 13-year cycle can be interpreted as the "beating" frequency of the QBO against the annual cycle, and the 26-year cycle, of course, would be the first harmonic of that beating frequency (Figs. 90-92)

The question remains whether feedback mechanisms with the ocean, as illustrated in Fig. 70, implying low-latitude SST variability as a triggering mechanism for the variability of latent-heat release in the ITCZ and of Hadley-cell intensity, could also be involved in the Atlantic QBO. Such a possibility is implied in results obtained by Markham and McLain (1977) who found a positive correlation between SST anomalies in certain regions of the equatorial Atlantic and rainfall in Cerá, northeastern Brazil (Fig. 93). Figure 67 shows the location of several oceanic areas for which SST-anomaly behavior was investigated. Figure 94 illustrates the time series of SST anomalies for several of these areas. Indeed, we find a $\mathrm{QBO}$ prevalent in regions off the coast of Senegal, as well as in the Gulf of Guinea, where cold upwelling water from coastal regions becomes entrained into the North- and South-Equatorial currents. It appears that this upwelling in the Gulf of Guinea is not as much forced by the local longshore component of the wind as the $E 1$ Niño (Houghton, 1976), but by coastal wind forcing several hundred kilometers to the east of the upwelling region (Bakun, 1978; Clarke, 1979). The trapping of internal gravity wave disturbances seems to play a major role in this coastal upwelling (0'Brien and Adamec, 1978; Adamec and O'Brien, 1978).

Lag correlations between $\left(-v_{\mathrm{N} . H}+\mathrm{v}_{\mathrm{S} . \mathrm{H} .}\right) / 2$ and SST anomalies in various equatorial areas of the Atlantic do not tell a very convincing story because of the rather low correlation coefficients. Especially in Area 13, warmest water tends to appear almost simultaneously with strongest trade-wind convergence (Fig. 95) perhaps indicating a feedback mechanism as expressed in Fig. 70. If SST anomalies, indeed, were assigned the role of a "switching mechanism" as postulated in that diagram, the time lag effect on the Hadley cell behavior would be rather short.

Lamb (1978) also finds positive SSl anomalies in the Gulf of Guinea associated with stronger-thannormal Atlantic trade winds, as measured by their resultant-wind fields. Such occurrences, when encountered during July-September, tend to pull the equatorial trough and the North Atlantic subtropical high farther south than normal, leading to drought conditions in the Subsaharan region.

As a final note, a rather pronounced $Q B O$ is evident in the SST anomalies of Area 1 in the Gulf Stream (Fig. 96). The correlation of this QBO with the one observed in $\left(-v_{N} . H .+v_{S} . H.\right) / 2$ as well as in $u_{N}$.H. of the Atlantic trade winds is poor (Fig. 97),

A negative correlation with the trade-wind convergence is indicated, however. A more detailed investigation will have to be carried out of the extent of the QBO in the aforementioned Gulf Stream region and its possible connection with events in other parts of the Atlantic subtropical gyre.

A spectrum analysis of SST anomalies in Area 1 shows a peak at approximately 14 months which is more prominent than that of the QBO (Fig. 98). The SST difference between Areas 1 and 2 reveals a similar spectral peak (Fig. 99). One might be tempted to ascribe this peak to the Chandler tide (see e.g. Bryson and Starr, 1977, 1978; Wilson, 1978; Starr and Bryson, 1978). On the other hand, one might voice the

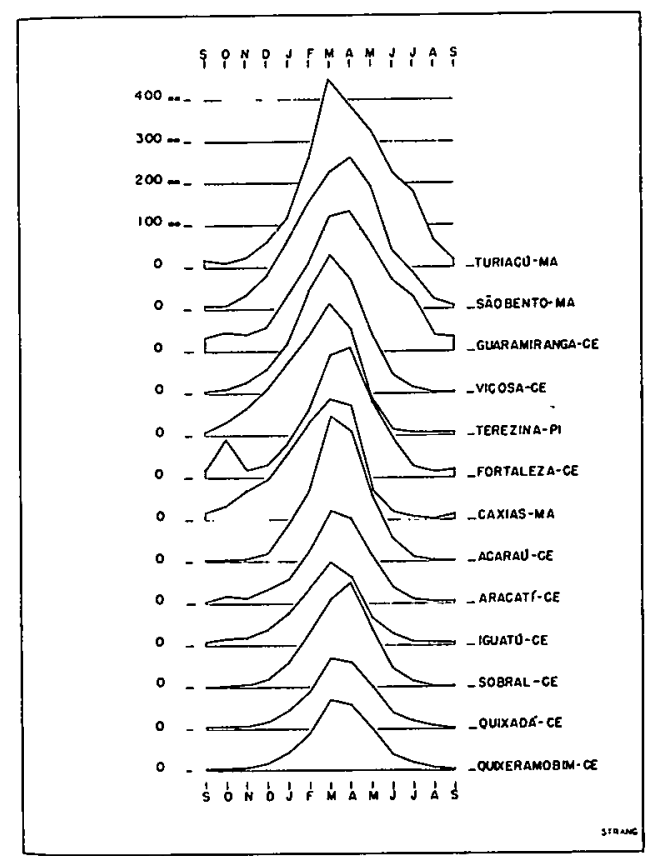

Fig. 89. Seasonal variation of precipitation at Brazilian stations representing "Type 3 " rainy seasons, i.e. precipitation peaking in March. (From Strang, 1972.)

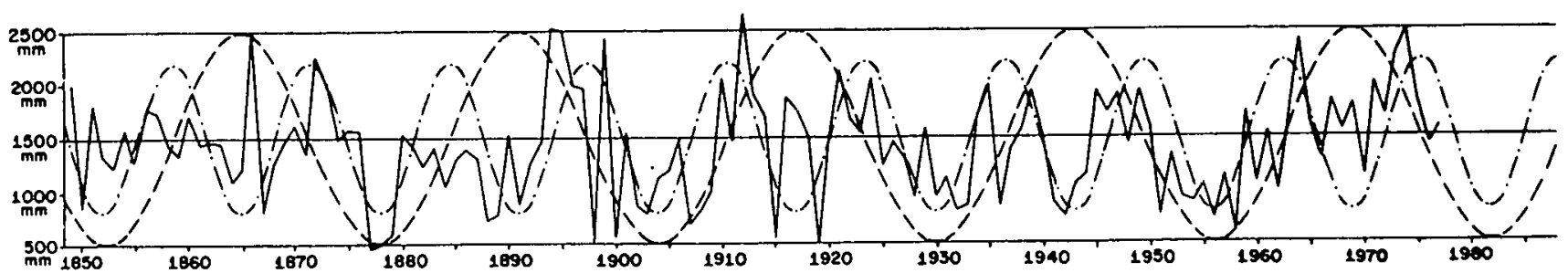

Fig. 90. Annual precipitation at Fortaleza, Ceará, Brazil from 1849 to 1977 (solid line). Sinusoidal curves of a 13-year cycle (dashed-dotted) and a 26-year cycle (dashed) are superimposed. (From Girardi and Teixeira, 1978.) 


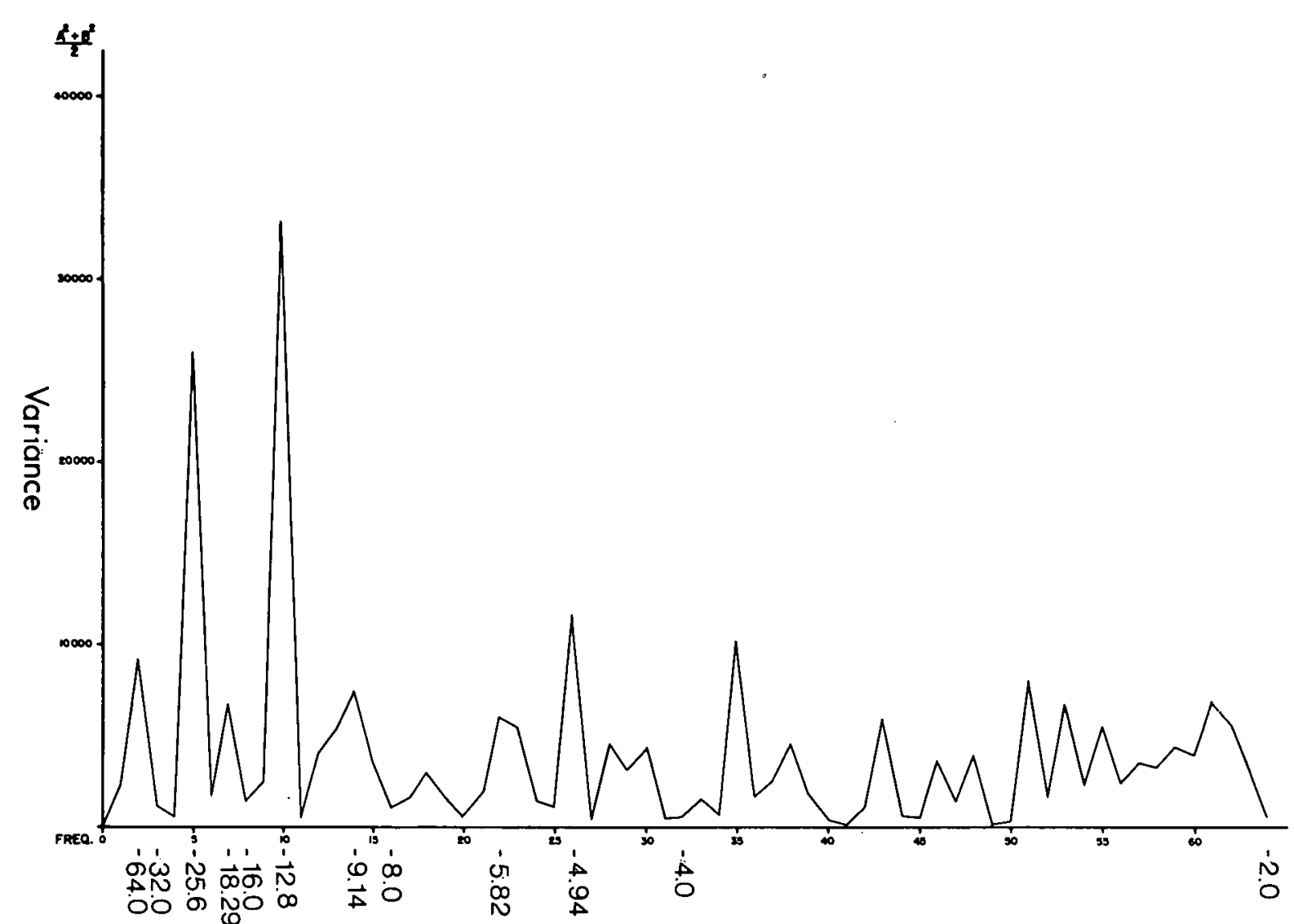

Fig. 91. Spectrum of annual precipitation at Fortaleza, Ceará, as a function of frequency, expressed as cycles per 129 years. Equivalent periods in years are also indicated along abscissa. (From Girardi and Teizeirà, 1978.)
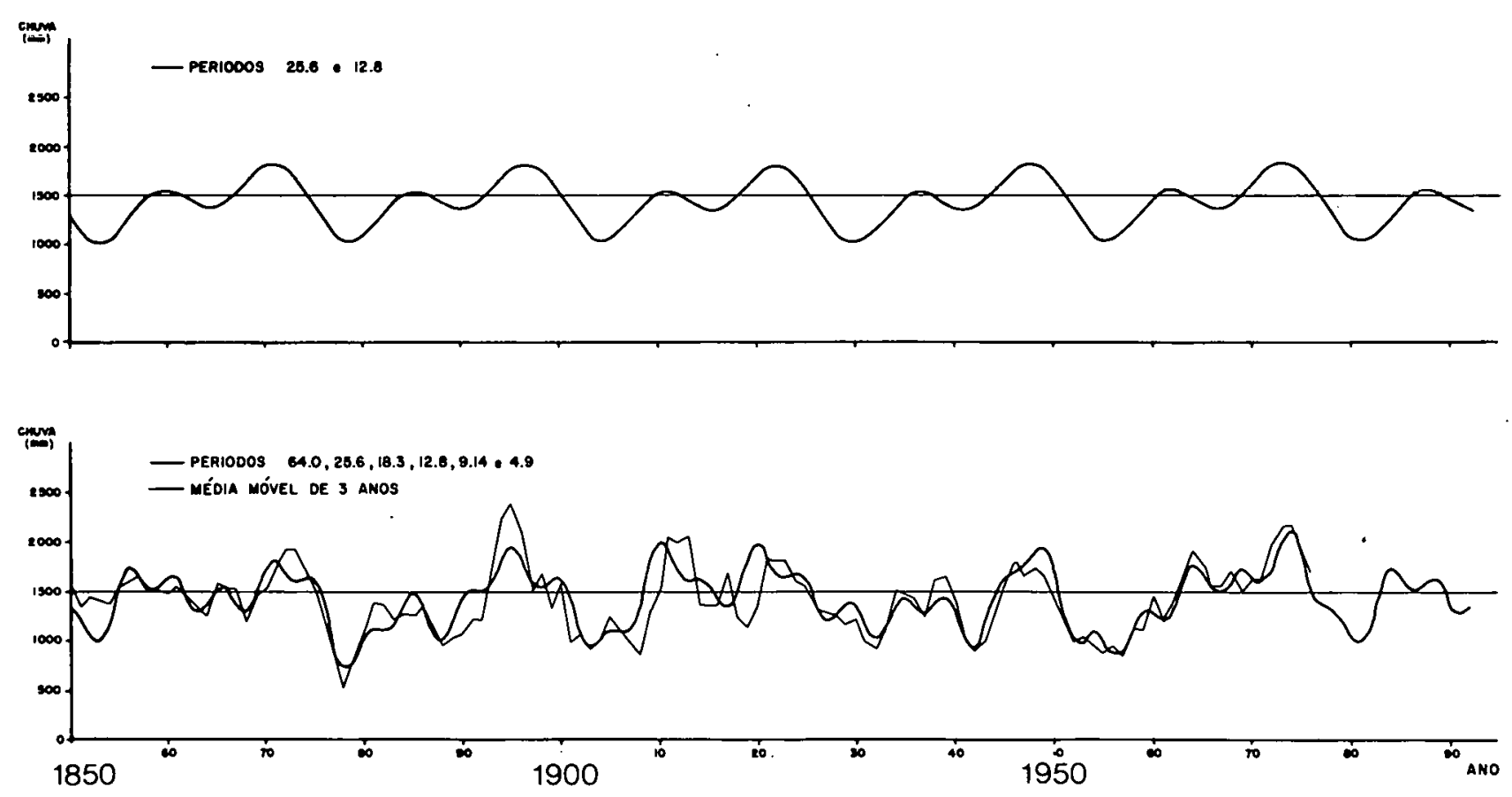

Fig. 92: Precipitation at Fortaleza, Ceará, Brazil, in mm. Upper diagram: Superposition of 25.6- and 12.8year cycles. Lower diagram: Superposition of $64.0^{-}, 25.6^{-}, 18.3-, 12.8^{-}, 9.14-$ and $4.9-y e a r$ cycles (heavy 1 ine) and 3 -year moving averages of observed precipitation (thin line). Years are marked along the abscissa. (From Girardi and Teixeira, 1978.) 


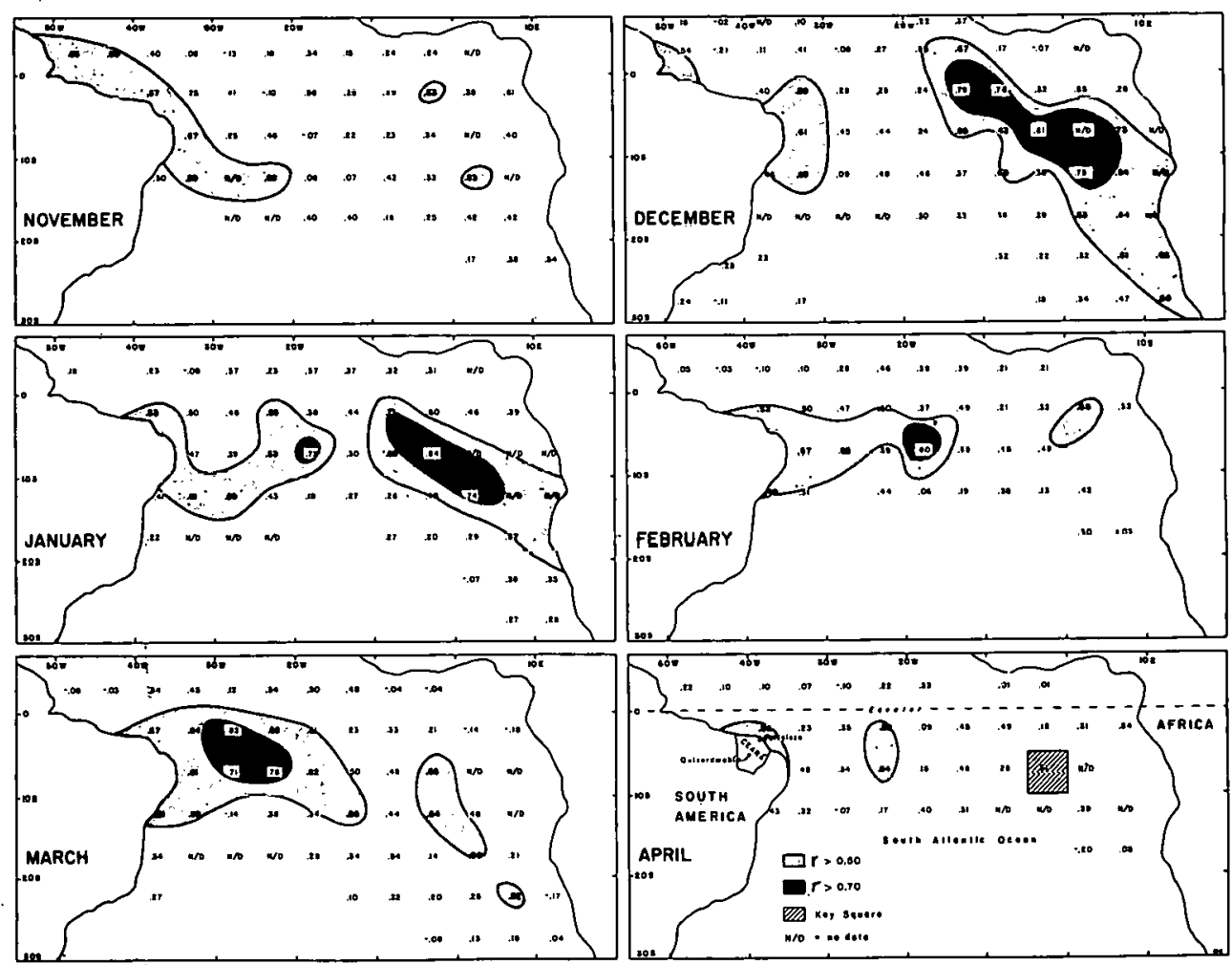

Fig. 93. Correlation between SST and January-February-March rainfall indices in Ceará. An area of high coefficient of correlation appears off the African coast in November, becomes strong in December, moves westward with the South Equatorial Current during January, February and March, and disappears in April. (From Markham and McLain, 1977.)

suspicion that the 14-month spectral peak shown in these two diagrams is the effect of two quasi-biennial oscillations interacting with each other, as is suggested by the horizontal lines with arrows, labelled in terms of months, in Fig. 96. It still remains to be investigated if the interaction of a QBO with the annual cycle of SST would produce fluctuations similar to those shown in Fig. 96. It also appears worth mentioning that the increase of QBO periods towards 1970 and the subsequent rapid decrease towards a minimum period in 1974 agrees we 11 with the trends of the zonal component of the North Atlantic trade winds, $u_{N . H}$, shown in Fig. 85 . This lends some support to our notion that the $Q B O$ in the SST anomalies of Area 1 are tied to the trade-wind $Q B O$, in spite of the weak correlations revealed by Fig. 97.

\section{CONCLUSIONS}

The foregoing discussion has pointed out the pussible existence of several powerful feedback mechanisms between ocean and atmosphere that could have a significant effect on interannual and long-term atmospheric variability. Some of these mechanisms involve the hydrological cycle through fluctuations in hemispheric or regional evaporation and precipitation rates. Unfortunately, these fluctuations are difficult to estimate from our data base, and the reliability of our preliminary estimates is questionable.

Since ocean surface temperatures over wide areas, especially in extratropical regions, reveal relatively large long-term trends, special attention should be devoted to the effects of SST anomalies on the oceanatmosphere energy exchange in the form of latent and sensible heat transfer through the interface. We are presently planning a detailed assessment of such energy transfers, and of the imprint that such transfers leave in the form of changes of atmospheric structure and heat content.
With the large observed and deduced changes in ocean surface temperatures and gyre circulations one might expect that gas exchange with the atmosphere, notably the exchange of $\mathrm{CO}_{2}$ might be modulated by oceanic trends. Newe1l and Weare (1976b) and Bacastow (1977) pointed out such possibilities. A detailed assessment should be made for ocean areas in all latitudes.

There is a distinct possibility that the stratospheric QBO is forced by tropospheric variability in the Atlantic sector. Some of the observational evidence to this effect, presented in this report, will have to be compared with theoretical approaches, notably those by Lindzen and Holton (1968). Several of the assumptions underlying these approaches, most likely, can now be refined in the light of new evidence. 

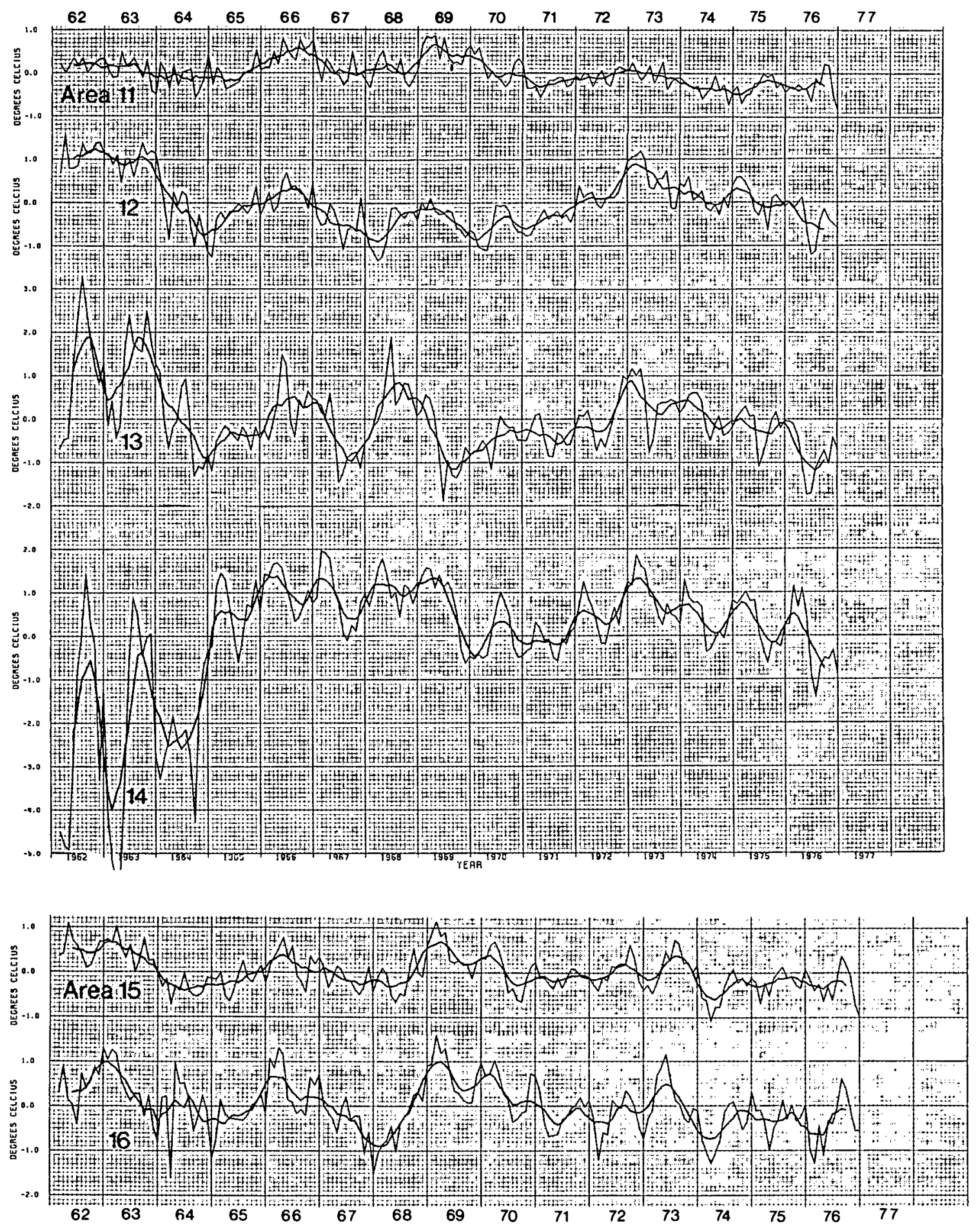

Fig. 94. SST anomalies $\left({ }^{\circ} \mathrm{C}\right.$ ) in Areas 11 to 16 (see Fig. 67). Thin lines indicate monthly anomalies, heavy lines are 7-month smoothed values. 


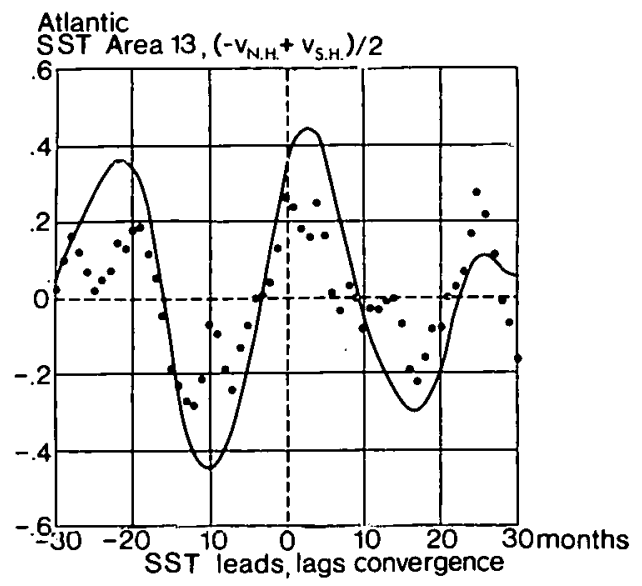

Fig. 95. Lag correlations between sea-surface temperature anomalies in Area 13 of the equatorial Atlantic (see Fig. 67 ) and $\left(-v_{\text {N.H. }}{ }^{+v_{S} \text { S. H. }}\right.$ )/2 of the Atlantic trade winds. Dots stand for correlations computed from unsmoothed monthly data. The line indicates correlations obtained from 7-month smoothed data sets. Correlation coefficients are given along the ordinate, time lags (in months) along the abscissa.

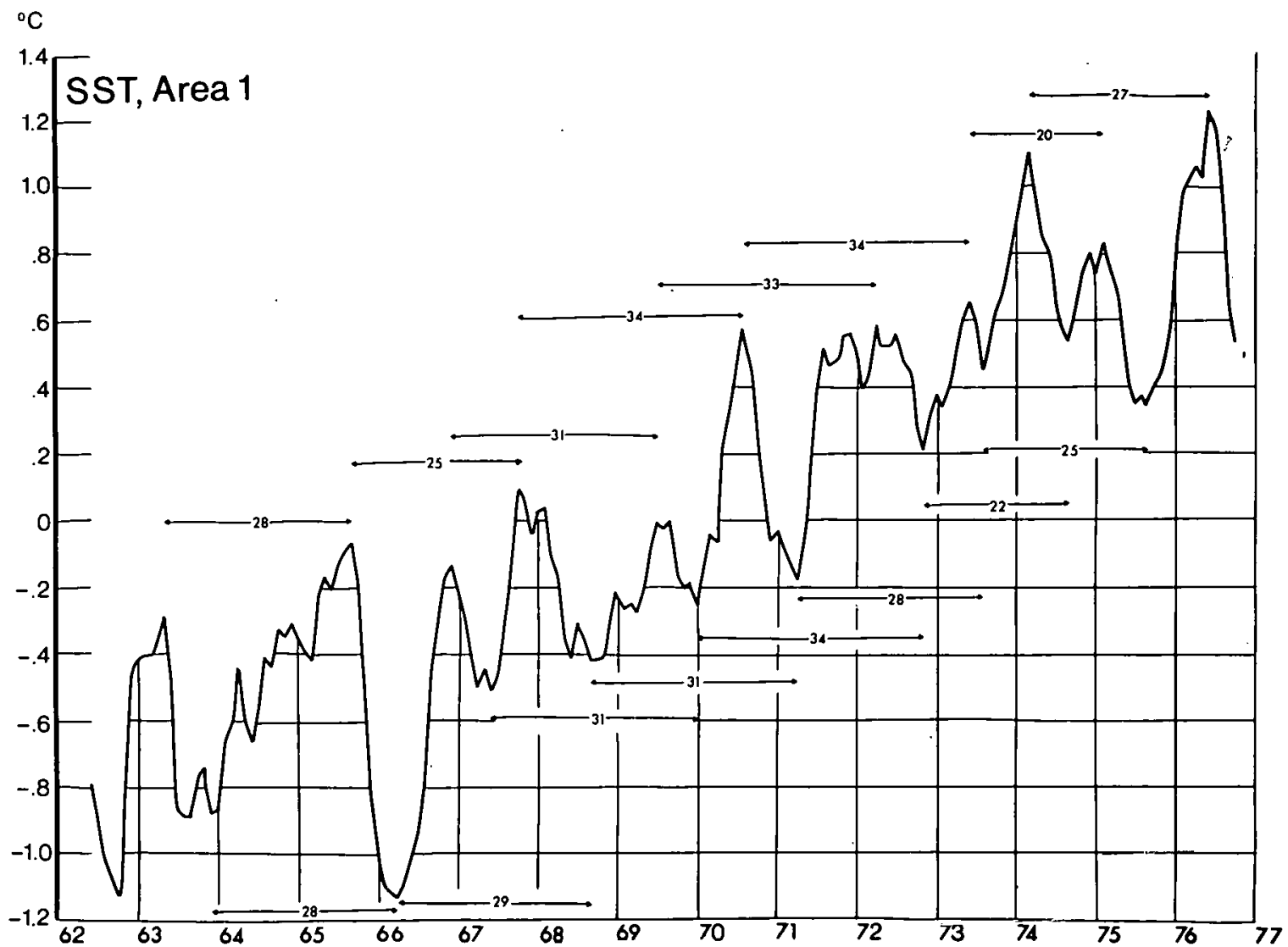

Fig. 96. SST anomalies $\left({ }^{\circ} \mathrm{C}\right.$ ) in Area 1 (see Fig. 6/). Horizontal scale indicates years. Horizontal marks with numbers indicate certain quasi-periodicities in months. 

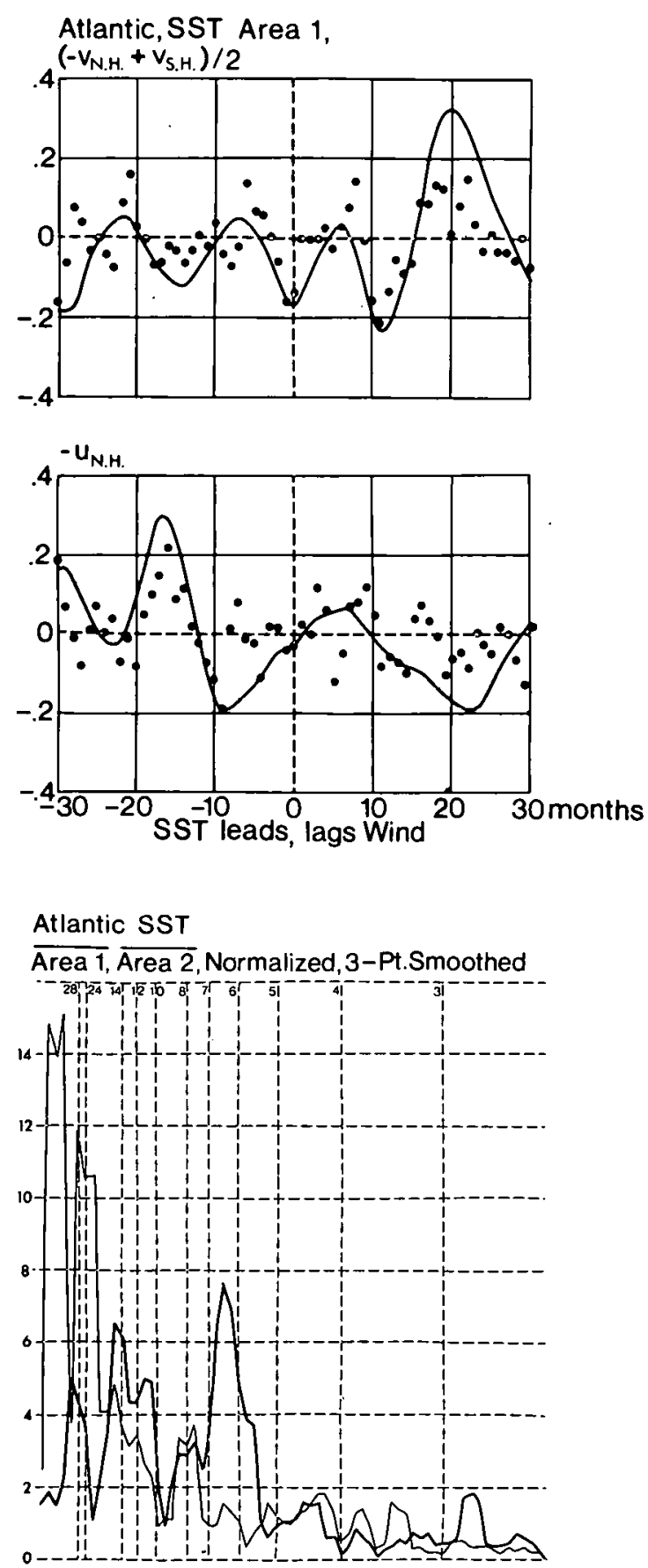

Fig. 98. Normalized, 3-point smoothed spectra of SST anomalies in Areas 1 (heavy line) and 2 (thin line) of the Atlantic (see Fig. 67). Periods in months are indicated along the top of the diagram.
Fig. 97. Lag correlations between sea-surface temperature anomalies in Area 1 of the North Atlantic (see Fig. 67) and $\left(-v_{\text {N.H. }}+V_{\text {S.H. }}\right) / 2$ (upper diagram) as well as $-u_{N}$.H. (lower diagram) of the Atlantic trade winds. Dots stand for correlations computed from unsmoothed, monthly data. The lines indicate correlations obtained from 7 -month smoothed data sets. Correlation coefficients are labelled along the ordinates, time lags in months along the abscissas of the diagrans.

\section{Atlantic $\Delta S S T$}

Area 1 - Area 2, Normalized 3-Pt.Smoothed

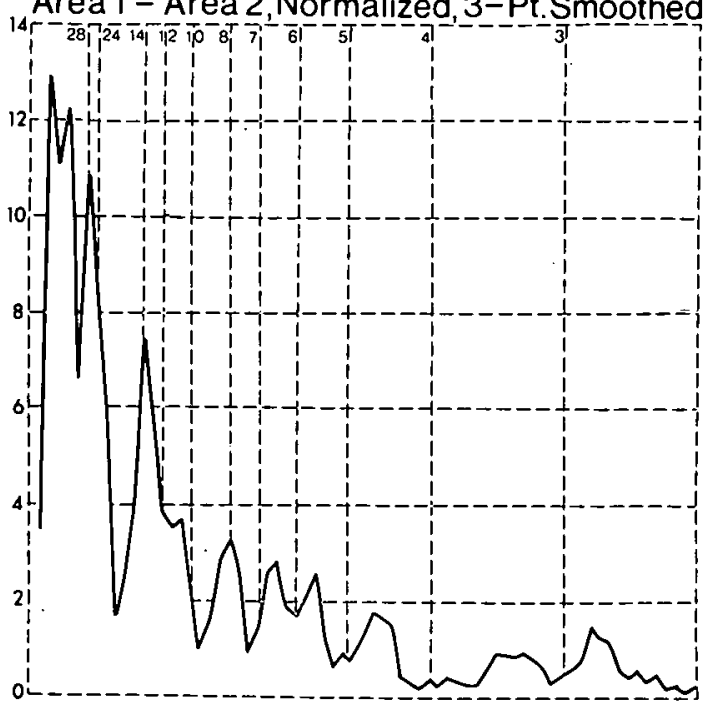

Fig. 99. Normalized, 3-point smoothed spectrum of the SST anomaly difference between Atlantic Areas 1 and 2 (see Fig. 67). Periods in months are indicated along the top of the diagram.
The interaction of trade-wind convergence, latent heat release in the ITCZ, and the intensity of the Hadley cell and of the subtropical jet stream will have to be checked more carefully and in a more quantitative manner than has been possible in this preliminary investigation.

There is evidence that individual wave disturbances in the ITCZ region operate along the feedback mechanisms involving trade-wind convergence and release of latent heat. Thompson et al. (1979) show a correlation between the meridional component of the trade winds in the GATE B-scale network, vertical velocities, and precipitation (Fig. 100). From a detailed budget analysis it became apparent that the vertical eddy fluxes in such wave disturbances supply energy to the large-scale flow, as postulated in our hypothesis. We, therefore, should attempt to explain 
the interannual variability of the intensity of the Hadley cell with the variability of either the frequency, or the intensity of these tropical wave disturbances, or a combination of both.

In this context it might be of interest to note that Rieh1 (1977) observed $20 \%$ of convective precipitation echoes penetrating the $200-\mathrm{mb}$ level in the summer of 1969 during a meteorological experiment in Venezuela. In 1972 the percentage was 35. Riehl ascribes the difference to adjustments in the maximum radar antenna tilt. We note from Fig. 73, however, that the trade-wind convergence was at a minimum during the summer of 1969 and much higher in 1972. Therefore it is possible that intensity changes of convective systems had taken place between the two perinds during which the Venezuela experiment had been running.

Wo should expect that the mean position of the ITCZ is also influenced by the energy releases occurring within its domain. Indications for such a possibility were given by Kraus (1977b).

The interactions of a $Q B O$ in the Atlantic trade winds, and of a somewhat longer but less pronounced periodicity in the Pacific trades, with the annual cycle provide intriguing possibilities of long-period "beating" frequencies appearing in some geophysical records. This area of investigation deserves more attention, but with carefully targeted and cautious approaches.

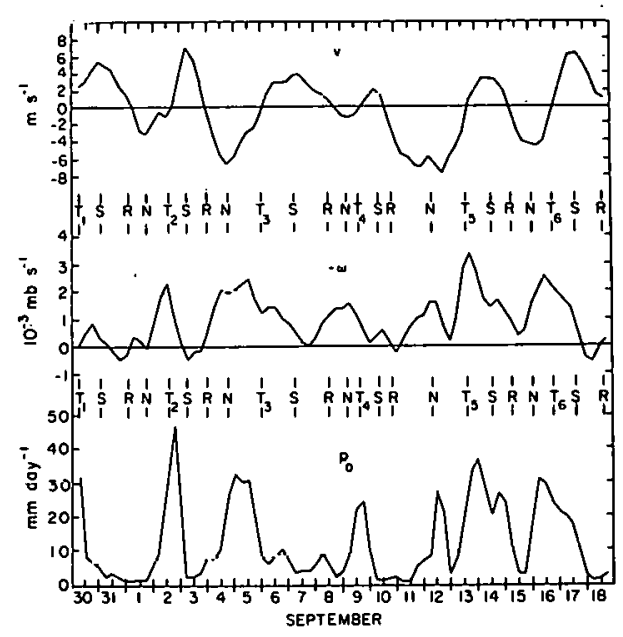

Fig. 100. Variations at the center of the GATE Bscale network of the meridional wind component $v(\mathrm{~m} / \mathrm{sec})$, the vertical velocity $-w$ at $700 \mathrm{mb}\left(10^{-3} \mathrm{mb} / \mathrm{sec}\right)$, and precipitation rate $P_{0}(\mathrm{~mm} /$ day $)$, during a period in AugustSeptember 1974 (Phase III of GATE).

(From Thompson et a1., 1979.) 
Adamec, D. and J.J. O'Brien, 1978: The seasonal upwelling in the Gulf of Guinea due to remote forcing. $\underline{\mathrm{J}}$. Phys. 0ceanogr., $\underline{8}$ (6), 1050-1060.

Albrecht, B.A., A.K. Betts, W.H. Schubert and S.K. Cox, 1979: A model of the thermodynamic structure of the trade-wind boundary layer: Part I. Theoretical formulation and sensitivity tests. J. Atmos. Sci. , 36 (1), 73-89.

Ange 11, J.K. and J. Korshover, 1977: Estimate of the global change in temperature, surface to $100 \mathrm{mb}$, between 1958 and 1975. Mo. Wea. Rev., 105, 375385.

and 1978: Estimate of global temperature variations in the $100-30 \mathrm{mb}$ layer between 1958 and 1977. Mo. Wea. Rev., 106 (10), 14221432.

Bacastow, R., 1977; Influence of the southern oscillation on atmospheric carbon dioxide. In: The fate of fossil fuel $\mathrm{CO}_{2}$ in the oceans (N.R. Andersen and A. Malahoff, editors). Plenum Press, New York, pp. 33-43.

Bakun, A., 1978: Guinea current upwelling. Nature, $271,147-150$.

Barnett, T.P., 1978: Estimating variability of surface air' temperature in the northern hemisphere. Mo. Wea. Rev., 106 (9), 1353-1367.

and K.E. Kenyon, 1975: Recent advances in the study of wind waves. Rep. Prog. Phys., 38, 667729.

and R.W. Preisendorfer, 1978: Multified analog prediction of short-term climate fluctuations using a climate state vector. J. Atmos. Sci., 35, $1771-1787$

Berlage, H.P., 1966: The southern oscillation and world weather. Mededeel. Verhandel., Kon. Ned. Meteor. Inst. , No. 88, 152 pp.

Bjerknes, J., 1966: A possible response of the atmospheric Hadley circulation to equatorial anomalies of ocean temperature. Tellus, 18, 820-829.

1969: Atmospheric teleconnections from the equatorial Pacific. Mon. Wea. Rev., 97, 163-172.

Brier, G.W., 1978: The quasi-biennial oscillation and feedback processes in the atmosphere-ocean-earth system. Mo. Wea. Rev., 106 (7), 938-946.

Bryson, R.A., 1974: The lessons of climatic history. Paper presented at Conference on Weather and Climate Change, Food Production and Interstate Conflict, Rockefeller Foundation, January, 1974.

and T.B. Starr, 1977: Chandler tides in the atmosphere. J. Atmos. Sci., 34, 1975-1986.

and 1978: Indications of Chandler compensation in the atmosphere. In: Climatic change and food production (K. Takahashi and $M$. $M$. Yoshino, editors). Univ. of Tokyo Press, 257-278.
Budyko, M.I., 1969: The effect of solar radiation variations on the climate of the earth. Tellus, 21, 611-619.

Bunker, A.F., and L.V. Worthington, 1976: Energy exchange charts of the North Atlantic 0cean. Bull. Amer. Meteor. Soc., 57, 670-678.

Camp. N.T., 1976: Role of strong atmospheric forcing events in the modification of upper ocean thermal structure during the cooling season. Ph.D. Thesis, Navel Postgraduate School, 175 pp.

and R.L. Elsberry, 1978: Ocean thermal response to strong atmospheric forcing, II. The role of one-dimensional processes. $\underline{J}$. Phys. Oceanogr. , $\underline{8}, 215-224$.

Clarke, A.J., 1979: On the generation of seasonal coastal upwelling in the Gulf of Guinea. $\mathrm{J}$. Geoph. Res., 84 (C7), 3743-3751.

Cornejo-Garrido, A.G. and P.H. Stone, 1977: On the heat balance of the Walker circulation. $\mathrm{J}$. Atmos. Sci., 34, 1155-1162.

Corona, T.J., 1978: The interannual variability of northern hemisphere precipitation. Colorado State University, Environmental Research Paper, No. $16,27 \mathrm{pp}$.

1979: Further investigation of the interannual variability of northern hemisphere continental precipitation. Colorado State University, Environmental Research Paper, No. 20, 20 pp.

Covey, D.L. and S. Hastenrath, 1978: The Pacific El Niño phenomenon and the Atlantic circulation. Mo. Wea. Rev. , 106 (9), 1280-1287.

Daly, A.W., 1978: The response of North Atlantic sea surface temperature to atmospheric forcing processes. Q. J. Roy. Meteor. Soc. , 104, 363-382.

Dorman, C.E. and J.F.T. Saur, 1978: Temperature anomalies between San Francisco and Honolulu, 1966-1974, gridded by an objective analysis. J. Phys. Oceanogr. , 8 (2), 247-257.

Ebdon, R.A., 1975: The quasi-biennial oscillation and its association with tropospheric circulation patterns. Met. Mag. , 104, 282-297.

Elsberry, R.L. and N.T. Camp, 1978: Oceanic thermal response to strong atmospheric forcing, I. Characteristics of forcing events. J. Phys. Oceanogr. , 8, 206-214.

and S.D. Raney, 1978: Sea surface temperature response to variations in atmospheric wind forcing. J. Phys. Oceanogr. , 8 (5), 881-887.

and R.W. Garwood, Jr., 1978: Sea surface temperature anomaly generation in relation to atmospheric storms. Bull. Amer. Meteor. Soc., 59, 786-789.

Favorite, F. and D.R. McLain, 1973: Coherence in transpacific movements of positive and negative anomalies of sea surface temperature, 1953-60. Nature, 224 (5412), 139-143. 
Fieux, M., and H. Stommel, 1975: Preliminary look at feasibility of using marine reports of sea surface temperature for documenting climatic change in the western North Atlantic. J. Marine. Res., Supplement, 83-95.

Girardi, C., and L. Teixeira, 1978: Prognóstico do tempo a longo prazo. Instituto de Atividades Espaciais, Centro Técnico, Aeroespacial, São José dos Campos, Relatório Técnico ECA-06/78, $18 \mathrm{pp}$.

Hasselmann, K., 1977: The dynamic coupling between the atmosphere and the ocean. World Meteorological Organization, Reports on Marine Science Affairs, WMO - No. 472, pp. 31-44.

Herman, J.R. and R.A. Goldberg, 1978: Sun, weather and climate. NASA, Scientific and Terhnical Informatioli Branch, NASA SP-426, $360 \mathrm{pp}$.

Hess, S.L., 1959: Introduction to theoretical meteorology. Holt and Co., New York, $362 \mathrm{pp}$.

Houghton, R.W., 1976: Circulation and hydrographic structure over the Ghana continental shelf during the 1974 upwelling. J. Phys. Oceanngr., 6, 909924.

Hulburt, H.E., J.C. Kindle, and J.J. O'Brien, 1976: A numerical simulation of the onset of El Niño. $\underline{J}$. Phys. Oceanogr. , 6 (5), 621-631.

Husby, D.M. and G.R. Seckel, 1975: Large-scale air sea interactions at Ocean Weather Station $V$, 1951-71. NOAA Tech. Rep. NMFS SSRF-696, 44 pp.

Ichiye, T. and J.R. Petersen, 1963: The anomalous rainfall of the 1957-58 winter in the equatorial central Pacific arid area. $\underline{j}$. Meteor. Soc. Japan, Ser. II, 41, 172-182.

Julian, P.R. and R.M. Chervin, 1978: A study of southern oscillation and Walker circulation phenomenon. Mo. Wea. Rev., 106, 1433-1451.

Katz, R.W., 1978: Persistence of subtropical African droughts. Mo. Wea. Rev., 106 (7), 1017-1021.

Kenyon, K.E., 1978: The surface layer of the eastern North Pacific in winter. $\underline{\mathrm{J}}$. Geoph. Res., 83 (C 12), 6115-6122.

Kirwan, A.D., Jr., G. McNally, S. Pazan and R. Wert, 1979: Analysis of surface current response to wind. $\underline{J}$. Phys. Oceanogr., 9 (2), 401-412.

Kraus, E.B., 1977a: Subtropical droughts and crossequatorial energy transports. Mon. Wea. Rev., 105 (8), $1009-1018$.

1977b: The seasonal excursion of the intertropical convergence zone. Mo. Wea. Rev., 105 (8), 1052-1055.

Kukla, G.J., 1978: Recent changes in snow and ice. In: Climatic change (J. Gribbin, editor). Cambridge Univ. Press, pp. 114-129.

Labitzke, K., 1977: Interannual variability of the winter stratosphere in the northern hemisphere. Mo. Wea. Rev., 105 (6), 762-770.
Laevastu, T.,' 1963: Energy exchange in the North Pacific: Its relation to weather and its oceanographic consequences. Part I - Formulas and nomographs for computation of heat exchange components over the sea. University of Hawaii, Hawaii Institute of Geophysics. Report No. 29, $15 \mathrm{pp}$.

Lamb, H.H., 1972: Climate: Present, past and future. Vo1. 1, Methuen, London, 613 pp.

1977: Climate: Present, past and future. Vol. 2, Methuen, London, $835 \mathrm{pp}$.

Lamb, P.J., 1978: Large-scale tropical Atlantic surface circulation patterns associated with Subsaharan weather anomalies. Tellus, 30, 240-251.

Leetillad, A., 19\%: Effects of the winter 1976-77 on the northwestern Sargasso Sea. Science, 198 (4313), 188-189.

Lindzen, R.S. and J.R. Holton, 1968: A theary of the quasi-biennial oscillation. J. Atmos. Sci., 25, 1095-1107.

and B. Farre11, 1977: Some realistic modifications of simple climate models. ‥ Atmos. Sci., 34, 1487-1501.

Lorenz, E.N., 1965: Available potential energy and the maintenance of the general circulation. Tellus, 7 (2), 157-167.

, 1967: The nature and theory of the general circulation of the atmosphere. World Meteor. Organiz., No. 218, TP. 115.

, 1978: Available energy and the maintenance of a moist circulation. Tellus, $30,15-31$.

1979: Numerical evaluation of moist available energy. Tellus, 31, 230-235.

Markham, C.G., 1974: Apparent periodicities in rainfall at Fortaleza, Cereá, Brazil. J. Appl. Met. , $\underline{13}$ (1), 176-179.

and D.R. McLain, 1977: Sea surface temperature related to rain in Cereá, north-eastern Brazil. Nature, 265 (5592), 320-323.

Matsuno, T., 1971: A dynamical model of the stratospheric sudden warming. ‥ Atmos. Sci., $\underline{28}$, 1479-1494.

McCreary, J., 1976: Eastern tropical ocean response to changing wind systems with application to El Niño. J. Phys. Oceanogr. , $\underline{6}, 632-645$.

McGuirk, J.P., 1977: Fluctuations in the atmosphere's energy cycle. Colorado State University, Environmental Research Paper No. 6, 59 pp.

, and E.R. Reiter, 1976: A vacillation in atmospheric energy parameters. J. Atmos. Sci., 33 (11), 2079-2093.

and 1977: Non-random fluctuations in atmospheric energy parameters. Beitr. Phys. der Atmosph. , 50, 239-246. 
McLain, D.R. and F. Favorite, 1976: Anomalously cold winters in the southeastern Bering Sea. Marine Science Communications, 2 (5), 299-334.

McWilliams, J.C. and P.R. Gent, 1978: A coupled air and sea model for the tropical Pacific. $J$. Atmos. Sci. , 35 (6), 962-989.

Meisner, B.N., 1976: A study of Hawaiian and Line Island rainfa11. Report UHMET-76-04, Dept. of Meteorol., Univ. of Hawaii, 83 pp.

Ming, K. and W. Lau, 1979: A numerical study of tropical large-scale air-sea interaction. ‥ Atmos. Sci., 36 (8), 1467-1489.

Mitche11, J.M., Jr., 1961: Recent secular changes of global temperature. Ann. N.Y. Acad. Sci., 95 (1), 235-250.

1979: Evidence of a 22-year rythm of drought in the western United States, related to the Hale solar cycle since the 17th century. In: SolarTerrestrial Influences on Weather and Climate, B.M. McCormac and T.A. Seliga, editors. Reidel Publishing Co., Dordrecht, Holland, pp. 125-143.

Moritz, R.E., 1979: Non-linear analysis of a simple sea ice-ocean temperature oscillation model. J. Geoph. Res. 84 (C8), 4916-4920.

Muench, H.S., 1965: On the dynamics of the wintertime stratospheric circulation. J. Atmos. Sci., 22 (4), 349-360.

Namias, J., 1978: Multiple causes of the North American abnormal winter 1976-77, Mo. Wea. Rev. , 106, 279-295.

Newe 11, R.E., and B.C. Weare, 1976a: 0cean temperatures and large scale atmospheric variations. Nature, 262 (5563), 40-41. and 1976b: Factors governing lrupospheric mean temperature. Science, 194, 1413-1414.

Nitani, H., 1972: Beginning of the Kuroshio. In: Kuroshio, physical aspects of the Japan current. (H. Stomme 1 and K. Yoshida, editors). Seattle, Univ. of Washington Press, pp. 129-163.

0'Brien, J.J. and D. Adamec, 1978: A simple model of upwelling in the Gulf of Guinea. Geoph. Res. Letters, $\underline{5}(8), 641-644$.

Office of Climatology, 1959: Climatological and oceanographic atlas for mariners, Vol. I. North Atlantic Ocean. U.S. Government Printing office.

1961: Climatological and oceanographic atlas for mariners, Vol. II. North Pacific Ocean. U.S. Government Printing office.

Patrinos, A.A.N., N.C.J. Chen and R.L. Miller, 1979: Spatial correlations of monthly rainfall. Applications in climatology and weather modification experiments. J. Appl. Meteor., 18 (6), 719-732.

Pearce, R.P., 1978: On the concept of available potential energy. Q. ‥ Roy. Meteor. Soc., 104, 737-755.

Pittock, A.B., 1978: A critical look at long-term sun-weather relationships. Rev. of Geoph. and Space Phys., 16, (3), 400-420.
Price, J.F., C.N.K. Mooers, and J.C. VanLeer, 1978: Observation and simulation of storm-induced mixed-layer deepening. $\underline{3}$. Phys. Oceanogr. $\underline{8}$ (4), 582-599.

Ramage, C.S., 1977: Sea surface temperature and local weather. Mo. Wea. Rev., 105 (4), 540-544.

Reiter, E.R., 1969a: Atmospheric transport processes. Part 1: Eneryy transfers and transformations. U.S. Atomic Energy Commission, TID-24868, 253 pp.

1969b: Mean and eddy motions in the atmosphere. Mo. Wea. Rev., 97 (3), 200-204.

1978a: The interannual variation of the oceanatmosphere system as a consequence of feedback mechanisms. Conference Proceedings, Evolution of Planetary Atmospheres and Climatology of the Earth, Nice (France), 16-20 October, 1978, pp. 509-522.

1978b: Long-term wind variability in the tropical Pacific, its possible causes and effects. Mo. Wea. Rev., 106, 324-330.

1978c: The interannual variability of the ocean-atmosphere system. J. Atmos. Sci., 35, 349-370.

1979a: Trade-wind variability, southern osciliation, and quasi-biennial oscillation. Archiv. Met. Geoph. Bioklim., Ser. A, 28, 113-126.

1979b: Some mechanisms affecting sea-surface temperature anomaly formation in the North Pacific. Archiv. Met. Geoph. Bioklim., Ser. A, $28,195-210$.

, 1979c: On the interannual variability of the ocean-atmosphere system. Proceedings on COSPAR Symposium, Remote Sounding of the Atmosphere from Space, H.-J. Bolle, editor, Innsbruck, May 1978, Pargamnn Press, New York, pp. 57-62.

and J.P. McGuirk, 1976: Studies on the vacillation of atmospheric energy parameters. Proceedings, Internat. Conference on the Simulation of Large-Scale Atmospheric Processes, Hamburg, Aug. 30-Sept. 4, 1976, pp. 251-258.

Rex, D.F., 1950a: Blocking action in the middle troposphere and its effects upon regional climate. I. Aerological study of blocking action. Tellus, 2 (3), 196-211.

, 1950b: Blocking action in the middle troposphere and its effect upon regional climate. II. Climatology of blocking action. Tellus, 2 (4), 275-301.

, 1951: The effect of Atlantic blocking action upon European climate. Tellus, $\underline{3}$ (2), 100-111.

Riehl, H., 1977: Vertical distribution of energy transfer and radar echo tops in the equatorial trough zone. Mo. Wea. Review, 105 (2), 230-231.

Roden, G.I., 1970: Aspects of the mid-Pacific transition zone. J. Geoph. Res., 75 (6), 1097-1109.

1972: Temperature and salinity fronts at the boundaries of the subarctic-subtropical transition zone in the Western Pacific. J. Geoph. Res. , 77 (36), 7175-7187. 
1975: On North Pacific temperature, salinity, sound velocity and density fronts and their relation to the wind and energy flux fields. J. Phys. Oceanogr., 5 (4), 557-571.

and D.F. Paskausky, 1978: Estimation of rates of frontogenesis and frontolysis in the North Pacific 0cean using satellite and surface meteorological data from January 1977 . J. Geoph. Res. , 83 (C9), 4545-4550.

Rosen, R.D., and D.A. Salstein, 1979: Variability in the annual fields of large-scale atmospheric water vapor transport. Mo. Wea. Rev., 107 (1), 26-37.

Rowntree, R.R., 1976: Response of the atmosphere to a tropical Atlantic Ocean temperature anomaly. Q. J. Roy. Meteor. Soc., 102, 607-625.

Saltzman, B., 1978: A survey of statistical-dynamical models of the terrestrial climate. Advan. Geophys. , 20, 183-304.

Sanderson, R.M., 1975: Changes in the area of Arctic sea ice, 1966 to 1974 . Meteor. Mag., 104, 313323.

Saur, J.F.T., 1978: 0ceanic conditions between the Hawaijan Islands and the U.S. west coast as monitored by ships of opportunity - 1975. In: Ocean variability. Effects on U.S. marine fishery resources - 1975 (J.R. Goulet, Jr. and E.D. Haynes, editors), NOAA Tech. Rep. NMFS Cir., 416, p. 151168.

L.E. Eber, D.R. McLain and C.E. Dorman, 1979: Vertical sections of semi-monthly mean temperature on the San Francisco-Honolulu route: From Expendable Bathythermograph Observations, June 1966-December .1974. NOAA Tech. Rep. NMFS SSRF$728,35 \mathrm{pp}$.

Seckel, G.R., and M.Y.Y. Yong, 1977: Koko Head, Oaker, sea-surface temperatures and salinities, 1956-1973, and Christmas Island sea-surface temperatures, 1954-73. Fishery Bulletin, 75 (4), 767-787.

Seigel, A.D., 1977: Oceanic latent and sensible heat flux variability and air-interaction. Colorado State University, Environmental Research Papers, No. $7,31 \mathrm{pp}$.

Sergin, V.Ya., 1979: Numerical modelling of the glaciers-ocean-atmosphere global system. $\underline{J}$. Geoph. Res., 84 (C7), 3191-3204.

Shoji, D., 1972: Time variation of the Kuroshio south of Japan. In: Kuroshio ( $H$. Stommel and $K$. Yoshida, editors), Seattle, Univ. of Washington Press, pp. 217-234.

Starr, A.M., 1976: Interannual variations and regional effects of hemispheric parameters. Colorado State University, Environmental Research Paper No. 4, 28 pp.

Starr, T.B. and R.A. Bryson, 1978: Reply. ․ Atmos. Sci., 35 (12), 2387-2389.

Stommel, H. and K. Yoshida, editors, 1972: Kuroshio, physical aspects of the Japan current. Seattle, Univ. of Washington Press, 517 pp.
Strang, D.M.G.D., 1972: Análise climatológica das normais pluviométricas do nordeste Brasileiro. Centro Técnico Aeroespacial, São José dos Campos, IAE-M-02/72, $29 \mathrm{pp}$.

1979: Utilização dos dados pluviométricas de Fortaleza, CE, visando determinar probabilidades de anos secos e chuvosos. Instituto de Atividades Espaciais, Centro Técnico Aeroespacial, Relatório Técnico ECA-03/79, 40 pp.

Thompson, R.M., S.W. Payne, E.E. Recker and R.J. Reed, 1979: Structure and properties of synoptic-scale wave disturbances in the intertropical convergence zone of the Eastern Atlantic. J. Atmos. Sci. , 36 (1), 53-72.

Walker, G.T., 1924: World Weather, II. Mem. India Met. Dep. , 24, 275-332.

Walsh, J.E., 1977: The incorporation of ice station data into a study of recent Arctic temperature fluctuations. Mo. Wea. Rev, 105, 1527-1535.

and C.M. Johnson, 1979: An analysis of Arctic sea ice fluctuations, 1953-77. ‥ Phys. Oceanogr., 9 (3), 580-591.

Warren, S.G., and S.H. Schneider, 1979: Seasonal simulation as a test for uncertainties in the parameterizations of a Budyko-Sellers zonal climate

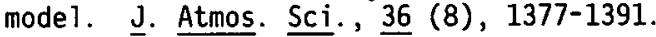

Weare, B.L., A.R. Navato, and R.E. Newe 11, 1976: Empirical orthogonal analysis of Pacific sea surface temperatures. ‥ Phys. Oceanogr., $\underline{6}$ (5), 671-678.

Wells, N.C. and K. Puri, 1979: Atmospheric feedback in a coupled ocean-atmosphere mode1. J. Geoph. Res. 84 (8), 4971-4984.

1979: The effect of a tropical sea surface temperature anomaly in a coupled ocean-atmosphere mode1. J. Geoph. Res., 84 (8), 4985-4997.

White, W. B., 1975: Secular variability in the largescale baroclinic transport of the North Pacific from 1950-1970. J. Mar. Res., 33, 144-155.

1977: Secular variability in the baroclinic structure of the interior North Pacific from 1950-1970. J. Mar. Res., 35 (3), 587-607.

, K. Hasunuma, and H. Solomon, 1978: Largescale seasonal and secular variability of the subtropical front in the western North Pacific from. 1954 to 1974. J. Geophys. Res., 83 (C9), 4531-4544.

Wiesnet, D.R. and M. Matson, 1979: The satellitederived northern hemisphere snow cover record for the winter of 1977-78. Mo. Wea. Rev., 107 (7), 928-933.

Wilson, C.R., 1978: Comments and additional investigations concerning "Chandler tides in the atmosphere". J. Atmos. Sci., 35 (12), 2381-2387.

Wilson, W.S., and J.P. Dugan, 1978: Mesoscale thermal variability in the vicinity of the Kuroshio extension. J. Phys. Oceanogr., 8 (3), 537-540. 
Wyrtki, K., 1974: Equatorial currents in the Pacific 1950-1970 and their relation to the winds. J. Phys. Oceanogr. , 5 (3), 450-459.

1975: El Niño - The dynamic response of the equatorial Pacific ocean to atmospheric forcing. J. Phys. Oceanogr. , 5, 572-584.

E. Stroup, W. Palzert, R. Williams, and W. Quinn, 1976: Predicting and observing El Niño. Science, 191, 343-346. 
Author: Elmar R. Reiter

ON THE DYNAMIC FORCING OF SHORT-TERM CLIMATE FLUCTUATIONS BY FEEOBACK MECHANISMS

Colorado State University Department of Atmospheric Science

Environmental Research Paper No. 21 September 1979. 62 pp.

NASA, Grant No. NSG 5340; NSF, Grant ATM 78-17835; DOE, Contract EY-76S-02-1340

The energies involved in the general circulation of the atmosphere, especially the zonal available potential energy, show considerable interannual variability, suggesting the presence of various internal feedback mechanisms in the ocean-atmosphere system. The presence or absence of stratospheric warming events and of tropospheric blocking absence of stratospheric warming evants and of tropospheric blocking
ridges has a profound effect on winter weather in the northern hemisphere. An interannual as well as a long-term variability of the hydrological cycle, largely ignored. in present climate research, can affect the general circulation especially through the generation of available potential energy. Such variations in the hydrological cycle become apparent in the variability of northern hemisphere continental precipitation. Effects also have to be susjected in the storage of precipitable water in the troposphere and in the evaporation rate from the ocean which, in turn, is influenced by the general circulation. Seasurface temperature (SST) variations appear to have some effect on the hydrological cycle.

Author: Elmar R. Reiter

\subsection{1:551.577.35}

ON THE DYNAMIC FORCING OF SHORT-TERM CLIMATE FLUCTUATIONS BY FEEDBACK MECHANISMS

Colorado State University

Department of Atmospheric Science

Environmental Research Paper No. 21

September 1979. $62 \mathrm{pp}$.

NASA, Grant No. NSG 5340; NSF, Grant ATM 78-17835; DOE, Contract EY-76S-02-1340

The energies involved in the general circulation of the atmosphere, especially the zonal available potential energy, show considerable interannual variability, suggesting the presence of various internal feedback mechanisms in the ocear-atmosphere system. The presence or absence of stratospheric warming events and of tropospheric blocking ridges has a profound effect on winter weather in the northern hemiridges has a profound effect on winter weather in the northern hemi-
sphere. An interannual as well as a long-term variability of the hydrological cycle, largely ignored in prese t climate research, can affect the general circulation especially through the generation of avajlable potential energy. Such variations in the hydrological cycle become apparent in the variability of northern hemisphere continental precipitation. Effects also have to be suspected in the storage of precipitable water in the troposphere and in the evaporation rate from the ocean which, in turn, is influenced by the general circulation. Seasurface temperature (SST) variations appear to have some effect on the hydrological cycle.
Author: Elmar R. Reiter

ON THE DYNAMIC FORCING OF SHORT-TERM CLIMATE FLUCTUATIONS BY FEEDBACK MECHANISMS

Subject Headings:

Colorado State University

Department of Atmospheric Science

Environmental Research Paper No. 21

Atmospheric Variability

Air-Sea Interactions

Precipitation Variability September 1979. 62 pp.

NASA, Grant No. NSG 5340; NSF, Grant ATM 78-17835; DOE, Contract EY-76S-02-1340

The energies involved in the general circulation of the atmosphere, especially the zonal available potential energy, show considerable interannual variability, suggesting the presence of various internal feedback mechanisms in the ocean-atmosphere system. The presence or absence of stratospheric warming events and of tropospheric blocking ridges has a profound effect on winter weather in the northern hemiridges has a profound effect on winter weather in the northern hemi-
sphere. An interannual as well as a long-term variability of the hydrological cycle, largely ignored in present climate research, can affect the general circulation especially through the generation of available potential energy. Such variations in the hydrological cycle become apparent in the variability of northern hemisphere continental precipitation. Effects also have to be suspected in the storage of precipitable water in the troposphere and in the evaporation rate from the ocean which, in turn, is influenced by the general circulation. Seaocean which, in turn, is influenced by the general circulation. Sea-
surface temperature (SST) variations appear to have some effect on the hydrological cycle.

Author: Elmar R. Reiter

$551.513 .1: 551.577 .35$

ON THE DYNAMIC FORCING OF SHORT-TERM CLIMATE FLUCTUATIONS BY FEEDBACK MECHANISMS

Colorado State University

Department of Atmospheric Science

Environmental Research Paper No. 21

September $1979.62 \mathrm{pp}$.

Subject Headings:

Atmospheric Variability

Air-Sea Interactions

Precipitation Variability Weather Effects

NASA, Grant No. NSG 5340; NSF, Grant ATM 78-17835; DOE, Contract EY-76S-02-1340

The energies involved in the general circulation of the atmosphere, especially the zonal available potential energy, show considerable interannual variability, suggesting the presence of various internal feedback mechanisms in the ocean-atmosphere system. The presence or absence of stratospheric warming events and of tropospheric blocking ridges has a profound effect on winter weather in the northern hemisphere. An interannual as well as a long-term variability of the hydrological cycle, largely ignored in present climate research, can affect the general circulation especially through the generation of available potential energy. Such variations in the hydrological cycle become apparent in the variability of northern hemisphere continental precipitation. Effects also have to be suspected in the storage of precipitable water in the troposphere and in the evaporation rate from the ocean which, in turn, is influenced by the general circulation. Seasurface temperature (SST) variations appear to have some effect on the surface temperature
hydrological cycle. 
These SST variations, appearing as large-scale and long lasting anomalies, can have a variety of causes, such as local anomalies in wind stress and advection within the large-scale oceanic current systems. These ocean currents appear to undergo interannual variations as well as long-term trends. The possible existence of feedback mechanisms between ocean and atmosphere seem to be evident in some of the data from the North Pacific and North Atlantic. One of these proposed mechanisms involves the variation in the convergence between the North and South Pacific trade-wind systems and is strongly reflected in rainfall variability within the dry region of the equatorial Pacific. Similar variations appear in low-latitude SST anomalies of selected regions, notably off the coasts of California and Peru, the latter area known for the "El Niño" phenomenon. That phenomenon also appears to be tied to the aforementioned trade-wind variability over the Pacific.

The convergence between the two trade-wind systems in the Atlantic region also undergoes marked interannual variations, strangely enough in a quasi-biennial cycle. This quasi-biennial oscillation (QBO) in tradewind convergence over the Atlantic (not present over the Pacific) appears to be tied to the global $\mathrm{QBO}$ of equatorial stratospheric winds and to regional rainfall regimes in the dry region of northeastern Brazil. A variability pattern of SST's with a QBO has been detected off the coast of Senegal, in the Gulf of Guinea and even in the Gulf Stream as it leaves the North American continental shelf. Possible physical connections between some of these $\mathrm{QBO}^{\prime} \mathrm{s}$ are pointed out by a hypothet ical feedback model. It is also suggested that interaction of a QBO with the annual cycle may lead to "beating frequencies" resembling climatic trends of a duration of several years, and being evident in some rainfall records of the dry region of northeastern Brazil.

These SST variations, appearing as large-scale and long lasting anomalies, can have a variety of causes, such as local anomalies in wind stress and advection within the large-scale oceanic current systems. These ocean currents appear to undergo interannual variations as well as long-term trends. The possible existence of feedback mechanisms between ocean and atmosphere seem to be evident in some of the data from the North Pacific and North Atlantic. One of these proposed mechanisms involves the variation in the convergence between the North and South Pacific trade-wind systems and is strongly reflected in rainfall variability within the dry region of the equatorial Pacific. Similar variations appear in low-latitude SST anomalies of selected regions, notably off the coasts of California and Peru, the latter area known for the "El Niño" phenomenon. That phenomenon also appears to be tied to the aforementioned trade-wind variability over the Pacific.

The convergence between the two trade-wind systems in the Atlantic region also undergoes marked interannual variations, strangely enough in a quasi-biennial cycle. This quasi-biennial oscillation (QBO) in tradewind convergence over the. Atlantic (not present over the Pacific) appears to be tied to the global QBO of equatorial stratospheric winds and to regional rainfall regimes in the dry region of northeastern Brazil. A variability pattern of SST's with a $\mathrm{QBO}$ has been detected off the coast of Senegal, in the Gulf of Guinea and even in the Gulf Stream as it leaves the North American continental shelf. Possible physical connections between some of these QBO's are pointed out by a hypothet $i$ cal feedback model. It is also suggested that interaction of a QBO with the annual cycle may lead to "beating frequencies" resembling climatic trends of a duration of several years, and being evident in some rainfall records of the dry region of northeastern Brazil.
These SST variations, appearing as large-scale and long lasting anomalies, can have a variety of causes, such as local anomalies in wind stress and advection within the large-scale oceanic current systems. These ocean currents appear to undergo interannual variations as well as long-term trends. The possible existence of feedback mechanisms between ocean and atmosphere seem to be evident in some of the data from the North Pacific and North Atlantic. One of these proposed mechanisms involves the variation in the convergence between the North and South Pacific trade-wind systems and is strongly reflected in rainfall variability within the dry region of the equatorial Pacific. Similar variations appear in low-latitude SST anomalies of selected regions, notably off the coasts of California and Peru, the latter area known for the "El Niño" phenomenon. That phenomenon also appears to be tied to the aforementioned trade-wind variability over the Pacific.

The convergence between the two trade-wind systems in the Atlantic region also undergoes marked interannual variations, strangely enough in a quasi-biennial cycle. This quasi-biennial oscillation (QBO) in tradewind convergence over the Atlantic (not present over the Pacific) appears to be tied to the global $Q B O$ of equatorial stratospheric winds and to regional rainfall regimes in the dry region of northeastern Brazil. A variability pattern of SST's with a QBO has been detected off the coast of Senegal, in the Gulf of Guinea and even in the Gulf Stream as it leaves the North American continental shelf. Possible physical connections between some of these QBO's are pointed out by a hypothet $i$ cal feedback mode1. It is also suggested that interaction of a $\mathrm{QBO}$ with the annual cycle may lead to "beating frequencies" resembling climatic trends of a duration of several years, and being evident in some rainfall records of the dry region of northeastern Brazil.

These SST variations, appearing as large-scale and iong lasting anomalies, can have a variety of causes, such as local anomalies in wind stress and advection within the large-scale oceanic current systems. These ocean currents appear to undergo interannual variations as well as long-term trends. The possible existence of feedback mechanisms between ocean and atmosphere seem to be evident in some of the data from the North Pacific and North Atlantic. One of these proposed mechanisms involves the variation in the convergence between the North and South Pacific trade-wind systems and is strongly reflected in rainfall variability within the dry region of the equatorial Pacific. Similar variations appear in low-latitude SST anomalies of selected regions, notably of $f$ the coasts of California and Peru, the latter area known for the "El Niño" phenomenon. That phenomenon also appears to be tied to the aforementioned trade-wind variability over the Pacific

The convergence between the two trade-wind systems in the Atlantic region also undergoes marked interannual variations, strangely enough in a quasi-biennial cycle. This quasi-biennial oscillation (QBO) in tradewind convergence over the Atlantic (not present over the Pacific) appears to be tied to the global $\mathrm{OBO}$ of equatorial stratospheric winds and to regional rainfall regimes in the dry region of northeastern Brazil. A variability pattern of SST's with a OBO has been detected of $f$ the coast of Senegal in the Gulf of Guinea and even in the Gulf Stream as it leaves the North American continental shelf. Possible physical connections between some of these QBO's are pointed out by a hypothetical feedback mode1. It is also suggested that interaction of a QBO with the annual cycle may lead to "beating frequencies" resembling climatic trends of a duration of several years, and being evident in some rainfall records of the dry region of northeastern Brazil. 
No. 1 On the Variability of Hemispheric Scale Energy Parameters, by J.P. McGuirk, E.R. Reiter and A.M. Barbieri, January 1975.

No. 2 On Determining Vertical Wind Velocities from Eole Constant-Density Balloon Data, by Robert M. Banta, June 1975.

No. 3 Atmospheric Eddy Transports and Their Efficiencies, by Srinivasan Srivatsangam, January 1976.

No. 4 Interannual Variations and Regional Effects of Hemispheric Parameters, by Ann M. Starr (neé Barbieri), July 1976.

No. 5 The Effects of Atmospheric Variability on Energy Utilization and Conservation, by E.R. Reiter et al., November 1976 .

No. 6 Fluctuations in the Atmosphere's Energy Cycle, by James P. McGuirk, March 1977.

No. 7 Oceanic Latent and Sensible Heat Flux Variability and Air-Interaction, by Anne 0. Seigel, April 1977.

No. 8 Observations of Stratospheric Thermal Structure from Satellites, by Thomas J. Kleespies, May 1977.

No. 9 Effects of Coal Mine Drainage on Macroinvertebrates of Trout Creek, Colorado, by Steven P. Canton and James V. Ward, April 1977.

No. 10 Potential Effects of $0 i 1$ Shale Extraction and Processing Activities on Macroinvertebrates of Piceance and Black Sulphur Creeks, Colorado, by Lawrence J. Gray and James V. Ward, April 1977.

No. 11 Modeling Atmospheric Dispersion of Lead Particulates From a Highway, by Paul C. Katen, July 1977.

No. 12 Residence Time of Atmospheric Pollutants and Long-Range Transport, by Teizi Henmi, Elmar R. Reiter and Roger Edsọn, July 1977.

No. 13 Quasi-Periodicities of Atmospheric Circulation and Their Application to Long-Range Weather Prediction, by S. Srivatsangam, Chi-Nan Hsiao, and Elmar R. Reiter, November 1977.

No. 14 The Effects of Atmospheric Variabllity on. Energy Utilization and Conservation, by Elmar R. Reiter, et al., February 1978.

No. 15 Long-Range Transport and Transformation of $\mathrm{SO}_{2}$ and Sulfate, by Teizi Henmi and Elmar R. Reiter, September 1978.

No. 16 The Interannual Variability of Northern Hemisphere Precipitation, by Thomas J. Corona, December 1978.

No. 17 Interannual Variation of Atmospheric Meridional Eddy Transports, by Chi-Nan Hsiao, April 1979.

No. 18 The Effects of Atmospheric Variability on Energy Utilization and Conservation, by Elmar R. Reiter, et al., March 1979 .

No. 19 Relationships Between Precipitation, Pressure and Ocean Temperature, by Patrick Allen, Haar, June 1979.

No. 20 Further Investigation of the Interannual Variability of Northern Hemisphere Continental Precipitation, by Thomas J. Corona, August 1979. 